RENATO NEVES PITTA

\title{
APLICAÇÃO INDUSTRIAL DE RE-IDENTIFICAÇÃO DE MODELOS DE MPC EM MALHA FECHADA
}

Dissertação apresentada à Escola

Politécnica da Universidade de São

Paulo para obtenção de título de Mestre em Engenharia

Área de Concentração:

Engenharia Química

Orientador: Prof. Dr. Darci Odloak 
Este exemplar foi revisado e alterado em relação à versão original, sob responsabilidade única do autor e com a anuência de seu orientador.

São Paulo, de fevereiro de 2012.

Assinatura do autor

FICHA CATALOGRÁFICA

Pitta, Renato Neves

Aplicação industrial de re-identificação de modelos de MPC em malha fechada / R.N. Pitta. -- ed.rev. -- São Paulo, 2012. $76 \mathrm{p}$.

Dissertação (Mestrado) - Escola Politécnica da Universidade de São Paulo. Departamento de Engenharia Química.

1. Controle preditivo 2. Coluna debutanizadora 3. Re-identificação em malha fechada I. Universidade de São Paulo. Escola Politécnica. Departamento de Engenharia Química II. t. 


\section{AGRADECIMENTOS}

Ao meu orientador Prof. Dr. Darci Odloak, pela paciência e persistência na condução do trabalho, bem como por semear as idéias essenciais para sua realização.

À Petrobras pelo incentivo e concessão dos recursos necessários para a realização deste trabalho.

Ao colega de Petrobras Dr. Antonio Carlos Zanin pelos ensinamentos constantes e pelo apoio e incentivo na execução dos testes.

Ao colega de Petrobras Jamhour pela solidariedade e pelo exemplo inspirador de trabalho árduo.

Aos colegas de CETAI André Seichi Ribeiro Kuramoto, Rodrigo Alvite Romano e Osmel Reyes pelas discussões sobre identificação.

À minha família pelo apoio sempre incondicional. 


\section{RESUMO}

A identificação de modelos é usualmente a tarefa mais significativa e demorada no trabalho de implementação e manutenção de sistemas de controle que usam Controle Preditivo baseado em Modelos (MPC) tendo em vista a complexidade da tarefa e a importância que o modelo possui para um bom desempenho do controlador. Após a implementação, o controlador tende a permanecer com o modelo original mesmo que mudanças de processo tenham ocorrido levando a uma degradação das ações do controlador.

Este trabalho apresenta uma aplicação industrial de re-identificação em malha fechada. A metodologia de excitação da planta utilizada foi apresentada em Sotomayor et al. (2009). Tal técnica permite obter o comportamento das variáveis de processo sem desligar o MPC e sem modificar sua estrutura, aumentando assim, o automatismo e a segurança do procedimento de re-identificação.

O sistema re-identificado foi uma coluna debutanizadora de uma refinaria brasileira sendo que os modelos fazem parte do controle preditivo multivariável dessa coluna de destilação. A metodologia foi aplicada com sucesso podendo-se obter os seis novos modelos para atualizar o controlador em questão, o que resultou em uma melhoria de seu desempenho.

Palavras-Chave: Controle Preditivo, Coluna Debutanizadora, Reidentificação em Malha Fechada. 


\begin{abstract}
Model identification is usually the most significant and time-consuming task of implementing and maintaining control systems based on models (MPC) concerning the complexity of the task and the importance of the model for a good performance of the controller. After being implemented the MPC tends to remain with the original model even after process changes have occurred, leading to a degradation of the controller actions.

The present work shows an industrial application of closed-loop re-identification. The plant excitation methodology used here was presented in Sotomayor et al. (2009). Such technique allows for obtaining the behavior of the process variables with the MPC still working and without modifying the MPC structure, increasing automation and safety of the re-identification procedure.
\end{abstract}

The system re-identified was a debutanizer column of a Brazilian refinery being the models part of the multivariable predictive control of this distillation column. The methodology was applied with reasonable success managing to obtain 6 new models to update this MPC, and resulting in improved control performance.

Keywords: Model predictive control, Debutanizer Column, Closed-Loop Reidentification. 


\section{Lista de Figuras}

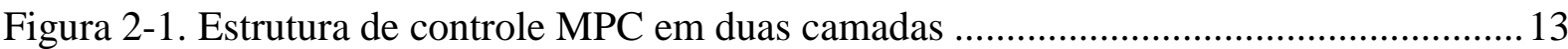

Figura 2-2. Identificação em malha fechada de MPC com excitação externa ......................... 17

Figura 3-1. Coluna estabilizadora com seus principais equipamentos, válvulas e variáveis de

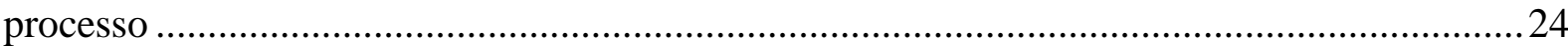

Figura 3-2. Controle regulatório e indicadores de temperatura, vazão e pressão.....................26

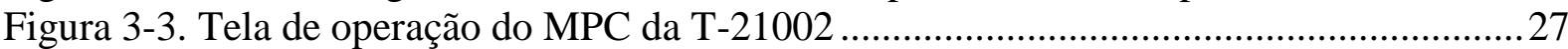

Figura 3-4. Variáveis manipuladas e controladas do MPC ......................................................2 29

Figura 3-5. Modelo identificado no comissionamento do MPC da T-21002 .......................... 32

Figura 4-1. Comparação das resposta ao degrau do modelo utilizado para planta (processo) com o modelo utilizado para o controlador (modelo) na simulação ........................................36

Figura 4-2. Comportamento das variáveis manipuladas ("setpoint" dos PIDs) durante a

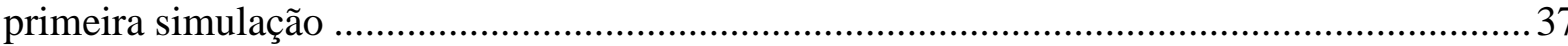

Figura 4-3. Comportamento das variáveis manipuladas ("setpoint" dos PIDs) durante a

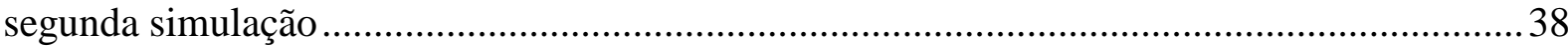

Figura 4-4. Comportamento das variáveis controladas durante a segunda simulação ..............38 Figura 4-5. Comparação dos ajustes das predições do modelo re-identificado (-- -- Novo modelo) e do modelo do controlador ( - - - - - Modelo antigo) ao processo para a variável controlada $y 1$. Simulação com dados utilizados para a re-identificação.

Figura 4-6. Validação cruzada do modelo re-identificado (-- -- Novo modelo) comparando seu ajuste ao processo ao ajuste do modelo do controlador (- - - - - Modelo antigo) para a variável controlada $y 1$ na simulação.

Figura 4-7. Comparação da resposta ao degrau do modelo re-identificado (-- -- Novo Modelo) e do modelo do controlador (- - - - - Modelo antigo) ao processo para a variável controlada $y 1$ referente às manipuladas $u 1$ e $u 2$

Figura 4-8. Comparação dos ajustes das predições do modelo re-identificado (-- -- Novo modelo) e do modelo do controlador (- - - - - Modelo antigo) ao processo para a variável controlada $y 2$. Simulação com dados utilizados para a re-identificação.

Figura 4-9. Validação cruzada do modelo re-identificado (-- -- Novo Modelo) comparando seu ajuste ao processo ao ajuste do modelo do controlador (- - - - - Modelo antigo) para a variável controlada $y 2$ na simulação.

Figura 4-10. Comparação da resposta ao degrau do modelo re-identificado (-- -- Novo Modelo) e do modelo do controlador (- - - - - Modelo antigo) ao processo para a variável controlada $y 2$ referente às manipuladas $u 1$ e $u 2$.

Figura 4-11. Comparação dos ajustes das predições do modelo re-identificado (-- -- Novo Modelo) e do modelo do controlador (- - - - - Modelo antigo) ao processo para a variável controlada $y 3$. Simulação com dados utilizados para a re-identificação.

Figura 4-12. Validação cruzada do modelo re-identificado (-- -- Novo Modelo) comparando seu ajuste ao processo ao ajuste do modelo do controlador (- - - - - Modelo antigo) para a variável controlada y3 na simulação

Figura 4-13. Comparação da resposta ao degrau do modelo re-identificado (-- -- Novo Modelo) e do modelo do controlador (- - - - - Modelo antigo) ao modelo usado para representar o processo para a variável controlada y3 referente às manipuladas $u 1$ e $u 2$

Figura 5-1. Sinal de excitação aplicado no teste de re-identificação A

Figura 5-2. Sinal de excitação aplicado no teste de re-identificação B.

Figura 5-3. "Setpoints" das variáveis manipuladas durante o teste de re-identificação A...... 49

Figura 5-4. Comportamento da controlada $y 1$ durante o teste de re-identificação A.............. 49

Figura 5-5. Comportamento da controlada $y 2$ durante o teste de re-identificação A...............50

Figura 5-6. Comportamento da controlada y3 durante o teste de re-identificação A..............50 
Figura 5-7. "Setpoints" das variáveis manipuladas durante o teste de re-identificação B ......51

Figura 5-8. Comportamento da controlada $y 1$ durante o teste de re-identificação B ...............51

Figura 5-9. Comportamento da controlada y2 durante o teste de re-identificação B ...............52

Figura 5-10. Comportamento da controlada y3 durante o teste de re-identificação B .............52

Figura 5-11. Predições do modelo re-identificado (-- --) e do modelo antigo usado no

controlador (- - - ). Para a variável controlada $y 1$. Dados utilizados para a re-identificação.. 55

Figura 5-12. Predições do modelo re-identificado (-- --) e do modelo antigo usado no

controlador (- - --). Para a variável controlada y1. Dados para validação cruzada.

Figura 5-13. Comparação da resposta ao degrau do modelo re-identificado (-- --) e do modelo antigo usado no controlador (-) para a variável controlada $y l$ referente às manipuladas $u l \mathrm{e}$ $u 2$.

Figura 5-14. Predições do modelo re-identificado (-- --) e do modelo antigo usado no controlador (- - - ). Para a variável controlada y2. Dados utilizados para a re-identificação. .56 Figura 5-15. Predições do modelo re-identificado (-- --) e do modelo antigo usado no controlador (- - --). Para a variável controlada y2. Dados para validação cruzada. Figura 5-16. Comparação da resposta ao degrau do modelo re-identificado (-- --) e do modelo antigo usado no controlador (-) para a variável controlada y2 referente às manipuladas $u 1 \mathrm{e}$ $u 2$.

Figura 5-17. Predições do modelo re-identificado (-- --) e do modelo antigo usado no controlador (- - --). Para a variável controlada y3. Dados utilizados para a re-identificação..58 Figura 5-18. Predições do modelo re-identificado (-- --) e do modelo antigo usado no controlador (- - --). Para a variável controlada y3. Dados para validação cruzada. Figura 5-19. Comparação da resposta ao degrau do modelo re-identificado (-- --) e do modelo antigo usado no controlador (-) para a variável controlada y3 referente às manipuladas $u 1 \mathrm{e}$ $u 2$.

Figura 5-20. Comparação da resposta ao degrau do modelo re-identificado (-- --) e do modelo usado no controlador (-) para a variável controlada y1 referente as manipuladas $u 1$ e $u 2$ para as 3 estruturas de modelo diferentes (COE,ARMAX,PEM) e para os dois testes A e B. O modelo com maior índice comp está destacado.

Figura 5-21. Comparação da resposta ao degrau do modelo re-identificado (-- --) e do modelo usado no controlador (-) para a variável controlada $y 2$ referente as manipuladas $u 1$ e $u 2$ para as 3 estruturas de modelo diferentes (COE,ARMAX,PEM) e para os dois testes A e B. O modelo com maior índice comp está destacado.

Figura 5-22 Comparação da resposta ao degrau do modelo re-identificado (-- --) e do modelo usado no controlador (-) para a variável controlada y3 referente as manipuladas $u 1$ e $u 2$ para as 3 estruturas de modelo diferentes (COE,ARMAX,PEM) e para os dois testes A e B. O modelo com maior índice comp está destacado.

Figura 5-23. Correlação cruzada entre as entradas $u 1$ e $u 2$ do teste A..................................67

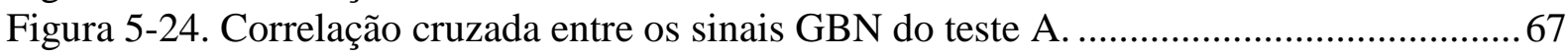

Figura 5-25. Comparação entre os modelo originais do controlador (-) e os novos modelos

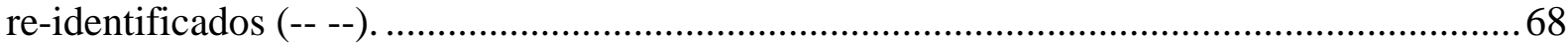

Figura 5-26. Aumento do PCAT médio após a utilização dos modelos re-identificados ........69 


\section{Lista de Tabelas}

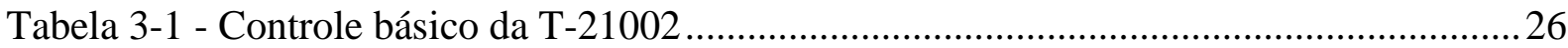

Tabela 3-2 - Valor máximo de PVR (especificação) - gasolina A ........................................ 28

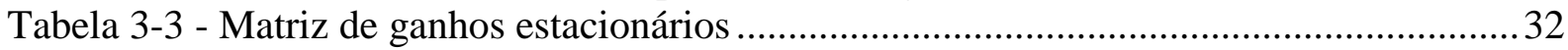

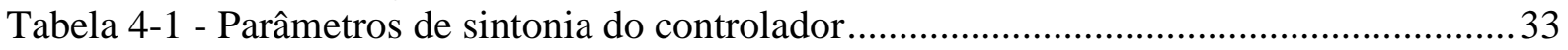

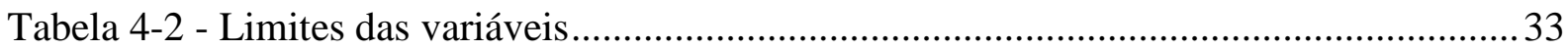

Tabela 5-1 - Modelos MISO contínuos identificados pela rotina coe .....................................54

Tabela 5-2: Resumo do desempenho da predição na validação cruzada dos três tipos de modelos usados na re-identificação para os dois testes (A e B) e para as três variáveis controladas através dos índices fit e $R_{T}^{2}$. Esses índices são também apresentados para os modelos originais do MPC. São destacados os três modelos que tem o maior índice comp

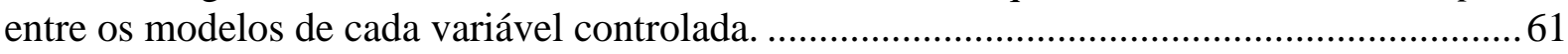

Tabela 5-3: Funções de transferência dos modelos substituídos no controlador ......................65 


\section{SUMÁRIO}

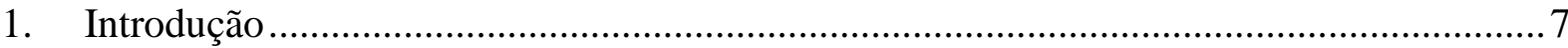

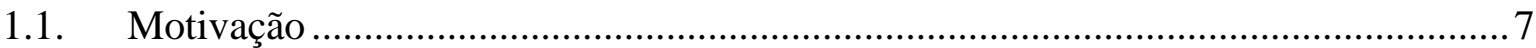

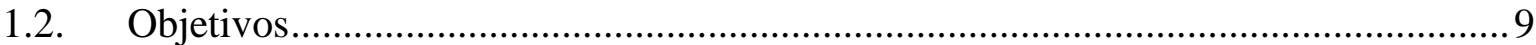

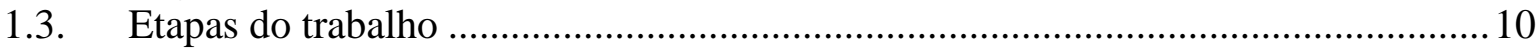

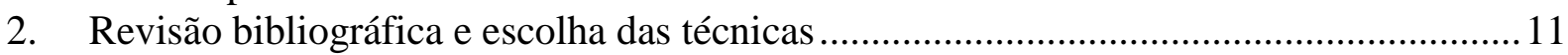

2.1. Controle Avançado e MPC .................................................................................... 11

2.1.1. Estrutura estudada: MPC em duas camadas e controle por faixas .................... 12

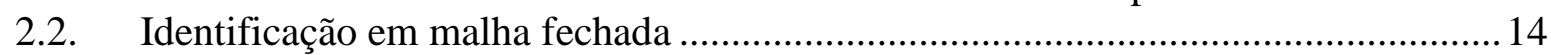

2.2.1. Métodos de excitação ............................................................................ 15

2.2.2. Métodos de obtenção dos parâmetros dos modelos.......................................... 21

2.2.3. Métodos escolhidos para estrutura e obtenção dos parâmetros dos modelos ...22

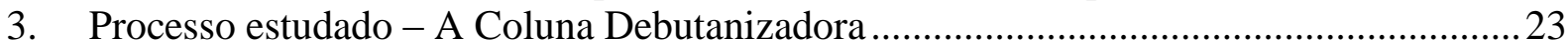

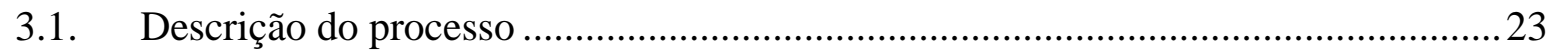

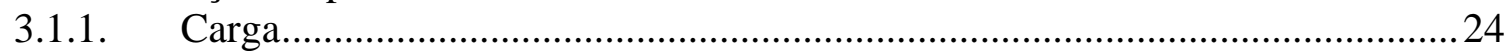

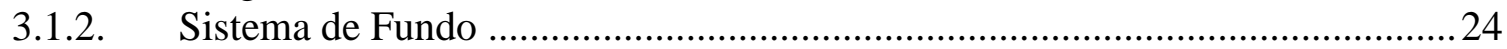

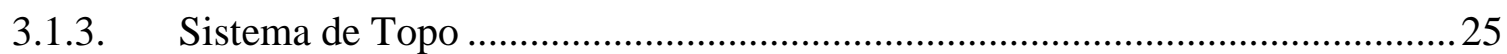

3.2. Descrição do sistema de controle da coluna debutanizadora .................................. 25

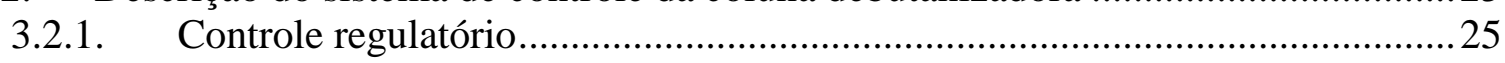

3.2.2. Controle preditivo multivariável baseado em modelos (MPC) ........................26

3.2.3. Objetivos do controle preditivo multivariável da T-21002 …..........................27

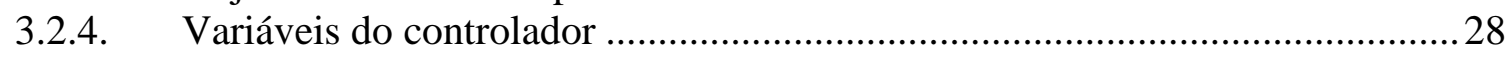

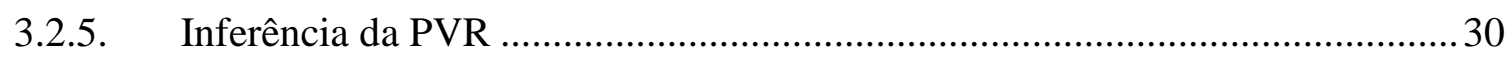

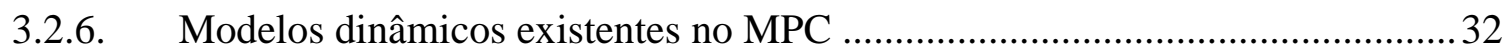

4. Simulação em Matlab do procedimento de re-identificação .............................................33

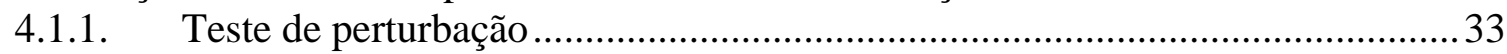

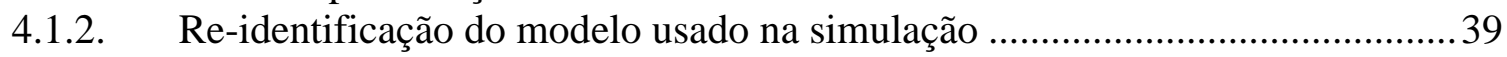

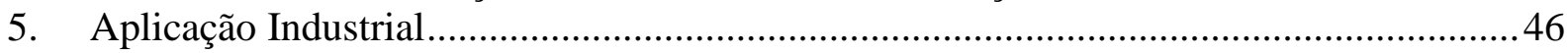

5.1 Teste de perturbação ................................................................................ 46

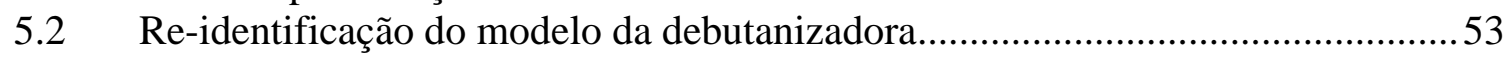

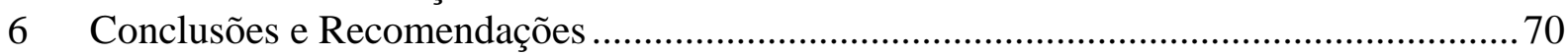

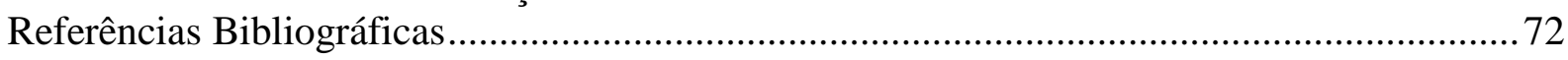

Apêndice 1 - Modelos ARX e ARMAX identificados a partir da resposta ao degrau para

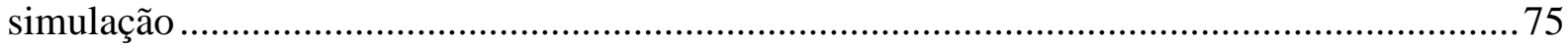

Apêndice 2 - Modelos re-identificados na simulação no domínio de Laplace.......................... 76 


\section{Introduçãa}

\subsection{Motivação}

Um dos fatores primordiais para a implantação bem sucedida de Controle Preditivo multivariável baseado em Modelos (MPC) é a utilização de modelos de processo representativos (Huang \& Tamayo, 2000). Estes modelos são usados para prever o comportamento futuro das variáveis controladas do sistema durante um horizonte de predição grande o suficiente para englobar todas as dinâmicas de processo que necessitam ser consideradas no cálculo da lei de controle.

Nas implantações de MPC é usual que o modelo de processo seja identificado usando testes em malha aberta nas fases iniciais do projeto do MPC. Nessa etapa os engenheiros de controle ou de processo permanecem na sala de controle durante muitas horas, normalmente no período noturno onde o processo sofre menos perturbações quando comparado ao período diurno, observando a reação do processo a alterações nele introduzidas, uma a uma (Miranda, 2005). São comuns as preocupações sobre a reação do processo às alterações introduzidas, como perda de qualidade dos produtos ou de produção levando muitas vezes a excitações incipientes do sistema. Um agravante dessas preocupações consiste no fato de que algumas malhas de controle PID tenham que ser abertas para realização desses testes.

O passo seguinte consiste em tratar os dados obtidos selecionando janelas adequadas e filtrando os ruídos de elevada frequência para então alimentar os dados obtidos em softwares de identificação. Caso alguns dos modelos identificados não sejam satisfatórios, principalmente quanto à magnitude e direção do ganho estacionário e à dinâmica dominante, é comum a realização de novos testes até que se obtenham modelos mais próximos do esperado.

Por ser uma tarefa dispendiosa em termos de recursos humanos os modelos do processo raramente são atualizados. Essa atualização faz-se necessária à medida que alguns modelos contidos no controlador não representam mais o processo de modo satisfatório, seja porque o processo apresenta comportamento dinâmico diferente do inicialmente identificado ou porque seu ganho estacionário mudou significativamente. Essas mudanças no processo são causadas por grandes variações de composição ou vazão de carga, desgaste natural dos equipamentos, depósitos, mudanças de especificação ou ponto de operação. 
Após certo período de tempo da implantação do MPC é comum que haja discordância entre planta e modelos levando à degradação da eficiência do sistema de controle e à consequente diminuição dos retornos financeiros esperados (Bauer e Craig, 2008). Dessa forma é necessário re-comissionar o MPC de tempos em tempos o que significa re-identificar o processo e, se necessário, re-sintonizar o controlador.

Essa re-identificação pode ser realizada de duas maneiras: desligando-se o MPC e alterando os valores de referência das variáveis manipuladas segundo critérios pré-definidos, denominada re-identificação em malha aberta, ou mantendo-se o MPC ligado e modificando alguns dos seus parâmetros para gerar um sinal suficiente para identificar o modelo, denominada re-identificação em malha fechada (Sotomayor et al., 2009).

As vantagens dos métodos de re-identificação em malha fechada com controladores MPC quando comparados aos testes em malha aberta são:

a) Economia de tempo porque o sinal de excitação é inserido simultaneamente e de forma automática em todas as entradas manipuladas. Essa estratégia leva a um menor tempo total do teste de identificação. Além disso, como o procedimento não demanda a presença de uma equipe para acompanhamento e monitoramento do teste, há uma considerável redução no custo do teste em termos de homens hora.

b) Manutenção da continuidade operacional do processo devida à não violação das restrições relacionadas aos equipamentos e especificações dos produtos, sendo, portanto uma técnica mais segura e barata. Não há necessidade da programação do teste dentro das atividades de produção da planta industrial porque o efeito nas vazões e especificações dos produtos é mínimo.

As desvantagens incluem possível redução na excitação, causada pelo "feedback" do controlador que tenta manter as variáveis controladas nos "set-points" desejados, levando a razões sinal/ruído baixas, e alta correlação entre as entradas levando, em última análise, a modelos não-representativos. No caso do controlador considerado neste trabalho onde as saídas do processo são controladas por faixas, existe a possibilidade dessa correlação não ser significativa, pois enquanto as saídas controladas permanecerem dentro das faixas o controlador não toma nenhuma ação de controle e as entradas podem ser manipuladas para excitar o processo. Portanto, um dos objetivos deste trabalho é verificar se a adoção do 
controle por faixas é favorável à re-identificação do modelo em um esquema com controlador MPC em malha fechada.

\subsection{Objetivos}

Poucas aplicações industriais de identificação em malha fechada têm sido reportadas na literatura. Por exemplo, Aling e Heintze (1992), Pasadyn et al. (1999) e Östring et al. (2003) descrevem, respectivamente, aplicações em uma caldeira industrial, em um reator industrial de $\mathrm{pH}$ e em um robô industrial da ABB. Entretanto, nesses trabalhos, a estrutura de controle é convencional com controladores PID.

O presente trabalho, como citado acima, tem como principal objetivo aplicar industrialmente em uma refinaria de petróleo uma das poucas propostas de re-identificação de modelos de processo para MPC em malha fechada existentes na literatura de controle, verificando sua viabilidade prática em termos de produzir um modelo aceitável e que resulte em melhorias na performance do controlador. O método empregado foi proposto em Sotomayor et al. (2009) e foi escolhido por aplicar-se especificamente para o MPC de duas camadas e controle das saídas por faixas, características comuns aos controladores das refinarias da Petrobras. A principal característica desse método de re-identificação é que a adaptação do controlador existente para o procedimento de re-identificação automática não exige nenhuma modificação no código do controlador, pois o sinal de excitação do processo é introduzido através dos parâmetros de sintonia da camada de cálculo dos "targets" ótimos para as variáveis manipuladas.

Sendo a metodologia estudada bem sucedida na aplicação industrial, pretende-se fomentar a prática de re-identificação de modelos em malha fechada em outros controladores preditivos existentes. Desta forma, o trabalho aqui descrito é o primeiro teste prático dessa metodologia que foi especialmente desenvolvida para MPC de duas camadas. Espera-se que com um maior número de aplicações de re-identificação em malha fechada haja um amadurecimento da técnica com novas contribuições para o aprimoramento em diversos casos industriais. 


\subsection{Etapas do trabalho}

Como primeira etapa do trabalho foi realizada uma pesquisa bibliográfica, tanto na área de MPC quanto de identificação em malha fechada, pontos focais desse trabalho, que será apresentada no capítulo a seguir.

Os capítulos seguintes abordam a implementação da técnica de re-identificação escolhida, iniciando com uma descrição do processo em que foi aplicada e com uma exposição dos objetivos do MPC desse processo. Para efetuar o teste industrial da técnica em questão optou-se por realizar preliminarmente uma simulação do sistema estudado em Matlab. Esta simulação compreende o sistema de controle preditivo multivariável bem como o teste de re-identificação, tendo como objetivo avaliar o comportamento do sistema e prever possíveis dificuldades de implementação no sistema real.

Após a validação da re-identificação na simulação parte-se então para a aplicação na planta de processo real. Após a obtenção dos novos modelos a última etapa consiste em substituir os modelos no controlador existente e avaliar seu desempenho. 


\section{Revisão bibliográfica e escolha das técnicas}

Nas seções que seguem nesse capítulo será apresentada uma visão geral sobre MPC e identificação de processos visto que são os dois tópicos de maior relevância para a aplicação realizada nesse trabalho. Na medida em que as diferentes abordagens são pontuadas também é destacado onde se encaixa o caso de aplicação detalhado no capítulo 3 dentro das diversas técnicas de MPC e identificação em malha fechada existentes.

\subsection{Controle Avançado e MPC}

Controle avançado é um conjunto de diferentes técnicas e algoritmos que incorporam um nível adicional de inteligência, em geral algum tipo de modelo do processo ou automação de um conjunto de regras heurísticas pré-definidas, em relação aos algoritmos de controle regulatório. A implantação de algoritmos de controle avançado pode ser feita utilizando-se o próprio sistema de controle regulatório, ou ainda em computadores de processo, que enviam as ações calculadas de controle para o sistema de controle regulatório (SDCD) ou para os elementos finais de controle.

$\mathrm{Na}$ grande maioria dos casos, o controle avançado não interage diretamente com o elemento final de controle. A atuação é feita através do sistema regulatório de controle e em geral o controle avançado determina os "setpoints" das malhas de controle regulatório. Essa forma de controle denominada controle supervisório é vantajosa pelo fato de aproveitar a robustez do sistema de controle regulatório. Em geral, o controle supervisório atua sobre o processo com frequência bem mais baixa que o regulatório.

O controle avançado engloba diversas áreas, tais como, por exemplo: controladores preditivos multivariáveis baseado em modelos (MPC), controladores baseados em lógica "fuzzy", controladores baseados em redes neurais, analisadores virtuais ou inferências.

O MPC, principalmente na indústria do petróleo (plantas petroquímicas e refinarias), vem sendo amplamente utilizado e se diferencia dos controladores regulatórios principalmente por atuar em mais de uma variável manipulada ao mesmo tempo, projetar suas ações de controle estimando o futuro do processo e possuir capacidade de trabalhar com as restrições do processo. 


\subsubsection{Estrutura estudada: MPC em duas camadas e controle por faixas}

O MPC em que foi aplicado o método de re-identificação é um sistema em duas camadas (ver Figura 2-1), o qual é comum na indústria de petróleo e petroquímica (Rotava e Zanin, 2005; Young, 2006). A camada superior, denominada camada estacionária, corresponde a um algoritmo de otimização econômica simplificada definida da seguinte forma:

$$
\min _{\Delta u_{s}, \delta_{y}}-W_{1} \Delta u_{s}+\left\|W_{2} \Delta u_{s}\right\|_{2}^{2}+\left\|W_{3} \delta_{y}\right\|_{2}^{2}
$$

Sujeito a:

$$
\begin{aligned}
& \Delta u_{s}=u_{s}-u_{a t} \\
& y_{s}=G_{0} \Delta u_{s}+\hat{y}(k+n / k) \\
& u_{\min } \leq u_{s} \leq u_{\max } \\
& y_{\min } \leq y_{s}+\delta_{y} \leq y_{\max }
\end{aligned}
$$

Onde $u_{a t}$ é o vetor de variáveis manipuladas no tempo atual $k, u_{s}$ é o vetor de "targets" para as variáveis manipuladas, $y_{s}$ é o vetor de saídas preditas no estado estacionário, $\hat{y}(k+n / k)$ é a predição da saída controlada no instante $k+n$ calculado no tempo $k$ ( $n$ é o horizonte do modelo ou o tempo de acomodação do modelo), $G_{0}$ é a matriz de ganhos estacionários do processo e $\delta_{y}$ é o vetor de variáveis de folga para as variáveis controladas.

W1, W2 e W3 são matrizes contendo parâmetros de sintonia do controlador. W1 é a matriz diagonal contendo os parâmetros de sintonia relativos à derivada parcial da função econômica do sistema com relação a cada variável manipulada do controlador. Em última instância estando todas as predições das variáveis controladas dentro de suas respectivas faixas são os sinais dos coeficientes de Wl que indicarão a direção que cada variável manipulada deve seguir. As magnitudes dos coeficientes de $W 1$ indicarão a velocidade com que a variável manipulada deverá seguir nessa direção. A velocidade, entretanto, é afetada por outros parâmetros de sintonia, tanto na própria camada estacionária, caso dos coeficientes de $W 2$, quanto na camada dinâmica, caso da matriz $R$ e $\Delta u_{\max }$.

A matriz W2 contém os parâmetros de sintonia relacionados ao custo de movimentação da variável manipulada em questão. Quanto maior o valor do coeficiente em 
W2 menor será a tendência da respectiva variável manipulada se movimentar. W3 contém os parâmetros de sintonia que são os pesos das variáveis de folga das variáveis controladas. $\mathrm{O}$ valor relativo dos coeficientes de W3 para cada controlada elencará uma ordem de prioridade para manutenção das variáveis controladas dentro de sua faixa operacional sendo que aquelas com maior coeficiente em W3 terão maior prioridade para serem mantidas dentro de sua faixa.

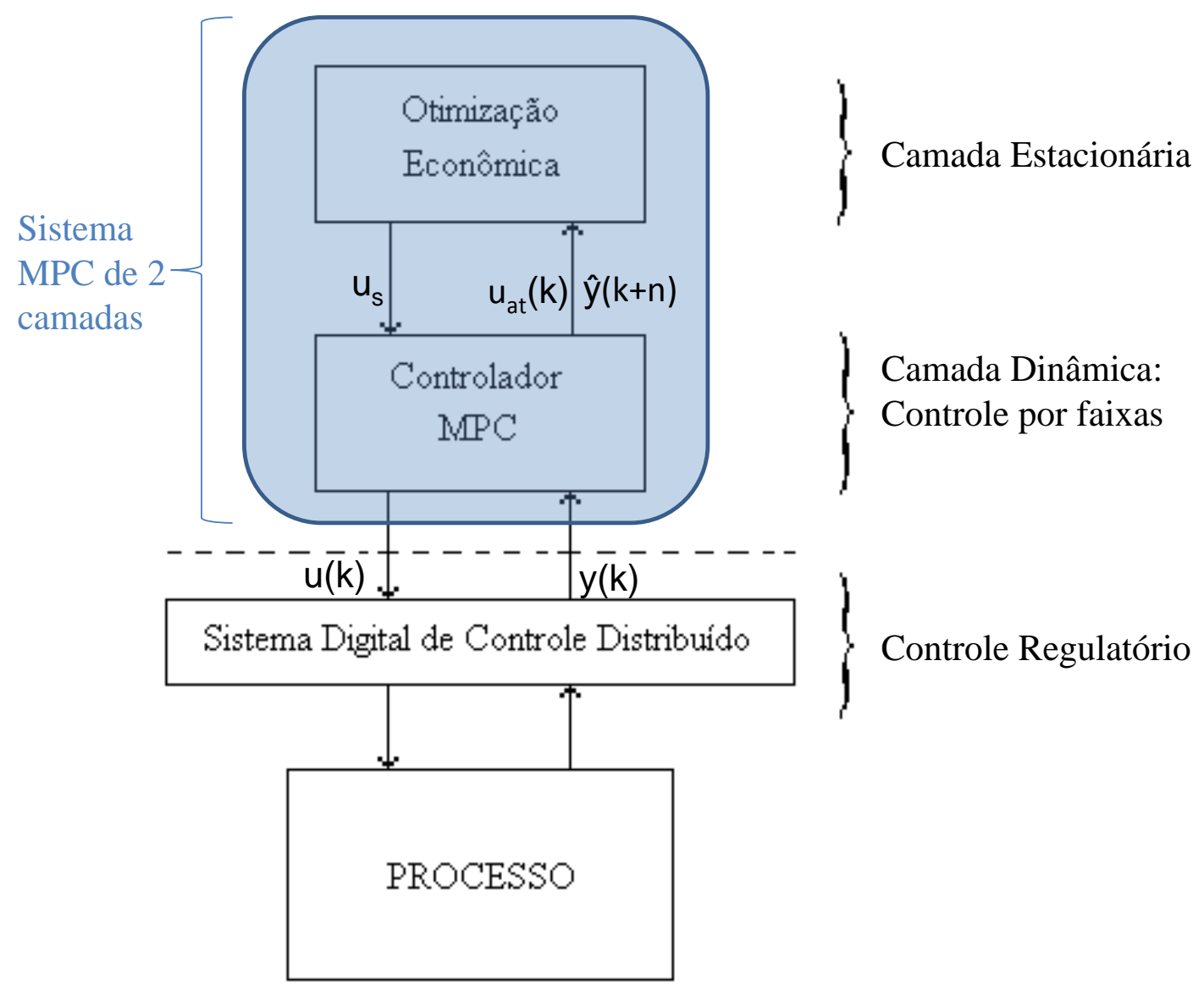

Figura 2-1. Estrutura de controle MPC em duas camadas

Como resultado da solução do problema (2.1), obtemos os "targets" das entradas $\left(u_{s}\right)$ que são passados ao controlador MPC propriamente dito, segunda camada do sistema denominada de camada dinâmica, neste caso um QDMC ("Quadratic Dynamic Matrix Control"), no qual as saídas são controladas por zonas. O QDMC soluciona o seguinte problema:

\footnotetext{
${ }^{1}$ O DMC (Cutler e Ramaker, 1980) é baseado em modelos não-paramétricos. Este controlador usa uma matriz triangular inferior conhecida como matriz dinâmica, o qual contém os coeficientes da resposta ao degrau (modelo FSR).
} 


$$
\begin{aligned}
\min _{\Delta u} & \sum_{i=1}^{p}\left\|Q\left(\hat{y}(k+i / k)-y_{\max , \min }(k+i)\right)\right\|_{2}^{2}+\sum_{j=1}^{m}\|R \Delta u(k+j-1 / k)\|_{2}^{2}+ \\
& \sum_{j=1}^{m}\left\|R_{u}\left(u_{a t}+\sum_{i=1}^{j} \Delta u(k+i-1 / k)-u_{s}\right)\right\|_{2}^{2}
\end{aligned}
$$

Sujeito a:

$$
\begin{aligned}
& -\Delta u_{\max } \leq \Delta u(k+j-1 / k) \leq \Delta u_{\max }, \quad j=1, \cdots, m \\
& u_{\min } \leq u_{a t}+\sum_{i=1}^{j} \Delta u(k+i-1 / k) \leq u_{\max }, \quad j=1, \cdots, m
\end{aligned}
$$

Onde $\hat{y}$ é o vetor de predições da saída, considerando o efeito das ações de controle futuras, e $\Delta u(k)=u(k)-u(k-1)$ é o vetor de incrementos das entradas. Os limites superiores das somatórias $p$ e $m$ são denominados, respectivamente, de horizonte de otimização e horizonte de controle. As matrizes $Q, R$ e $R u$ contêm parâmetros de sintonia da camada dinâmica do controlador. $Q$ é a matriz de pesos das controladas, $R$ é a matriz que representa o custo de movimentação das manipuladas e os coeficientes de $R u$ ponderam a distância de cada manipulada de seu target.

\subsection{Identificação em malha fechada}

Segundo Aguirre (2004) identificação de sistemas é a área do conhecimento que estuda maneiras de modelar e analisar sistemas a partir de observações, ou seja, de dados. Essa área tem sido alvo intensivo de pesquisa nos últimos 30 anos. Como resultado, inúmeras técnicas foram desenvolvidas as quais podem, em geral, ser classificadas em métodos do erro da predição (e.g. Ljung, 1999), métodos das variáveis instrumentais (e.g. Söderström e Stoica, 1983), métodos no subespaço de estados (e.g. Van Overschee e De Moor, 1996) e métodos de correlação e análise espectral (e.g. Jenkins e Watts, 1968). O presente trabalho utilizará métodos de erro da predição sendo este o método mais usado na geração de modelos para controle de processos.

A identificação em malha fechada tem surgido como uma ferramenta adequada para identificação de modelos para controle (Landau, 2001). Isso porque o controlador tenta preservar o desempenho do sistema, reduzindo os efeitos de distúrbios e mantendo o processo 
dentro da faixa operacional, os dados obtidos podem gerar modelos confiáveis sem incertezas significativas. Além disso, a presença do controlador tem uma vantagem adicional se o processo é mal-condicionado, como é o caso de colunas de destilação de alta pureza, onde as variáveis controladas apresentam forte correlação. No controle deste tipo de processo é importante identificar modelos que tenham uma boa estimativa nas direções de menor ganho e, para isto, é vital que as variáveis manipuladas exibam certa correlação, o que é criado naturalmente pela re-alimentação (Zhu, 2003).

Podemos dividir o problema de identificação em malha fechada em duas etapas complementares: o teste de identificação através da perturbação da planta e a posterior determinação dos parâmetros do modelo do processo a ser identificado.

\subsubsection{Métodos de excitação}

No aspecto da identificação é necessário que a entrada de processo seja persistentemente excitante (PE) (Ljung, 1999) e é interessante minimizar a correlação-cruzada entre as entradas (Sotomayor et al., 2009). Deve-se verificar, portanto, se a metodologia proposta produzirá tais entradas estando o MPC operando em malha fechada. Para confirmar essa premissa pode-se utilizar a seguinte definição:

Definição $1^{2}$ : Um sinal discreto no tempo é dito persistentemente excitante de ordem $n$ se (Söderström e Stoica, 1989):

O seguinte limite existe:

$$
r_{u}(\tau)=\lim _{N \rightarrow \infty} \frac{1}{N} \sum_{t=1}^{N} u(k+\tau) u^{T}(k)
$$

E a matriz:

$$
R_{u}(\eta)=\left[\begin{array}{cccc}
r_{u}(0) & r_{u}(1) & \cdots & r_{u}(\eta-1) \\
r_{u}(-1) & r_{u}(0) & \cdots & \vdots \\
\vdots & \vdots & \ddots & \vdots \\
r_{u}(1-\eta) & \cdots & \cdots & r_{u}(0)
\end{array}\right]
$$

\footnotetext{
2 Na Definição 1, se o sinal $u(k)$ é ergódico então $r_{u}(\tau)$ é a função de autocorrelação e $R_{u}(\eta)$ é a matriz de covariância comum do sinal de entrada. Da mesma forma, se o determinante de $R u(\eta)>0$, então o sinal $u(k)$ é persistentemente excitante de ordem $\eta$. Se $u(k)$ é persistentemente excitante de ordem $2 * \eta$, então um sistema com ordem $<=\eta$ é identificável.
} 


\section{É positiva definida.}

No aspecto de processo uma excitação adequada da planta envolve a manipulação das entradas de forma que as saídas permanecem dentro de suas faixas sem haver necessidade do controlador tomar ações para controlá-las. Além disso, é premissa básica que as entradas serão excitadas dentro de uma faixa operacional e atenderão às restrições de movimento máximo.

De acordo com alguns pacotes comerciais MPC, a duração do teste deve ser de seis a oito vezes o tempo máximo de estabilização do processo multiplicado pelo número de entradas, incluindo distúrbios medidos ${ }^{3}$ (Conner e Seborg, 2004). Baseado nisto, estimativas indicam que um projeto MPC típico terá cerca de $75 \%$ dos seus recursos, em tempo e dinheiro, gastos no trabalho de identificação, podendo atingir 90\% segundo Andersen e Kümmel (1992). Deve-se considerar, portanto, que o mecanismo de excitação automática do processo deva funcionar sem supervisão por períodos que podem chegar a dias, dependendo do tempo de estabilização e do número de entradas do sistema.

Dependendo da forma como esta perturbação é realizada, podem-se classificar as técnicas de identificação em malha fechada para sistemas MPC de três formas: com aplicação de uma excitação externa, com aplicação de uma excitação interna e com auto-excitação. Uma breve explicação desses métodos será apresentada nas subseções seguintes.

\footnotetext{
${ }^{3} T_{\text {teste }}=[6 \mathrm{a} 8] \cdot T_{\max } \cdot\left(n_{u}+n_{d}\right)$, onde $\mathrm{n}_{\mathrm{u}}$ e $\mathrm{n}_{\mathrm{d}}$ são, respectivamente, o número de variáveis manipuladas e o número de variáveis de distúrbio medidas e $\mathrm{T}_{\max }$ é o tempo máximo de estabilização do processo.
} 


\subsubsection{Excitação com aplicação de um sinal externo}

Neste caso, um sinal persistente de teste é adicionado nas variáveis manipuladas (Celaya et al., 2004; Kline et al., 2006), no "setpoint" das variáveis controladas ${ }^{4}$, ou em ambos (Zhu e Butoyi, 2002), conforme mostrado na Figura 2-2.

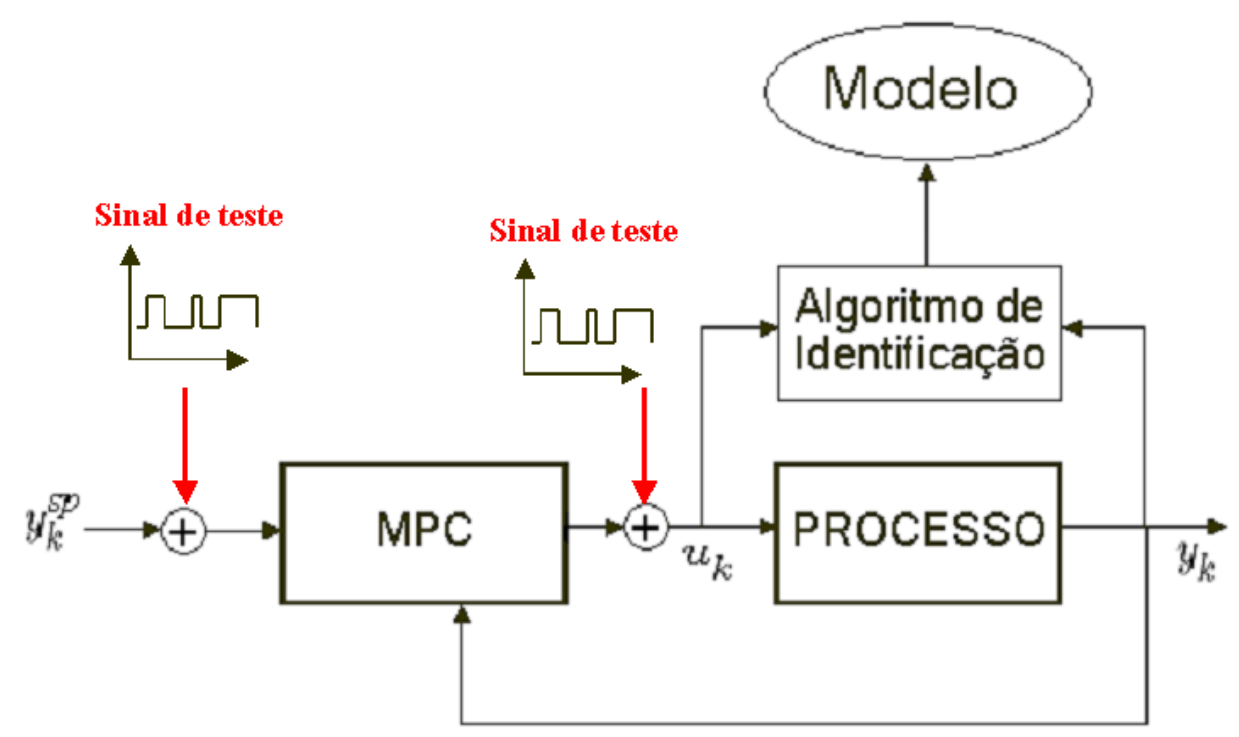

Figura 2-2. Identificação em malha fechada de MPC com excitação externa

O esquema da Figura 2-2 é comumente usado com sucesso em vários processos industriais operando sob MPC, principalmente em refinarias e indústrias petroquímica, por exemplo, através do software comercial Tai-Ji ID baseado na teoria assintótica (ASYM) de Ljung (1985).

\subsubsection{Excitação com aplicação de um sinal interno}

A desvantagem de aplicar uma excitação externa é a falta de uma forma sistemática de projetar o sinal de teste, o que pode resultar em excessiva ou insuficiente excitação para o sistema. Uma excitação excessiva (e.g. aumentando o nível do sinal de teste) pode comprometer os objetivos de controle, e uma excitação insuficiente pode comprometer os objetivos de identificação. Especialmente, no caso de sistemas MIMO, projetar sinais de teste que garantam tanto a controlabilidade como a identificabilidade do processo é muito difícil.

\footnotetext{
${ }^{4}$ A aplicação do sinal PE no "setpoint" pode ser realizada quando o controlador é quadrado e, pelo menos, moderadamente bem ajustado (Doma et al., 1996).
} 
Para contornar este problema, Sagias e Nikolaou (2001) propõem incluir, na função objetivo de um MPC convencional, objetivos de controle e objetivos de identificação, onde o sinal de teste é aplicado nas variações do sinal de controle, conforme mostrado a seguir:

$$
\begin{aligned}
& J_{k}=(1-\lambda)\left[\sum_{i=1}^{p}\left(\hat{y}(k+i)-y_{s p}\right)^{T} Q\left(\hat{y}(k+i)-y_{s p}\right)+\sum_{i=1}^{m} \Delta_{s}(k+i-1)^{T} R \Delta u(k+i-1)\right]+ \\
& \lambda\left[\sum_{i=1}^{m}\left(\Delta v(k+i-1)-\Delta_{u u_{\theta x e}}\right)^{T} P\left(\Delta u(k+i-1)-\Delta \varepsilon_{\theta x c}\right)\right] \\
& \text { Sinal de teste }
\end{aligned}
$$

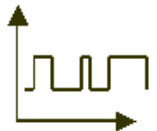

A proposta de Sagias e Nikolaou (2001) não muda substancialmente o problema de otimização QP, cuja solução ajusta as ações de controle orientadas ao controle regulatório das saídas do processo, e os sinais orientados à identificação, para as entradas do processo. Desta forma, as exigências de identificabilidade são alcançadas, enquanto que a segurança do processo e as especificações da qualidade do produto, expressas em termos de "hard constraints", são satisfeitas. O operador pode escolher a agressividade e eficiência da identificação mudando simplesmente os pesos relativos de ambos objetivos. Quando $\lambda=0$, a identificação é finalizada e o novo modelo pode ser aplicado no controlador. Os sinais de teste são PRBS, construídos usando diferentes polinômios característicos para evitar a correlaçãocruzada das entradas. Um dos problemas dessa formulação é que ela não pode ser aplicada em controladores existentes, pois são necessárias mudanças no código do programa que representa o controlador.

Outro método é apresentado por Miranda (2005), que propõe perturbar as restrições ativas das variáveis controladas com sinais PE, neste caso PRBS. Esta proposta é interessante, já que as perturbações nos limites acabam funcionando na prática como "setpoints" das variáveis controladas sendo, portanto, uma forma alternativa de perturbar os "setpoints" para sistemas não quadrados. Como exemplo, Miranda (2005) aplica sua metodologia para estimar um modelo ARX MIMO de uma coluna industrial de destilação atmosférica. O modelo 
identificado foi substituído no controlador com uma melhora significativa no seu desempenho.

O método empregado nesse trabalho também faz parte da classe de métodos classificados como de excitação interna. Esse método foi apresentado em Sotomayor et al. 2009 e será detalhado na subseção 2.2.1.4 deste trabalho.

\subsubsection{Com auto-excitação}

Visando garantir controle e identificação simultâneos, Genceli e Nikolaou (1996) propõem o MPCI (“Model Predictive Control and Identification”), onde uma condição PE das entradas (matriz de covariância) é incluída como restrição (mantida acima de um valor mínimo) no problema de otimização, a qual pode ser ligada ou desligada conforme haja interesse em se realizar a identificação. Esta formulação assegura que as entradas do processo sejam excitadas tal que possam gerar dados informativos sobre a dinâmica do processo, porém, mantendo as saídas nos "setpoints" desejados.

Além dos parâmetros habituais de sintonia de um MPC, o MPCI traz alguns parâmetros como nível de excitação, tamanho da janela de identificação, peso da restrição adicional e fator de esquecimento. Na tese de Ballin (2008) são estudadas diferentes formulações dá técnica de MPCI aplicadas em controladores com modelos em espaço de estado tipo OPOM (Modelos Orientados à Predição da Saída). Esse método apresenta também a desvantagem da necessidade de se alterar significativamente o programa do controlador e, portanto, não pode ser utilizado com controladores comerciais.

\subsubsection{Método de excitação aplicado neste trabalho}

A estratégia de controle das saídas por zonas no MPC impossibilita a implementação da estratégia de identificação em malha fechada mais comum que introduz o sinal de excitação através dos "setpoints" das saídas. Por outro lado, ela pode possibilitar a aplicação de técnicas de identificação em malha aberta se o sinal de excitação for tal que as variáveis controladas se mantenham dentro de suas zonas com um mínimo de ação de controle em feedback. Essa condição se torna mais favorável ainda quando o controlador tem duas camadas com a camada superior (estática) gerando "targets" para as entradas na camada 
inferior (dinâmica). Nesse caso, o processo pode ser excitado através desses "targets" se eles forem gerados convenientemente.

No presente trabalho para gerar essa excitação utiliza-se um sinal de excitação binário $(+1,-1)$ que multiplica o coeficiente $W 1$ do termo linear na função objetivo da camada de cálculo do "targets", podendo, portanto ser classificado como um método de excitação interno. Dessa maneira quando o controlador for usado para re-identificação do modelo do processo, o problema do cálculo do target ficará escrito da seguinte forma (Sotomayor et al., 2009):

$$
\min _{\Delta u_{s}, \delta_{y}}-\left(W_{e x c} W_{1}\right)^{T} \Delta u_{s}+\left\|W_{2} \Delta u_{s}\right\|_{2}^{2}+\left\|W_{3} \delta_{y}\right\|_{2}^{2}
$$

Onde Wexc é uma matriz diagonal cujos componentes podem assumir os valores binários $1 \mathrm{ou}-1$. Dessa forma, se o produto $W_{\text {exc }} W_{l}$ é positivo (negativo) o target calculado deverá ocasionar um aumento (redução) da manipulada $u_{i}$ até que esta atinja seu limite superior (inferior) ou as predições das controladas saiam da zona de controle.

Observe que se Wexc for igualada à matriz unitária volta-se a produzir a equação (2.1) e o controlador retorna a seu modo normal de operação. Essa facilidade de alterar os modos do controlador entre operação normal e identificação sugere grande aplicabilidade em MPCs com estruturas semelhantes à apresentada anteriormente. O sinal de excitação Wexc deve ser projetado para que as correlações cruzadas entre as entradas do processo sejam minimizadas.

Na re-identificação do modelo de processo, o interesse está em um determinado intervalo de frequências em vez de todo o espectro. Isto se deve ao fato de que a faixa de frequências de interesse de um MPC é geralmente concentrada na parte inferior do espectro. Um dos sinais de teste usualmente adotados no processo de identificação, o "Generalized Binary Noise" (GBN), proposto por Tulleken (1990) tem um único parâmetro relacionado à probabilidade de chaveamento. Este parâmetro permite a manipulação do espectro de potência do sinal de teste, de modo que a energia possa ser concentrada na faixa de baixa frequência. Devido a esta facilidade o GBN é considerado um sinal de excitação adequado para a reidentificação de processos industriais no âmbito de controle (Zhu, 2001) e, assim, o sinal de teste proposto por Sotomayor et al. (2009) e utilizado nesse trabalho é um GBN com parâmetros adequados. Considerando o tempo médio de comutação do sinal GBN como sendo 
igual a um terço do tempo de estabilização do processo (Zhu, 2001), pode-se calcular sequências de sinais independentes de mesma magnitude \pm 1 para cada uma das manipuladas pelo controlador. Assume-se que uma estimativa do tempo de estabilização é previamente conhecida através do modelo atual utilizado no controlador

\subsubsection{Métodos de obtenção dos parâmetros dos modelos}

As técnicas de identificação em malha fechada podem ser classificadas dependendo da natureza do controlador e das suposições a respeito do modelo do ruído, em três diferentes métodos (Ljung, 1999).

O método direto usa os sinais de entrada e saída do processo, ignorando a presença do controlador, da mesma forma que uma identificação em malha aberta. Não necessita de software específico sendo que algoritmos de predição do erro do modelo podem ser usados de forma direta. O método requer um modelo adequado do ruído para evitar "bias" no modelo da planta sendo que experimentos muito ruidosos podem comprometer o modelo obtido.

O método indireto usa os sinais do "setpoint" e saída do processo, requerendo perfeito conhecimento da estrutura do controlador. Não funciona se o controlador apresenta nãolinearidades e não há necessidade de conhecer a representação do ruído. Como o controlador MPC com restrições é um controlador não linear de estrutura desconhecida, pois a estrutura vai depender das restrições ativas, este método não pode ser aplicado para controladores MPC.

O método conjunto de entrada e saída usa os sinais de entrada e saída como sendo as saídas de um sistema aumentado cujas entradas são o "setpoint" e o ruído. Fornece estimativa consistente, independente do modelo de ruído usado, desde que o controlador tenha uma determinada estrutura LTI ("Linear Time-Invariant”). Permite realizar a identificação não só dos modelos da planta e do ruído como também do controlador. Mais uma vez esse método se torna questionável se o controlador incluir restrições que podem se tornar ativas. 


\subsubsection{Métodos escolhidos para estrutura e obtenção dos parâmetros dos modelos}

Em princípio os modelos obtidos pela estratégia adotada neste trabalho podem ser identificados de forma direta, pois a formulação de controle das saídas por zonas possibilita a minimização do efeito da realimentação nas entradas, possibilitando um maior sucesso da aplicação desse método de obtenção dos parâmetros do modelo.

Com relação à estrutura do modelo utilizado foram escolhidos inicialmente modelos contínuos MISO (múltiplas entradas e uma saída) com estrutura OE ("erro na saída”) para representar o processo (Sotomayor et al., 2009). Procedimentos para resolver o problema de cálculo de parâmetros de modelos MISO OE têm sido desenvolvidos como uma extensão dos procedimentos para sistemas SISO (uma entrada e uma saída), resultando na estimação das funções de transferência com denominadores comuns, o que não é muito realista em muitas aplicações práticas. No presente trabalho, é usado o CONTSID toolbox ${ }^{5}$ (Garnier et al., 2003; Garnier e Gilson, 2006), que inclui métodos para estimar sistemas MISO descritos por várias funções de transferências com diferentes denominadores. Em especial, foi usada a rotina coe (“continuous output error”) baseada no algoritmo de programação não-linear LevenbergMarquardt, levando em conta, novamente, o conhecimento dos valores dos parâmetros do modelo usado no controlador como solução inicial do problema de otimização. É necessário enfatizar que o CONTSID toolbox não estima tempos mortos. Estes parâmetros são mantidos constantes e definidos a priori.

Alternativamente um modelo com estrutura ARMAX (auto- regressivo com média móvel e entradas exógenas) foi identificado. A estrutura ARMAX é adequada a identificações em malha fechada, pois, havendo um modelo independente para o distúrbio pode-se trabalhar melhor com os casos em que há correlação entre entrada e saída.

Também foi empregada em alguns casos a rotina pem do Matlab que identifica modelos em espaço de estado com ordem variável para minimizar o erro quadrático entre a predição do modelo e os dados do processo.

\footnotetext{
${ }^{5}$ Disponível em: http://www.cran.uhp-nancy.fr/contsid.
} 


\section{Processo estudado - A Coluna Debutanizadora}

O processo considerado para teste da metodologia de re-identificação em malha fechada descrito na seção anterior foi uma torre estabilizadora de nafta da área de destilação da Refinaria Henrique Lage (REVAP). Esse processo, descrito na seção 3.1, foi escolhido por apresentar um sistema de controle baseado em um MPC com apenas duas manipuladas e três controladas e nenhum distúrbio medido. $\mathrm{O}$ fato de possuir relativamente poucas manipuladas e controladas ${ }^{6}$ facilita o trabalho de análise pormenorizada dos modelos e de validação inicial da técnica de re-identificação. Além disso, o desempenho do MPC existente deixava bastante a desejar caracterizado por um baixo fator de operação (percentagem do tempo em que o MPC permanece ligado) e baixo tempo em que o controlador mantém o processo no ponto ótimo (normalmente definido por restrições ativas). O baixo desempenho era traduzido em um comportamento oscilatório das variáveis manipuladas. Essa perda de desempenho pode ser justificada por inadequação do modelo à realidade do processo. Desde a última parada total para manutenção da unidade em outubro de 2008 sabe-se, por exemplo, que a eficiência de troca dos permutadores de topo e fundo da torre diminuiu provavelmente devido à incrustação ou depósito além de tubos inutilizados por apresentarem vazamento. Os modelos existentes no controlador foram identificados no final de 2006 com a unidade com pouco tempo de campanha.

\subsection{Descrição do processo}

A coluna estabilizadora possui 35 pratos valvulados e seu objetivo é promover a separação do Gás Liquefeito de Petróleo ou GLP, constituído basicamente por propano e butanos (C3, C4 e iC4), da nafta leve estabilizada constituída por hidrocarbonetos contendo de 5 a 10 átomos de carbono (C5+). Dessa forma, o componente-chave leve na coluna é o nbutano e o componente-chave pesado o isopentano. A Figura 3-1 apresenta um fluxograma simplificado do processo apresentando os principais equipamentos envolvidos e as condições operacionais típicas.

\footnotetext{
${ }^{6}$ Comparativamente o controle do conversor da unidade de craqueamento catalítico apresenta 10 manipuladas, 17 controladas e 3 distúrbios medidos.
} 


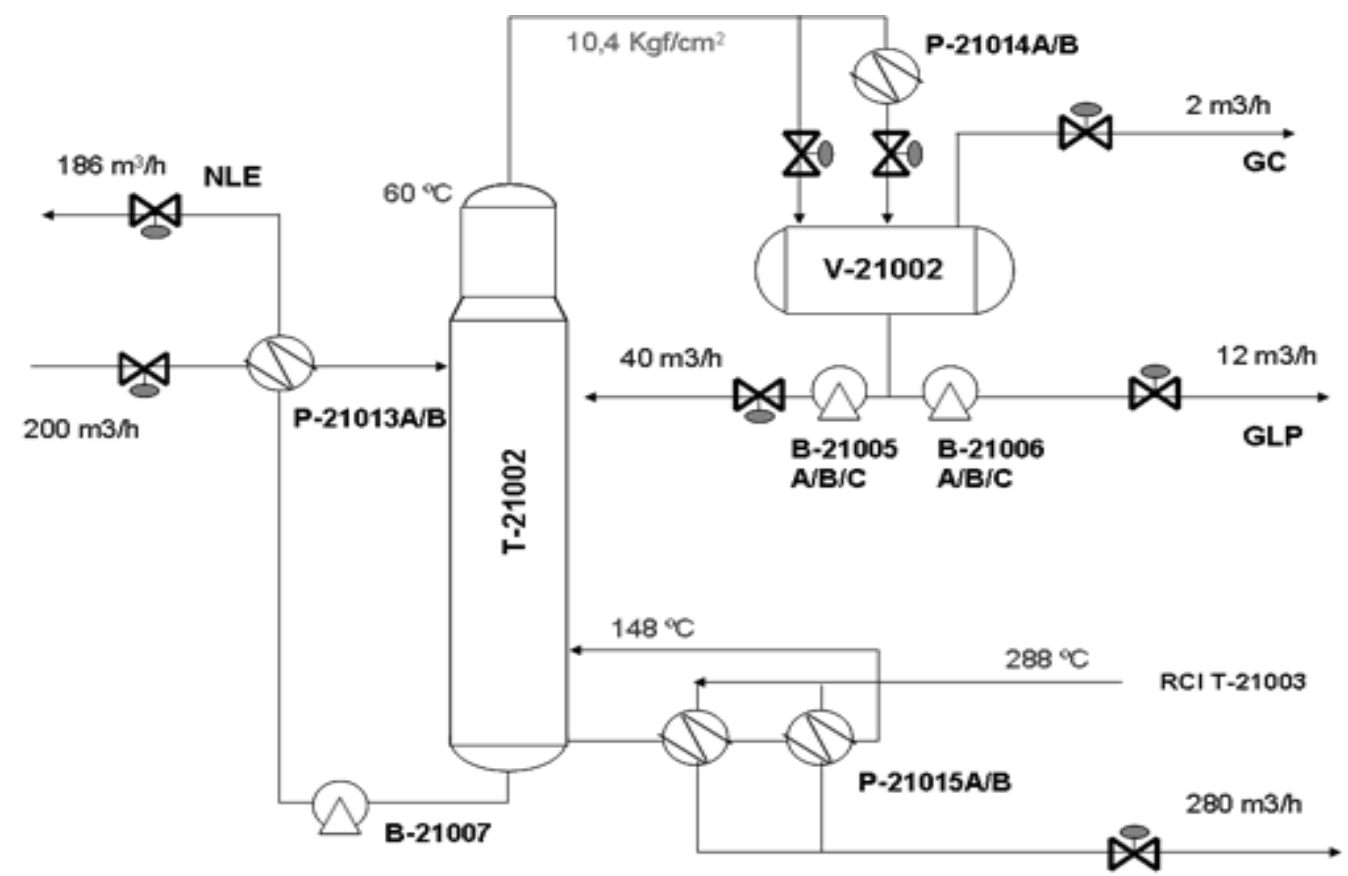

Figura 3-1. Coluna estabilizadora com seus principais equipamentos, válvulas e variáveis de processo

\subsubsection{Carga}

A carga desta coluna constitui-se da nafta leve e da nafta pesada não estabilizadas provenientes respectivamente do vaso de topo da coluna pré-fracionadora e do vaso de topo da coluna de destilação atmosférica. A vazão de carga varia entre $150 \mathrm{~m}^{3} / \mathrm{h}$ e $250 \mathrm{~m}^{3} / \mathrm{h}$ dependendo das condições e é admitida na torre estabilizadora (T-21002) entre os pratos 17 e 18, sendo antes aquecida nos pré-aquecedores de carga (P-21013 A/B) trocando calor com o próprio produto de fundo da torre.

Existem alternativas para admissão da carga entre os pratos 21 e 22, 23 e 24 e 25 e 26. A vazão de carga para a coluna é controlada operando em cascata com um controlar de nível do vaso de topo da coluna pré-fracionadora com sintonia pulmão (Friedman, 1994).

\subsubsection{Sistema de Fundo}

A carga térmica necessária ao processo é fornecida por uma corrente de refluxo circulante intermediário da torre atmosférica que troca calor nos P-21015 A/B, com a corrente de produto de fundo da T-21002, que retorna aquecida para a coluna. A nafta estabilizada acumulada sob controle de nível no fundo da torre é bombeada pela B21007 para tanque de nafta petroquímica e/ou de gasolina, cedendo antes calor nos P-21013 A/B. 


\subsubsection{Sistema de Topo}

Os vapores de GLP que deixam a torre estabilizadora pelo topo são condensados nos P-21014 A/B trocando calor com água de resfriamento e recebidos no V-21002. Parte desses hidrocarbonetos condensados retorna a torre estabilizadora bombeados pelas B-21005 A/B/C sob controle de vazão do FC-21007, constituindo o refluxo de topo.

O restante do GLP produzido é enviado para uma torre absorvedora através das B21006 A/B/C sob controle de nível, que mantém constante o nível no V-21002. Essa torre absorvedora utiliza como líquido absorvedor uma solução aquosa de Dietanolamina (DEA) que tem a função de retirar $\mathrm{H}_{2} \mathrm{~S}$ da corrente de GLP. Antes de seguir para o parque de esferas onde é armazenado para ser enviado por dutos para as companhias distribuidoras o GLP passa por um tratamento cáustico com solução aquosa de $\mathrm{NaOH}$ para retirada de mercaptans.

O controle de pressão no sistema de topo é feito por dois controladores, conforme esquema da Figura 3-2, sendo que o primeiro controlador atua aliviando os não condensáveis do tambor de topo para UFCC ou controlando o efluente do condensador parcial dos gases de topo (P-21014 A/B) através de um controle "split-range" e o segundo, promove o contorno dos P-21014 A/B de parte dos vapores de topo da T-21002, estrutura conhecida como "hotby-pass" (Sloley, 2001). Essa estrutura garante um controle de pressão no vaso de topo evitando cavitação das bombas de retirada de GLP.

\subsection{Descrição do sistema de controle da coluna debutanizadora}

\subsubsection{Controle regulatório}

O controle regulatório compreende o conjunto de malhas de controle que atua sobre os elementos finais de controle, como as válvulas, utilizando geralmente como algoritmos de controle o PID. Estes controladores caracterizam-se por serem monovariáveis, possuírem elevada frequência de amostragem da variável controlada e atuação sobre o elemento final, e realizar controle por retroalimentação.

A Figura 3-2 apresenta a estrutura de controle regulatório e os principais indicadores de temperatura, pressão e vazão da T-21002. A função dos controladores foi resumida na Tabela 3-1. 


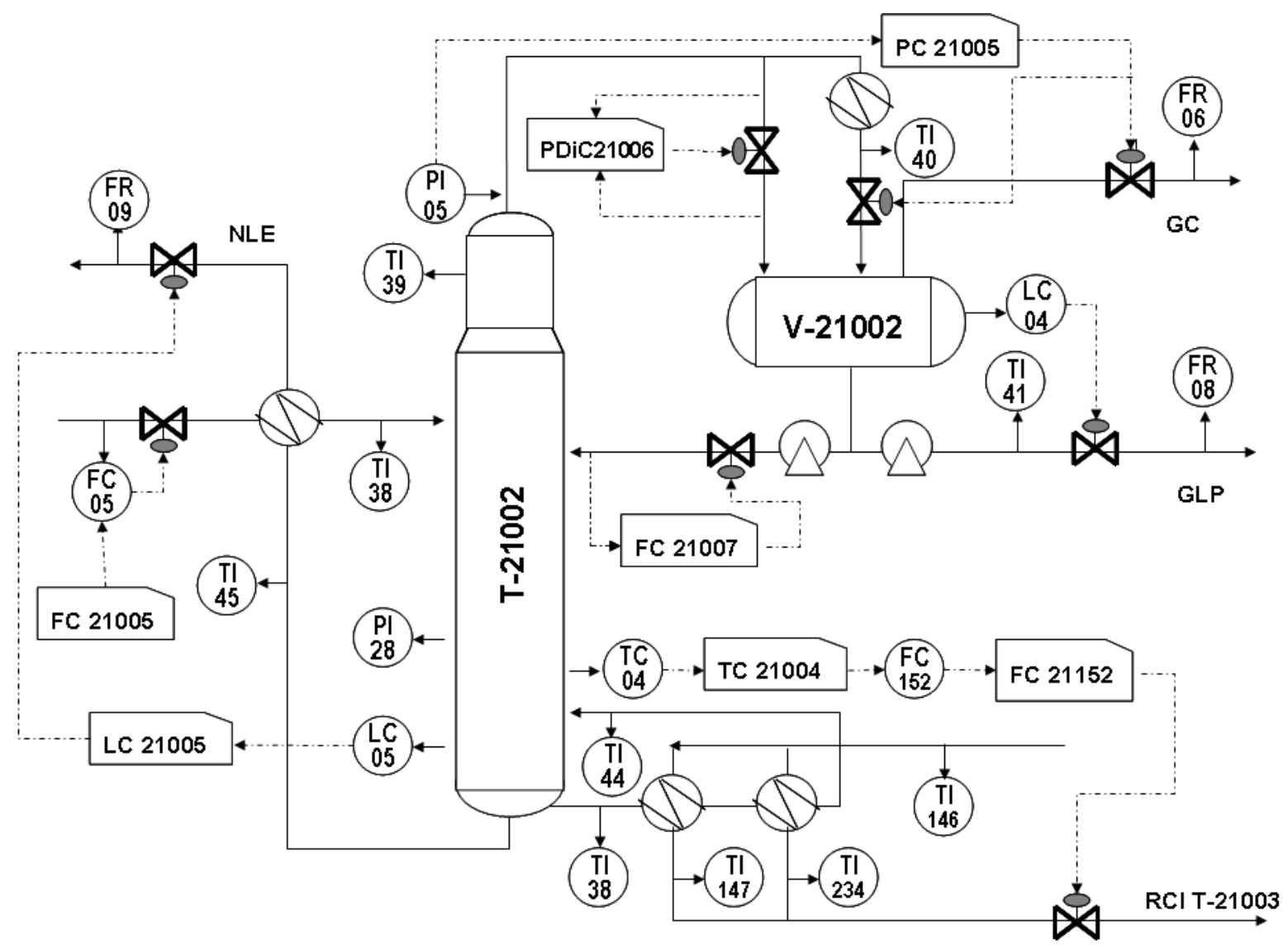

Figura 3-2. Controle regulatório e indicadores de temperatura, vazão e pressão

Tabela 3-1 - Controle básico da T-21002

\begin{tabular}{|l|l|}
\hline \multicolumn{1}{|c|}{ Controlador } & \multicolumn{1}{c|}{ Objetivo } \\
\hline FC21005 & $\begin{array}{l}\text { Controle de vazão de alimentação da T-21002. Recebe "setpoint" do } \\
\text { controlador de nível do vaso condensador da torre de pré-fracionamento V- } \\
21001\end{array}$ \\
\hline LC21005 & Controle de nível da T-21002 \\
\hline TC21004 & Controle de temperatura do prato 33. Envia "setpoint" para o FC21152 \\
\hline FC21152 & $\begin{array}{l}\text { Controle da vazão de refluxo circulante intermediário da coluna atmosférica } \\
\text { que passa pelos P15A/B }\end{array}$ \\
\hline FC21007 & Controle de vazão de refluxo para a T-21002 \\
\hline LC21004 & Controle de nível do V-21002 \\
\hline PC21005 & Controle de pressão de topo da T-21002 \\
\hline PdIC21006 & Controle de pressão diferencial entre o topo da torre estabilizadora e o V-21002 \\
\hline
\end{tabular}

\subsubsection{Controle preditivo multivariável baseado em modelos (MPC)}

Como mencionado anteriormente, desde 2006 atuando sobre o nível de controle regulatório da coluna debutanizadora, temos o nível de controle avançado que é constituído pelo controlador MPC e por algoritmos de inferência de propriedades dos produtos. O 
software de MPC empregado é o SICON (Sistema Integrado de Controle), software proprietário da Petrobras (Moro, 1997). O equacionamento do controlador foi abordado na subseção 2.1.1 deste documento. A interface de leitura e escrita no controlador é feita através do protocolo OPC. Os técnicos de operação interagem com o controlador definindo as faixas operacionais das variáveis controladas e manipuladas e ligando e desligando as variáveis manipuladas. Essas ações são realizadas através da tela de operação do SDCD apresentada na Figura 3-3.

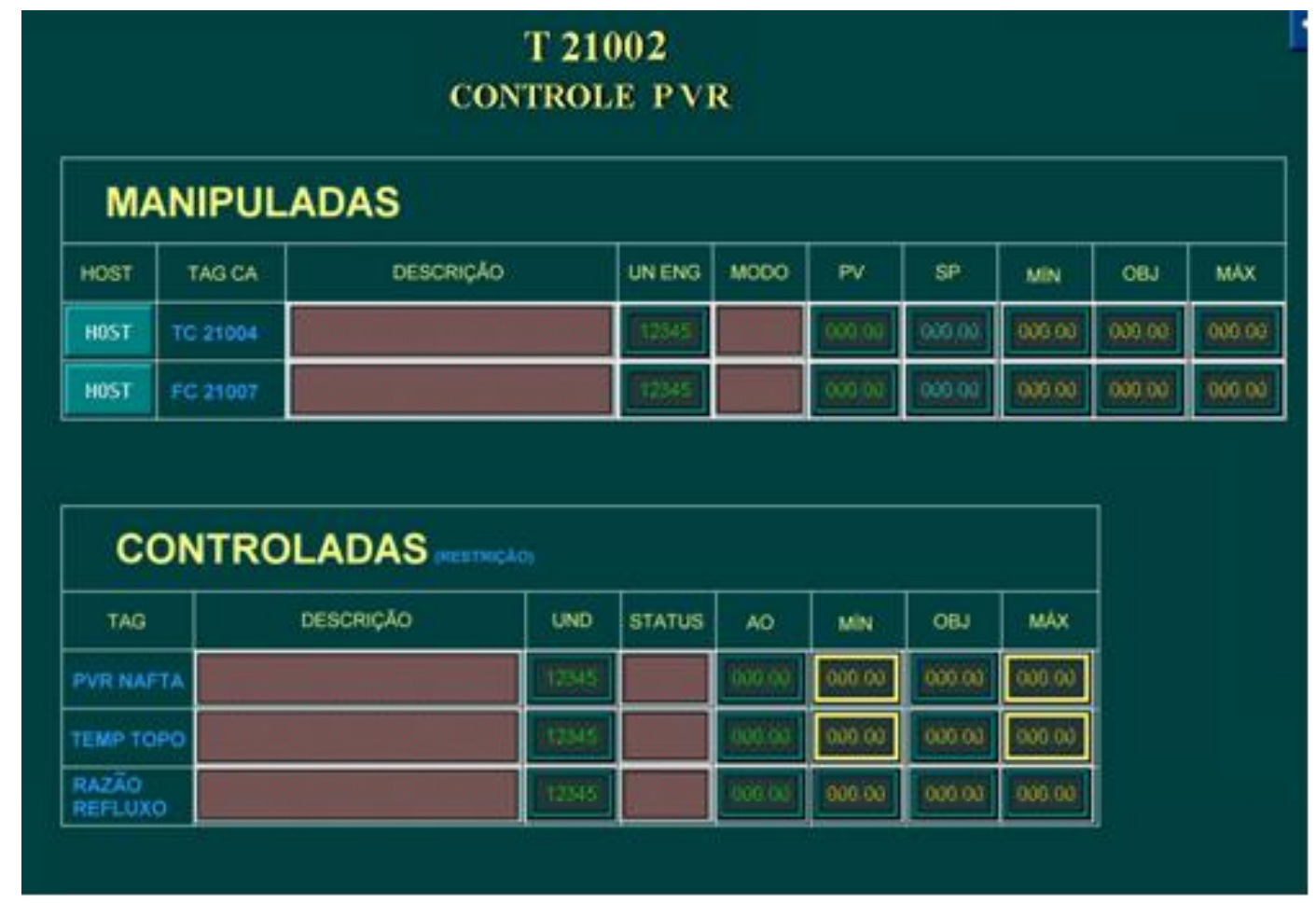

Figura 3-3. Tela de operação do MPC da T-21002

\subsubsection{Objetivos do controle preditivo multivariável da T-21002}

O objetivo de produção usual na torre estabilizadora consiste na maximização de produto de fundo através da incorporação de frações leves no mesmo, tendo como restrição o valor máximo da Pressão de Vapor Reid (PVR) da nafta leve estabilizada. A diretriz de maximizar a corrente de fundo deve-se ao maior valor agregado da nafta leve estabilizada frente ao GLP. Caso os valores de mercado se invertam a estratégia deve ser revista.

A Tabela 3-2 apresenta os valores máximos especificados de PVR da Nafta Estabilizada que compõem o pool de gasolina para os meses de verão e inverno. Esses valores são utilizados como referência para os limites da variável controlada PVR dentro do MPC. 
Tabela 3-2 - Valor máximo de PVR (especificação) - gasolina A

\begin{tabular}{|c|c|}
\hline Período & PVR máximo (kPa) \\
\hline Verão (nov., dez., jan., fev., mar.) & 62 \\
\hline Inverno (abr., maio, jun., jul., ago., set., out.) & 69 \\
\hline
\end{tabular}

A NLE pode ser comercializada como nafta petroquímica ou como gasolina. Grande parte da NLE é vendida como nafta petroquímica. A especificação quanto ao teor de leves da nafta petroquímica é menos restritiva do que para gasolina, permitindo maior incorporação de butanos na nafta.

Além da restrição de PVR, resultante do objetivo de produção, também há a necessidade de se manter um fracionamento mínimo entre GLP e NLE principalmente para evitar o surgimento de corrosão na nafta estabilizada. A corrosão, outra especificação do produto, indica presença de compostos sulfurados no produto.

Esse fracionamento mínimo é obtido mantendo-se a temperatura de topo acima de um valor mínimo, o qual varia conforme a condição de operação da unidade e está principalmente vinculado com a carga da unidade, e mantendo uma razão de refluxo dentro de uma faixa operacional.

\subsubsection{Variáveis do controlador}

A Figura 3-4 apresenta o conjunto de variáveis manipuladas, controladas e distúrbios que fazem parte do MPC. Este controlador é composto por duas variáveis manipuladas e três variáveis controladas.

\subsubsection{Variáveis Manipuladas}

O controlador possui dois graus de liberdade usualmente denominados como variáveis manipuladas. O grau de liberdade mais importante para os objetivos de produção é o valor de "setpoint" (SP) do PID da temperatura do prato 33 da torre estabilizadora (TC21004SP). Esse prato é denominado prato sensível da torre, pois uma variação em seu valor de temperatura representa maior variação na composição do produto de fundo do que uma variação na temperatura dos outros pratos. Pode-se afirmar que o valor dessa temperatura define o corte da nafta leve para uma determinada alimentação e pressão da coluna. 
Com o intuito de aumentar a produção de nafta leve estabilizada em detrimento de GLP o controle minimiza essa temperatura atendendo às restrições impostas pelos limites das controladas, principalmente da PVR. A faixa operacional dessa temperatura vai de $143^{\circ} \mathrm{C}$ a $155^{\circ} \mathrm{C}$.

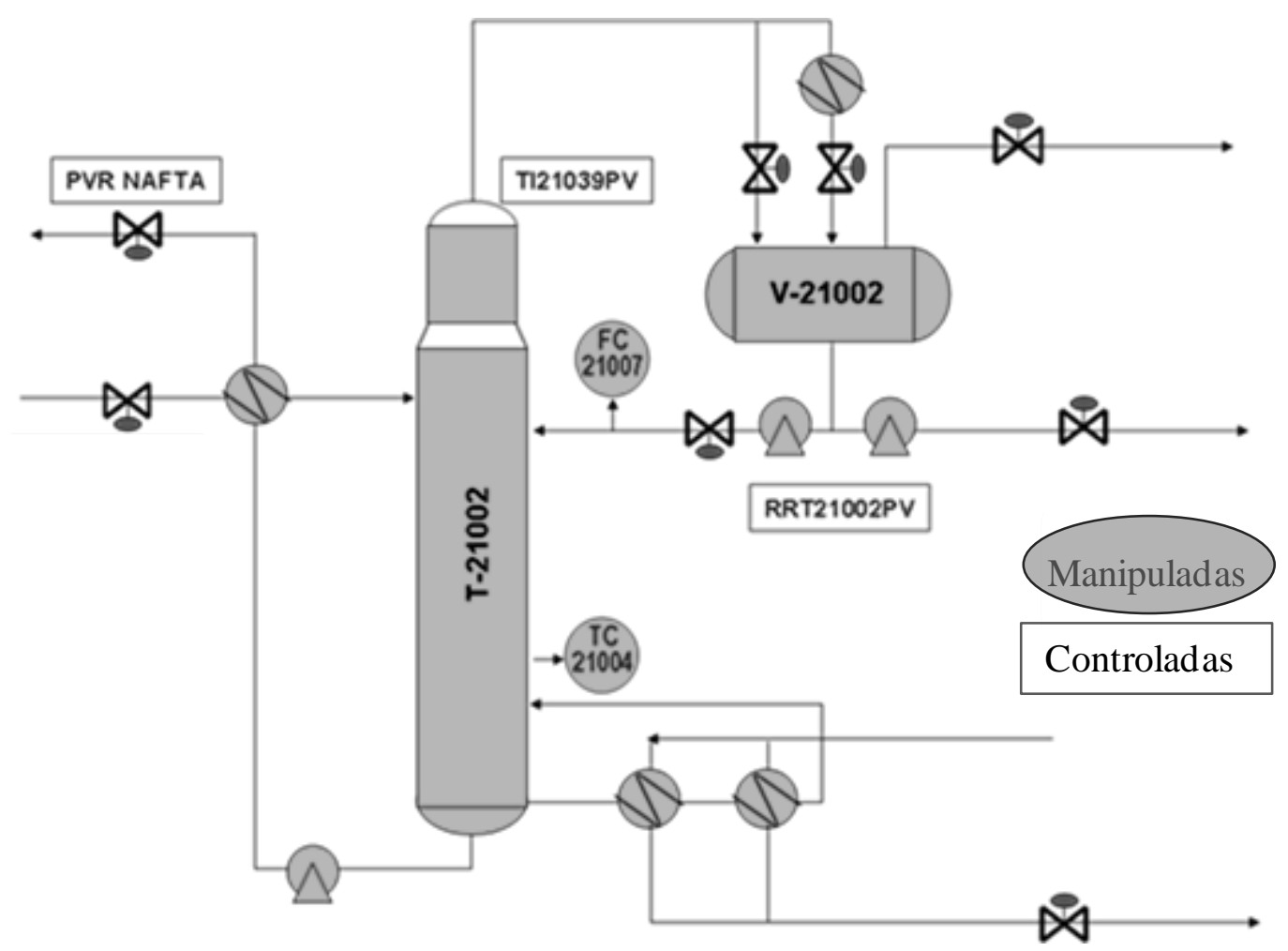

Figura 3-4. Variáveis manipuladas e controladas do MPC

O segundo grau de liberdade do MPC é o "setpoint" do PID de vazão de Refluxo da torre estabilizadora (FC21007SP). A vazão de refluxo define a qualidade do fracionamento na coluna. Sua faixa operacional se encontra entre $20 \mathrm{~m} 3 / \mathrm{h}$ e $60 \mathrm{~m} 3 / \mathrm{h}$. A direção normal de otimização dessa variável é buscar o máximo da faixa respeitando as restrições impostas pelas variáveis controladas.

\subsubsection{Variáveis Controladas}

As variáveis controladas estão associadas às restrições operacionais que se traduzem em restrições do MPC frente aos objetivos de otimização. Na torre estabilizadora o controlador apresenta três variáveis controladas já citadas anteriormente: a PVR, a temperatura de topo e a razão de refluxo. 
A pressão de vapor Reid (PVR) é uma medida da volatilidade da nafta, sendo definida como a pressão absoluta do produto a $100^{\circ} \mathrm{F}\left(37,8^{\circ} \mathrm{C}\right)$ como determinada pelo teste ASTM-D323. A gasolina automotiva apresenta em sua especificação (Portaria ANP no 309 27/12/2001) valores mínimo (45 KPa) e máximos (vide Tabela 3-2), pois na partida a frio do motor, a gasolina deve vaporizar para que a faísca possa detoná-la e na partida com o motor aquecido a gasolina não deve se expandir ao ponto de impedir a entrada do ar na câmara de combustão.

Não há medição da PVR em tempo real, ou seja, diferentemente de outras variáveis de processo como vazão, pressão, temperatura a PVR só é medida através de ensaios de laboratório realizados mediante a coleta de uma amostra da nafta leve estabilizada. Dessa forma para controlar a PVR foi desenvolvida uma correlação (inferência) que estima o valor da PVR da nafta baseada em condições operacionais medidas em tempo real. Essa inferência, bem como a atualização de seu valor através de dados de laboratório será abordada na subseção 3.2.5.

A temperatura de topo (TTopo) da torre estabilizadora é uma restrição operacional, pois se deve evitar que esta atinja valores muito baixos podendo acarretar no surgimento de corrosão na corrente de fundo. Sua faixa operacional vai de $64{ }^{\circ} \mathrm{C}$ a $54{ }^{\circ} \mathrm{C}$.

A Razão de Refluxo (RR21002) da torre estabilizadora é definida como a vazão de refluxo dividida pela soma da vazão de GLP com a própria vazão de refluxo. O objetivo desta variável controlada é manter o fracionamento da torre com uma eficiência adequada podendo variar de 0,7 a 0,9 .

\subsubsection{Inferência da PVR}

A principal variável controlada deste MPC é a PVR da corrente de nafta estabilizada. Esta variável é calculada utilizando a estrutura padrão do SICON. Os algoritmos de inferências são compostos de duas etapas:

Etapa de predição: a propriedade inferida é calculada na mesma frequência do controlador (1 vez/minuto) utilizando modelos matemáticos e variáveis de processo que são medidas (pressão, vazão, temperatura). 
Etapa de Correção: nesta etapa é realizada a correção periódica da propriedade inferida a partir de valores de laboratório. Esta correção é feita através do cálculo da diferença entre o valor de laboratório e uma média do valor inferido, para um período de 30 minutos antes do momento da coleta.

O cálculo do algoritmo PVR é baseado na temperatura e na pressão do fundo da fracionadora. A equação utilizada é:

$$
\begin{aligned}
& \text { PVR }=10^{\left[\log _{10}(\mathrm{P}) \times(1-\mathrm{AUX})+\log _{10}\left(\mathrm{P}_{-} \mathrm{INT}\right) \times \mathrm{AUX}\right]} \\
& A U X=\left(\frac{\left(T_{-} I N T+230\right) \times\left(T+T_{-} B I A S-37,8\right)}{\left(T+T_{-} B I A S-T_{-} I N T\right) \times 267,8}\right)
\end{aligned}
$$

PVR = Pressão de Vapor de Reid $\left(\mathrm{kgf} / \mathrm{cm}^{2} \mathrm{a}\right)$

$\mathrm{P}=$ pressão no fundo da torre $\left(\mathrm{kgf} / \mathrm{cm}^{2} \mathrm{~g}\right)$

$\mathrm{T}=$ Temperatura do fundo da torre $\left({ }^{\circ} \mathrm{C}\right)$. Aqui está se utilizando a temperatura do prato 33 da T-21002.

T_BIAS = correção aplicada na temperatura de fundo através da análise de laboratório $\left({ }^{\circ} \mathrm{C}\right)$

T_INT e P_INT representam a temperatura e a pressão do ponto de interseção das curvas de pressão de vapor para os componentes leve e pesado.

A correção da temperatura, T_BIAS, é adicionada à temperatura do fundo e é calculada por:

$$
\begin{aligned}
& \mathrm{T}_{-} \mathrm{BIAS}=\frac{1}{\mathrm{Y}}-230-\mathrm{T}_{-} \mathrm{AM} \\
& Y=\frac{\log \left[\frac{P \_M A}{P V R_{l a b}}\right] \times \frac{\left(T_{-} I N T-37,78\right)}{267,8 .\left(T_{-} I N T+230\right)}}{\log \left[\frac{P V R_{l a b}}{P_{-} I N T}\right]}+\frac{1}{267,8}
\end{aligned}
$$

P_AM = pressão do fundo no momento da amostragem $\left(\mathrm{kgf} / \mathrm{cm}^{2} \mathrm{~g}\right)$

$\mathrm{T} \_\mathrm{AM}=$ temperatura do fundo no momento da amostragem $\left({ }^{\circ} \mathrm{C}\right)$

PVRlab $=$ resultado de laboratório para a PVR $\left(\mathrm{kgf} / \mathrm{cm}^{2} \mathrm{a}\right)$ 


\subsubsection{Modelos dinâmicos existentes no MPC}

A Figura 3-5 apresenta os modelos identificados para o sistema em setembro e outubro de 2006, próximo ao início de operação do controlador. Até o presente trabalho nenhuma reidentificação fora realizada no sistema e os modelos do controlador permaneciam idênticos aos apresentados na Figura 3-5.

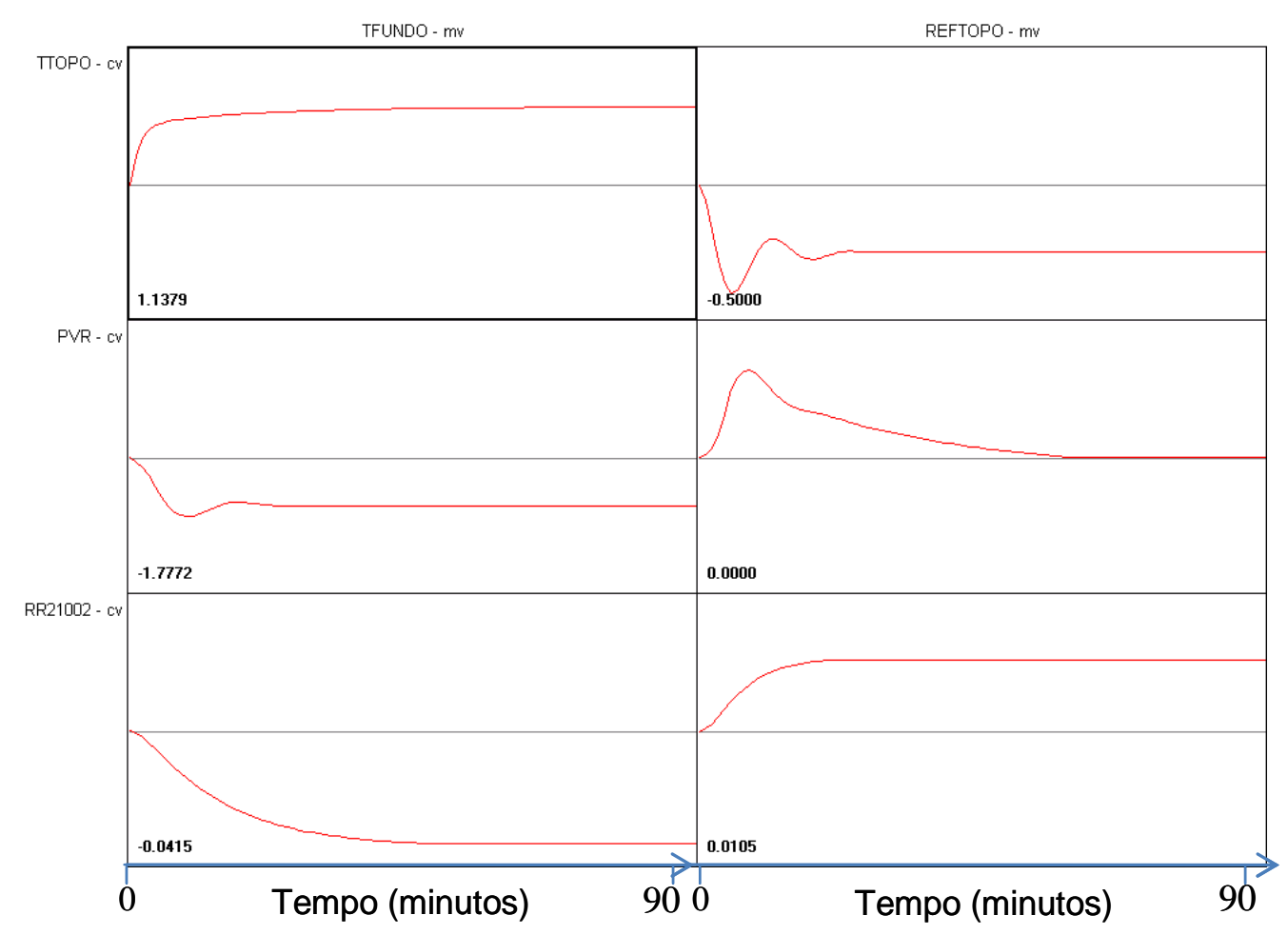

Figura 3-5. Modelo identificado no comissionamento do MPC da T-21002

A matriz de ganhos estacionários está na Tabela 3-3.

Tabela 3-3 - Matriz de ganhos estacionários

\begin{tabular}{|l|c|c|}
\hline & TC21004SP & FC21007SP \\
\hline T TOPO & 1,14 & $-0,5$ \\
\hline PVR NAFTA & $-1,78$ & 0 \\
\hline RR21002 & $-0,04$ & 0,01 \\
\hline
\end{tabular}




\section{Simulação em Matlab do procedimento de re-identificação}

Para testar o procedimento de re-identificação a ser implementado no MPC da coluna debutanizadora, foi inicialmente realizada uma simulação em Matlab, incluindo: a coluna representada por modelos lineares, o controlador existente no processo real e o método de reidentificação.

\subsubsection{Teste de perturbação}

A simulação, que foi realizada baseada no trabalho de Sotomayor et al. (2009), consiste em duas rotinas em Matlab, uma para o QDMC e outra com uma programação quadrática para resolver a otimização econômica da camada estacionária, ambas baseadas nas rotinas programadas em Fortran para o software SICON.

Nesse controlador as variáveis são normalizadas e os ranges para normalização, utilizados na simulação, foram os mesmos considerados no controlador existente na planta real. Todos os parâmetros de sintonia ${ }^{7}$ do controlador bem como os limites das variáveis manipuladas e controladas foram igualados na simulação ao controlador real, os valores empregados são apresentados na Tabela 4-1 e Tabela 4-2 seguindo a nomenclatura apresentada nas equações (2.1) e (2.2).

Tabela 4-1 - Parâmetros de sintonia do controlador

\begin{tabular}{|c|c|c|c|c|c|c|}
\hline$W 1$ & $W 2$ & $W 3$ & $p$ & $Q$ & $m$ & $R$ \\
\hline$\left[\begin{array}{ll}-80 & 50\end{array}\right]$ & [300 90] & {$\left[\begin{array}{lll}60 & 90 & 30\end{array}\right]$} & 90 & {$\left[\begin{array}{lll}1 & 0,5 & 0,2\end{array}\right]$} & 2 & {$\left[\begin{array}{ll}1 & 1\end{array}\right]$} \\
\hline
\end{tabular}

Tabela 4-2 - Limites das variáveis

\begin{tabular}{|c|c|c|c|c|}
\hline$y_{\max }$ & $y_{\min }$ & $u_{\max }$ & $u_{\min }$ & $\Delta u_{\max }$ \\
\hline$[64690,9]$ & {$\left[\begin{array}{lll}54 & 45 & 0,7\end{array}\right]$} & {$\left[\begin{array}{lll}15560\end{array}\right]$} & {$\left[\begin{array}{lll}14420 & 0,2 & {[0,5}\end{array}\right]$} \\
\hline
\end{tabular}

Para efeito de simulação os modelos de resposta ao degrau existentes no controlador real, apresentados na Figura 3-5, foram considerados como o modelo da planta na simulação. Como modelos do controlador da simulação foram utilizados modelos identificados a partir da resposta ao degrau contida no controlador real. Para essa identificação foram utilizados modelos ARX e quando estes não se ajustavam bem a resposta ao degrau utilizaram-se

\footnotetext{
${ }^{7} \mathrm{O}$ parâmetro de sintonia $R u$ não possui acesso pelo usuário no SICON ficando dentro do código fonte com valor unitário. Isso ocorre porque esse valor é suficiente para garantir que a saída do MPC siga o "target" calculado pela camada estacionária.
} 
modelos ARMAX para se obter melhor ajuste. O tempo morto baseado nos modelos existentes no controlador é próximo de um período de amostragem (1 minuto) e esse foi o valor empregado nessas identificações. A ordem dos modelos foi obtida utilizando-se uma ordem elevada e observando se o modelo se adequava bem à resposta ao degrau. Os parâmetros dos modelos obtidos são apresentados no Apêndice 1 .

Nessa etapa não houve uma preocupação em se obter modelos que se ajustassem exatamente ao modelo do controlador até porque uma diferença entre modelo e planta é imprescindível para avaliar-se o resultado da re-identificação. As diferenças entre os modelos que representarão o processo e os modelos identificados para serem usados no controlador da simulação são apresentados na Figura 4-1. Para facilitar a leitura dos gráficos, daqui para frente, as variáveis temperatura de fundo, refluxo de topo, temperatura de topo, PVR e razão de refluxo serão denominadas como $u 1, u 2, y 1, y 2$ e $y 3$ respectivamente.

Como perturbações do controlador foram utilizados dois sinais GBN, um para cada manipulada, de magnitude \pm 1 multiplicando o parâmetro $W 1$ da função objetivo da camada de cálculo do target (camada estacionária). Conforme explicitado na seção 2.2.1.4 o tempo de chaveamento médio, parâmetro dinâmico ser escolhido para gerar o sinal, será de 1/3 do maior tempo de assentamento das variáveis controladas (Sotomayor et al., 2009). Assim para a manipulada $u l$ foi estimado um tempo de assentamento de 50 minutos, baseado na resposta de $y 1$ e $y 3$; já para $u 2$ foi estimado um tempo de assentamento de 60 minutos, baseado na resposta de $y 2$.

A duração da simulação compreende o tempo para a realização do teste de identificação somado a uma janela de tempo que conterá os dados para a validação cruzada dos modelos obtidos (Garcia, 2005). Os tempos aqui considerados devem ser reproduzíveis na planta, isso significa que se deve escolher uma janela suficiente para identificar os novos modelos, mas sem que a otimização do processo fique desnecessariamente desligada por muito tempo. No presente trabalho a duração do teste foi baseada no horizonte de predição do controlador seguindo a heurística utilizada em Conner e Seborg (2004): 


$$
T_{\text {teste }}=6^{*} H_{\text {pred }}{ }^{*} n_{u}
$$

Onde $T_{\text {teste }}$ é a duração do teste em intervalos de amostragem, $H_{\text {pred }}$ é o horizonte de predição do controlador em intervalos de amostragem e $n_{u}$ é o número de variáveis manipuladas $^{8}$. Pode-se utilizar o horizonte de predição ao invés do maior tempo de assentamento, pois o horizonte de predição é configurado no controlador com valores iguais (ou um pouco superiores) ao maior tempo de assentamento.

\footnotetext{
${ }^{8}$ Caso haja distúrbios medidos acrescentar a esse valor.
} 

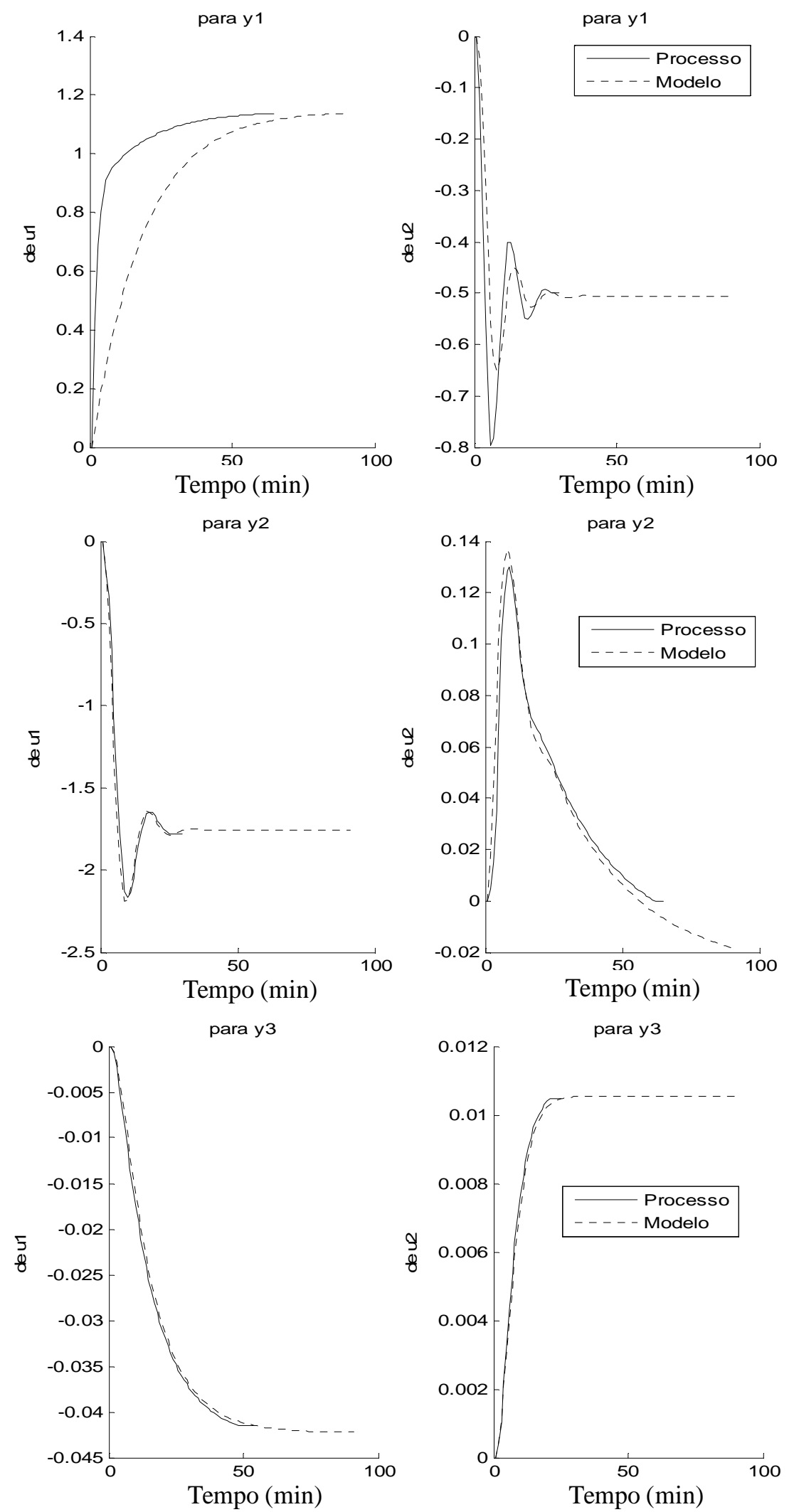

Figura 4-1. Comparação das resposta ao degrau do modelo utilizado para planta (processo) com o modelo utilizado para o controlador (modelo) na simulação 
No caso estudado como temos $H_{\text {pred }}=90$ minutos e $n_{u}=2$, o $T_{\text {teste }}$ será de 1080 minutos. Foram acrescidos 300 minutos a duração total da simulação para gerar dados para validação cruzada.

Como pode ser verificado na Figura 4-2 a variável manipulada $u 2$ não parece ser muito excitada pelo sinal GBN na camada estacionária. De fato o valor de $u 2$ não variou mais do que $16,5 \%$ de sua faixa, o que inutiliza esses dados para identificação do modelo com essa variável. Como o "setpoint" da variável $u 2$ seguiu o "target" o problema de excitação está na própria camada estacionária. Dessa feita para realizar o segundo teste reduziu-se por um fator de 10 os coeficientes da matriz $W 2$, peso de atenuação dos movimentos das variáveis manipuladas. Para garantir que o "setpoint" continue seguindo o "target" multiplicou-se por 2 os valores de máxima variação das variáveis manipuladas, $\Delta u_{\max }$.
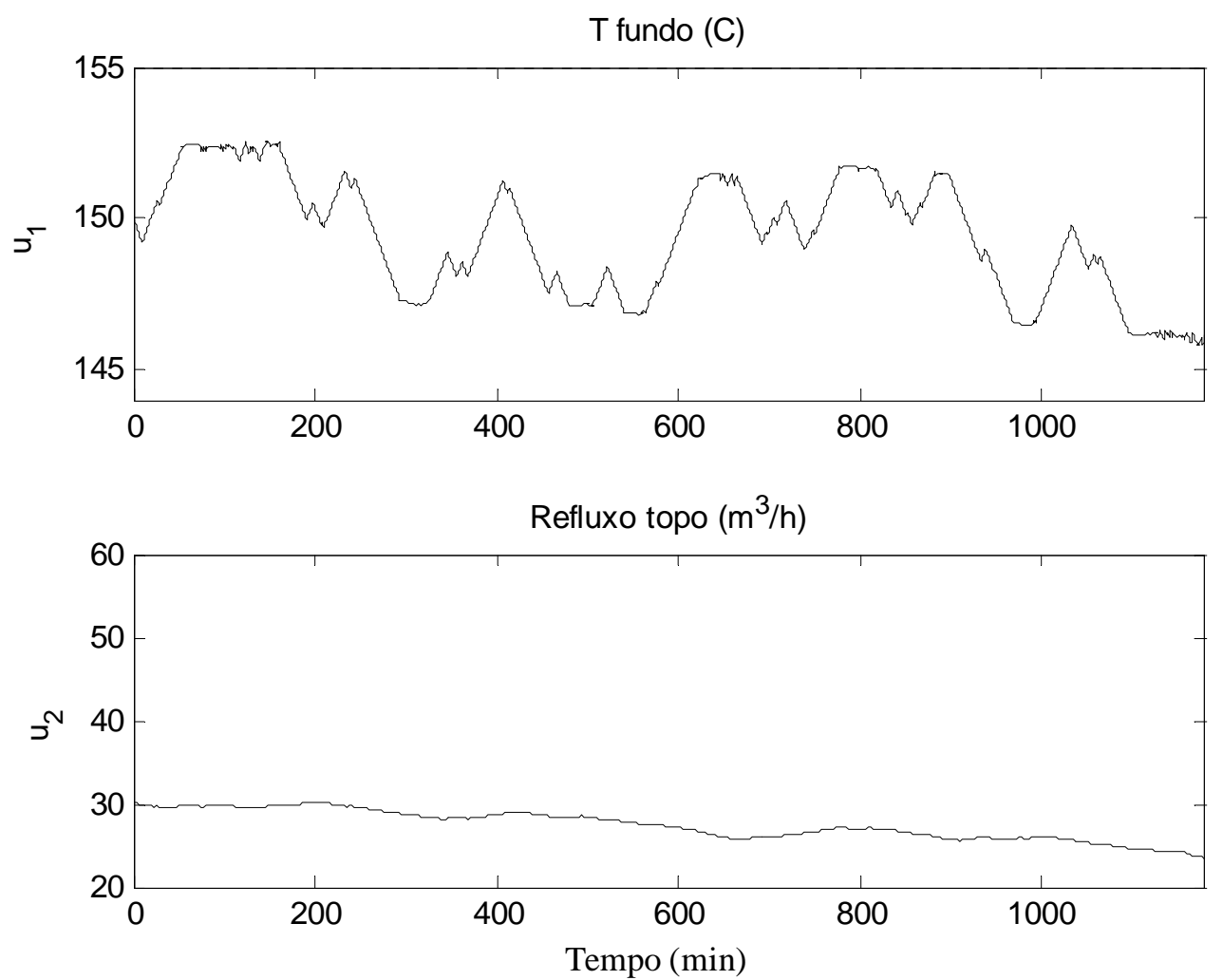

Figura 4-2. Comportamento das variáveis manipuladas ("setpoint" dos PIDs) durante a primeira simulação

O resultado da segunda simulação é apresentado de forma gráfica nas Figura 4-3 (comportamento das variáveis manipuladas) e Figura 4-4 (comportamento das variáveis controladas). 

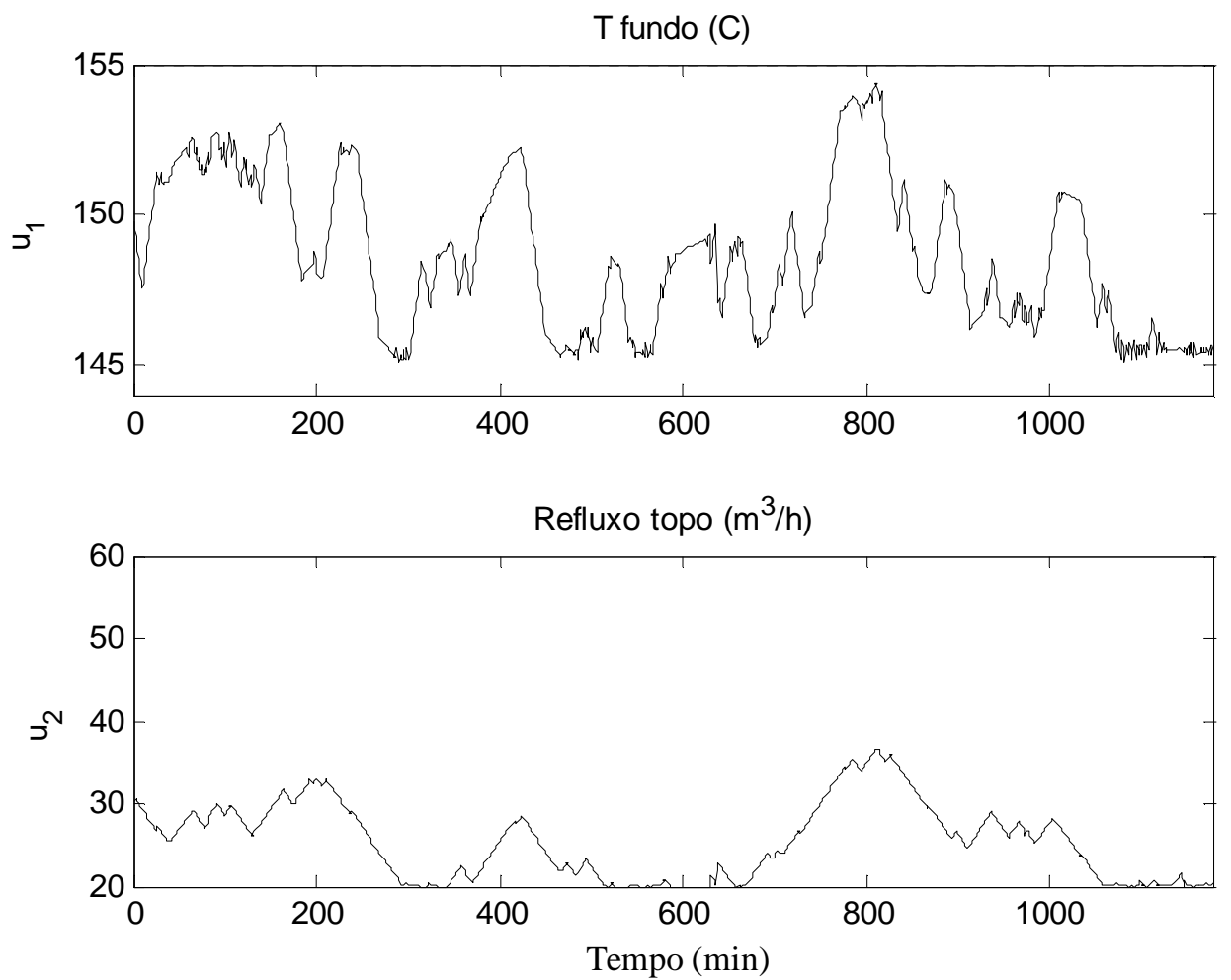

Figura 4-3. Comportamento das variáveis manipuladas ("setpoint" dos PIDs) durante a segunda simulação
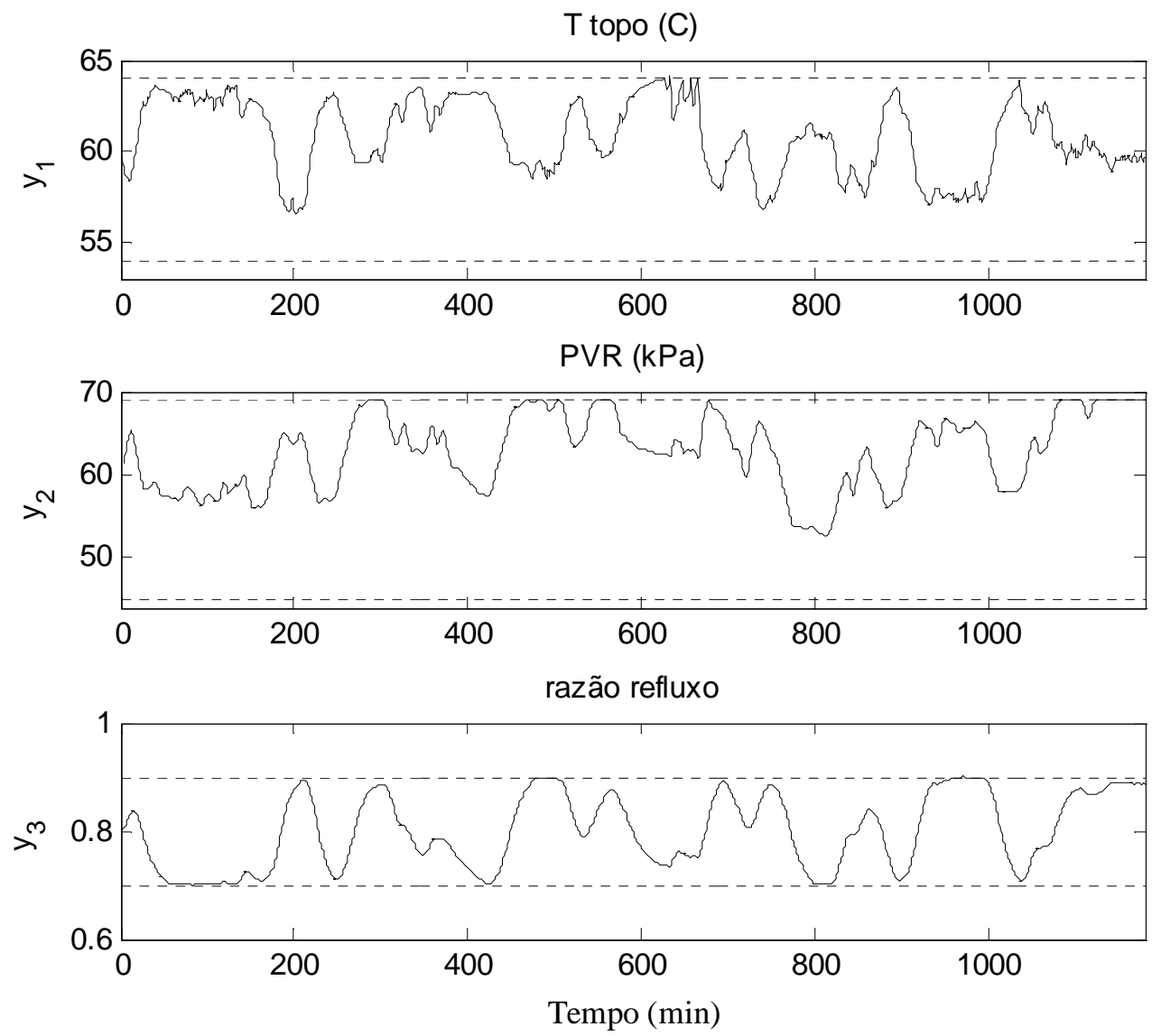

Figura 4-4. Comportamento das variáveis controladas durante a segunda simulação 
Como era esperado observa-se que as variáveis manipuladas apresentam uma variação maior do que no primeiro teste, a variável $u 2$ agora percorre cerca de $50 \%$ da sua faixa. Mesmo com essa maior variação das manipuladas as variáveis controladas permaneceram contidas em suas faixas de controle, representadas na Figura 4-4 pelas linhas horizontais pontilhadas, como era previsto já que o controlador está em malha fechada.

\subsubsection{Re-identificação do modelo usado na simulação}

A próxima etapa consiste em utilizar os dados de $u$ e $y$ obtidos na simulação para reidentificar os modelos do processo. Os métodos de identificação foram discutidos previamente na subseção 2.2.3 desse trabalho. Para a simulação foram identificados modelos contínuos somente com estrutura OE. Para essa identificação foi utilizada a rotina coe (Garnier et al., 2003; Garnier e Gilson, 2006) adotando o modelo usado no controlador como estimativa inicial do modelo.

No experimento de identificação foi usada uma janela de 900 amostras de dados de entrada e saída. Como índices de desempenho do resultado são utilizados o coeficiente fit, o qual indica o percentual de ajuste dos dados de saída do modelo às saídas medidas, e o coeficiente de determinação $R_{T}^{2}$, o qual indica o quão bem a saída do modelo explica o comportamento da saída do sistema. O valor de fit deve se aproximar de $100 \%$ e o valor de $R^{2}{ }_{T}$ deve ficar próximo de 1 em condições ideais. A equação dos índices é apresentada em (4.2) e (4.3).

$$
\begin{aligned}
& \text { fit }=100 \times\left(1-\frac{\operatorname{norm}(\hat{y}-y)}{\operatorname{norm}(y-\operatorname{mean}(y))}\right) \\
& R_{T}^{2}=1-\frac{\operatorname{var}(\hat{y}-y)}{\operatorname{var}(y)}
\end{aligned}
$$

Onde $y$ é a saída do processo e $\hat{y}$ é a saída estimada pelo modelo.

Para cada controlada são apresentadas três figuras, a primeira compara os ajustes dos modelos aos dados usados para a re-identificação do novo modelo, a segunda apresenta a validação cruzada, e a terceira compara as respostas ao degrau do processo do novo modelo e 
do antigo modelo do controlador. Segundo Garcia (2005), a validação cruzada é um dos testes mais importantes empregados na identificação de sistemas e consiste em se avaliar o desempenho de modelos submetidos a um conjunto de dados para o qual os modelos não foram ajustados, ou seja, um conjunto de dados diferente do utilizado na estimação dos parâmetros, que pode ser um subconjunto de dados do mesmo teste, reservados exclusivamente para validação ou um novo conjunto de dados, oriundo de outro teste.

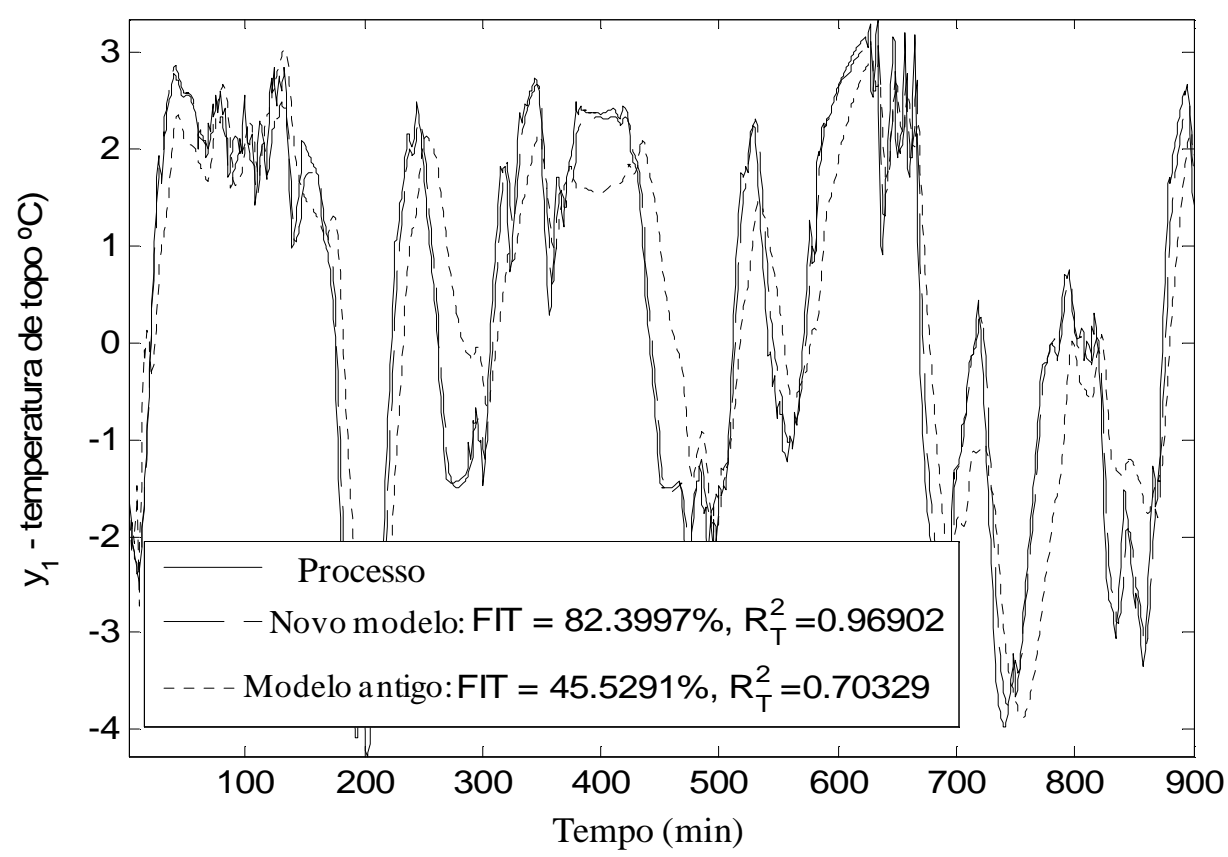

Figura 4-5. Comparação dos ajustes das predições do modelo re-identificado (-- -- Novo modelo) e do modelo do controlador (...... . Modelo antigo) ao processo para a variável controlada $y l$. Simulação com dados utilizados para a re-identificação. 


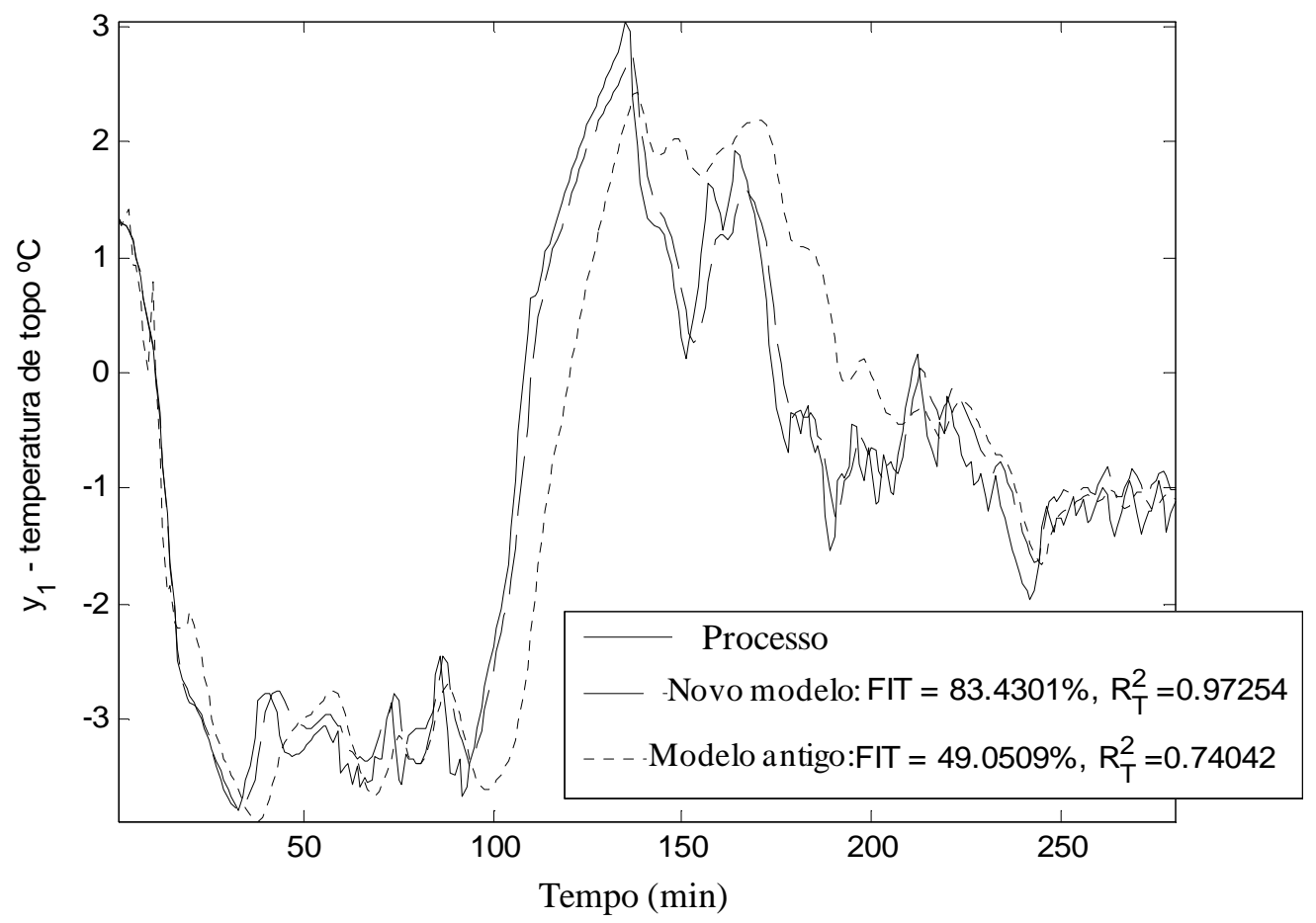

Figura 4-6. Validação cruzada do modelo re-identificado (-- -- Novo modelo) comparando seu ajuste ao processo ao ajuste do modelo do controlador (...... Modelo antigo) para a variável controlada yl na simulação.
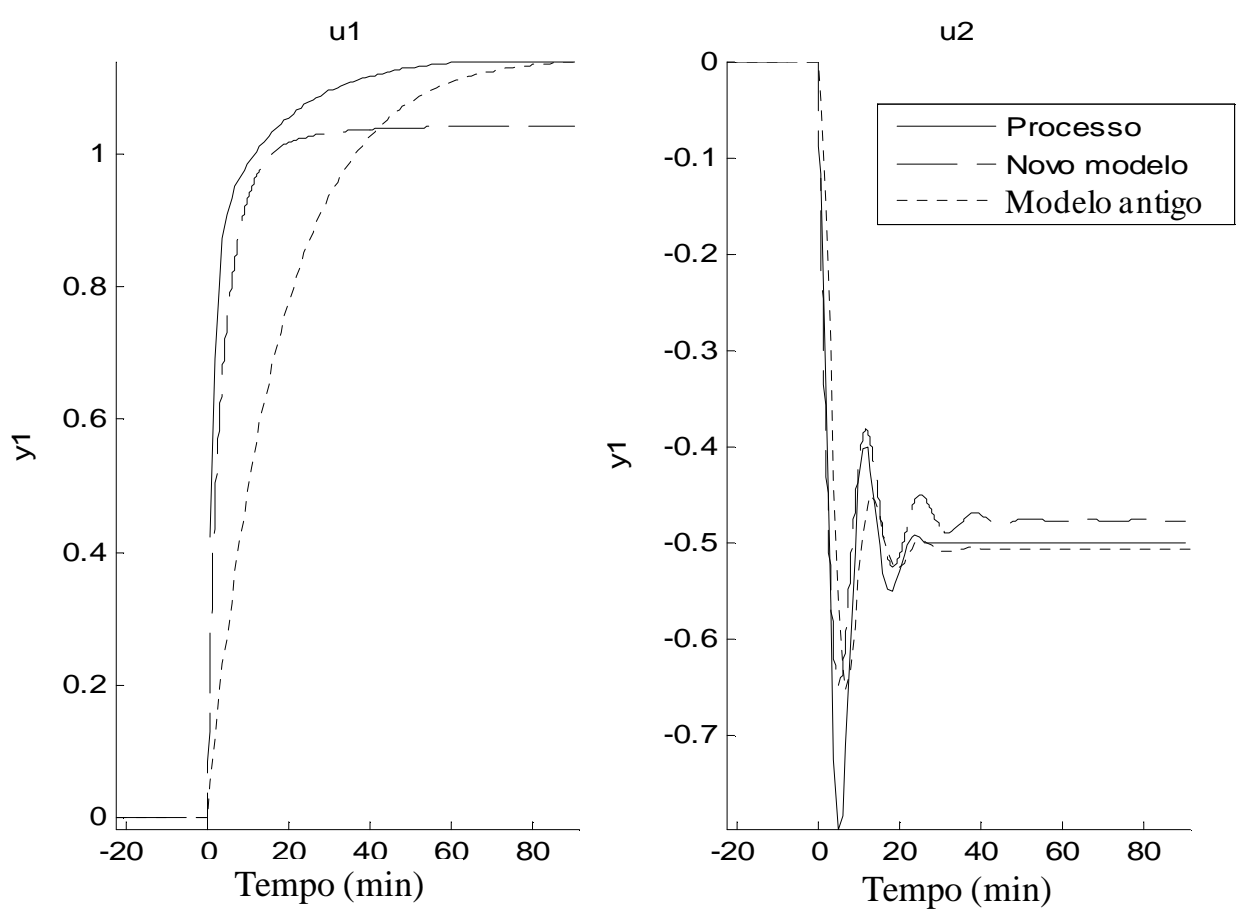

Figura 4-7. Comparação da resposta ao degrau do modelo re-identificado (-- -- Novo Modelo) e do modelo do controlador (....... Modelo antigo) ao processo para a variável controlada yl referente às manipuladas $u 1$ e $u 2$. 


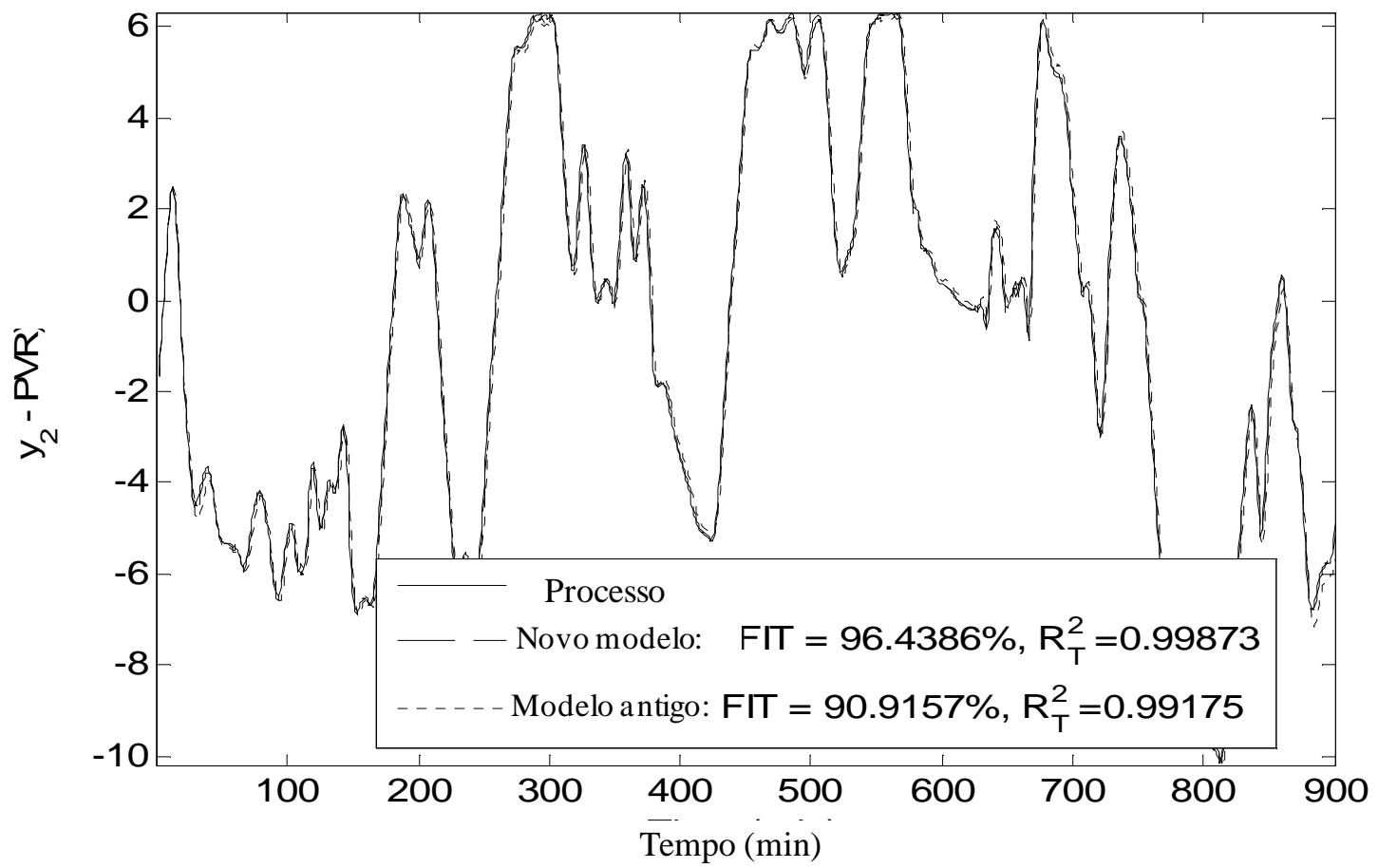

Figura 4-8. Comparação dos ajustes das predições do modelo re-identificado (-- -- Novo modelo) e do modelo do controlador (....... Modelo antigo) ao processo para a variável controlada y2. Simulação com dados utilizados para a re-identificação.

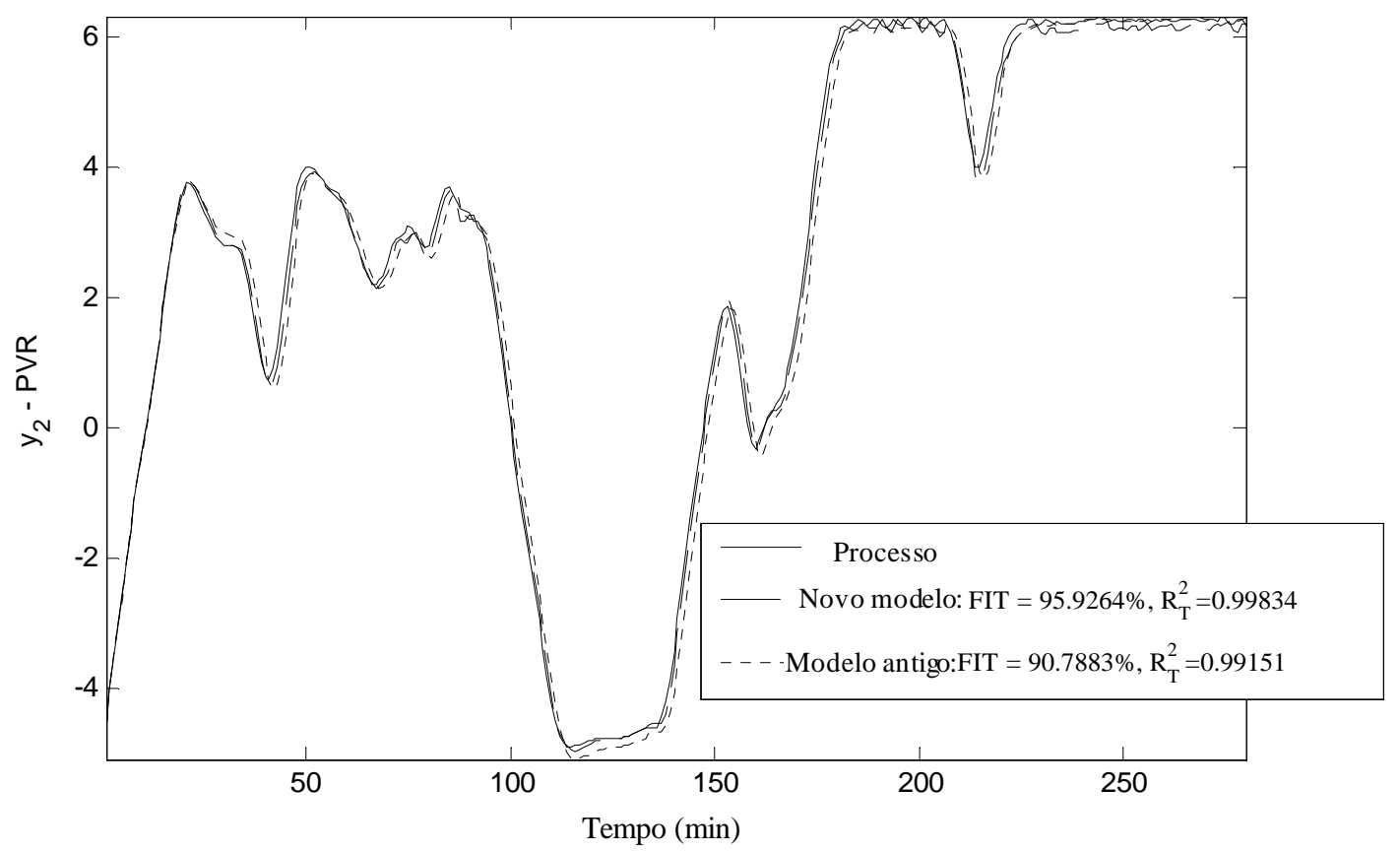

Figura 4-9. Validação cruzada do modelo re-identificado (-- -- Novo Modelo) comparando seu ajuste ao processo ao ajuste do modelo do controlador (...... Modelo antigo) para a variável controlada y2 na simulação. 
u1
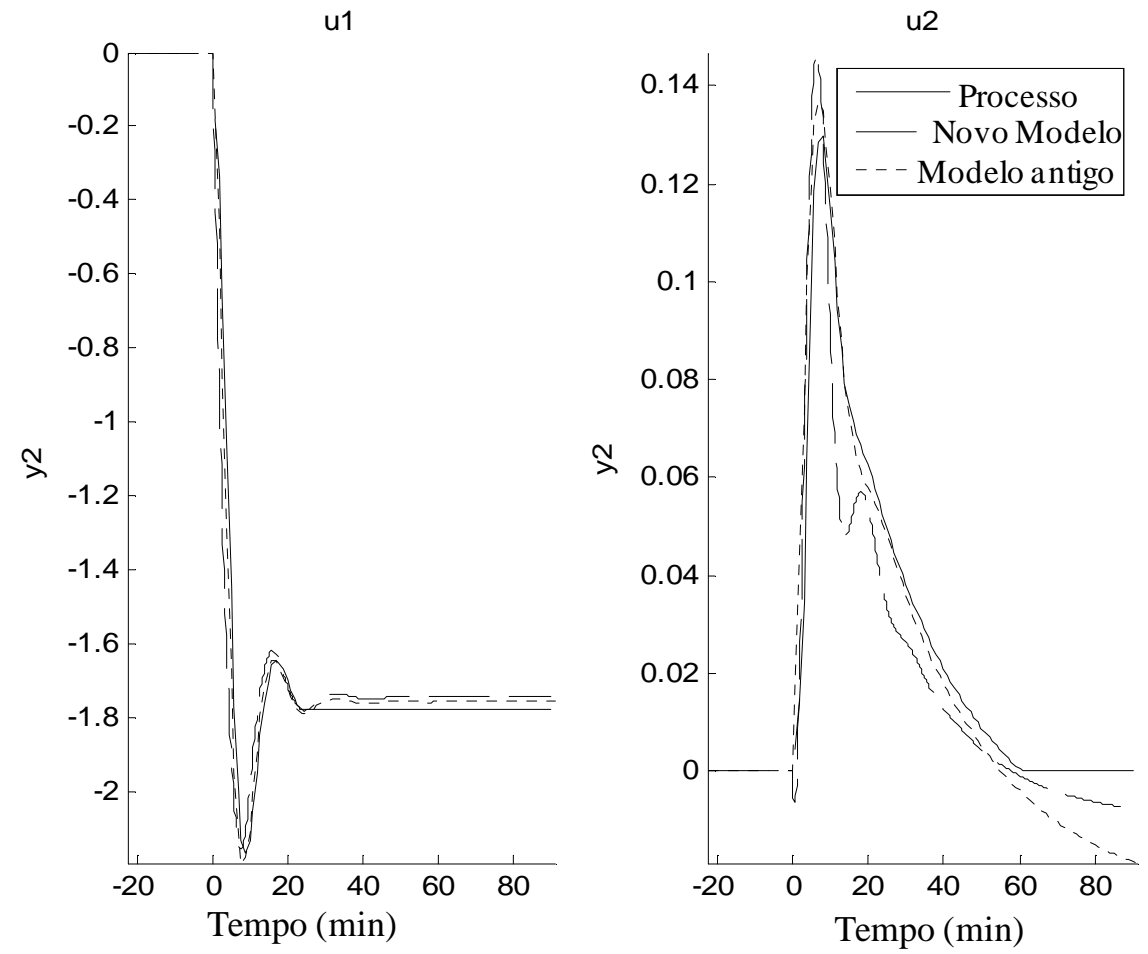

Figura 4-10. Comparação da resposta ao degrau do modelo re-identificado (-- -- Novo Modelo) e do modelo do controlador (....... Modelo antigo) ao processo para a variável controlada y2 referente às manipuladas $u 1$ e $u 2$.

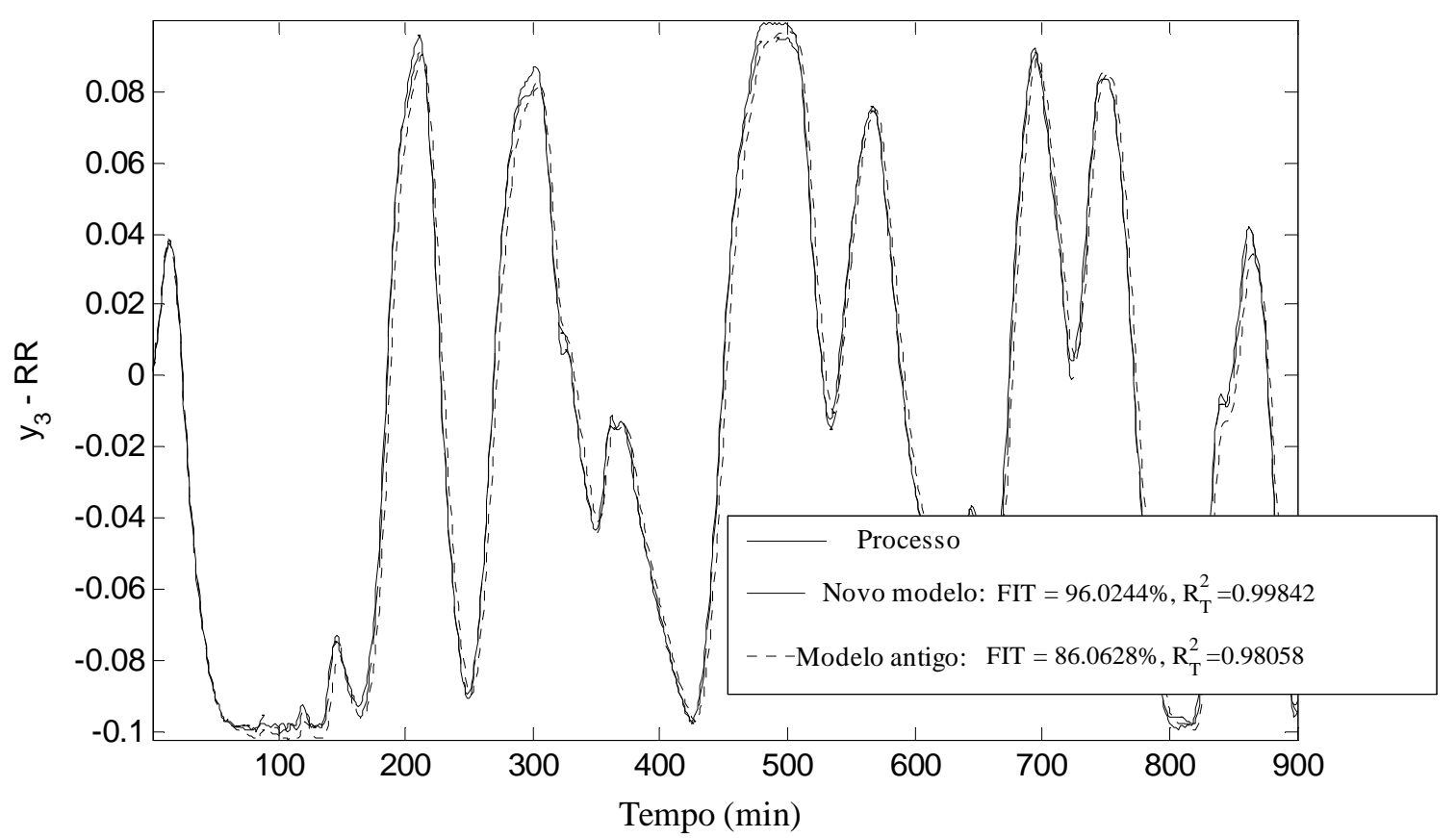

Figura 4-11. Comparação dos ajustes das predições do modelo re-identificado (-- -- Novo Modelo) e do modelo do controlador (....... Modelo antigo) ao processo para a variável controlada y3. Simulação com dados utilizados para a re-identificação. 


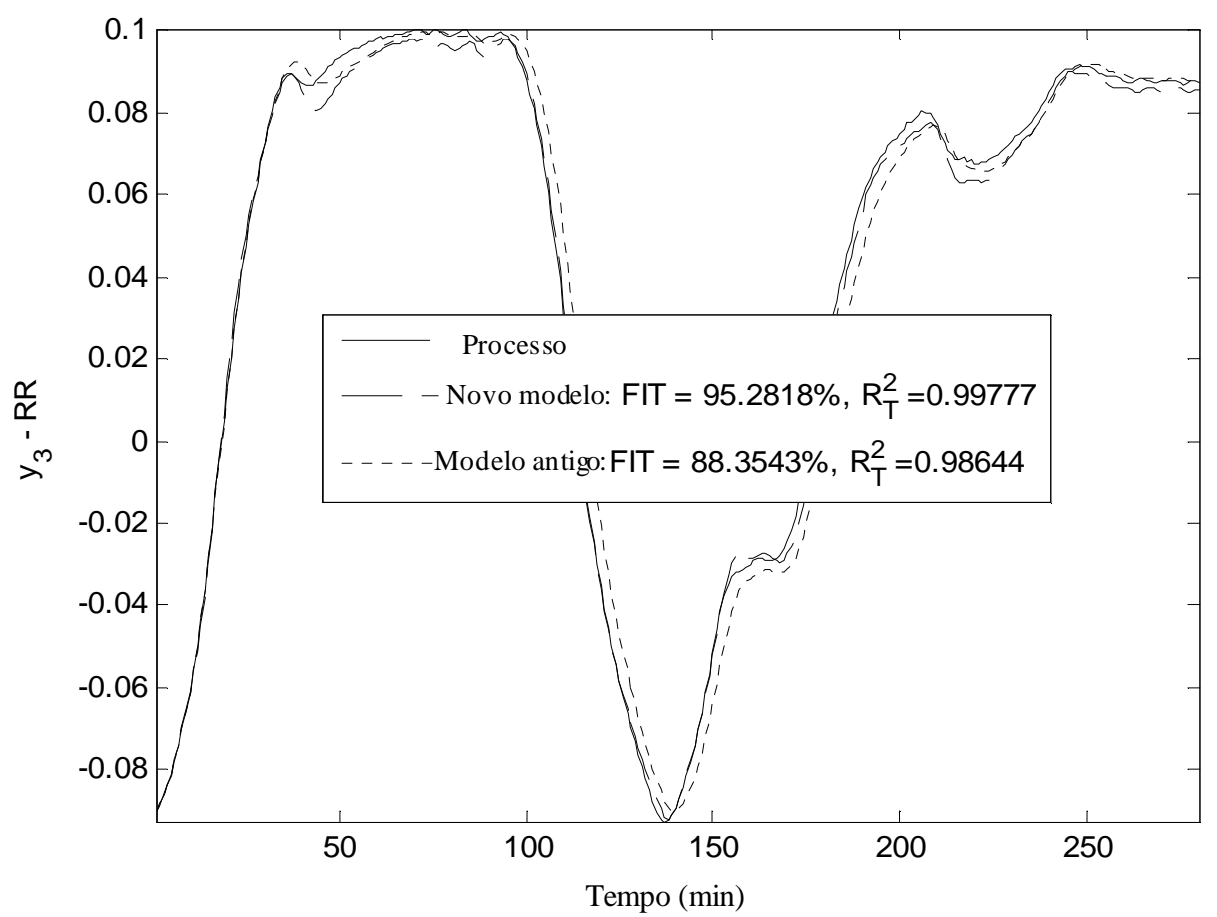

Figura 4-12. Validação cruzada do modelo re-identificado (-- -- Novo Modelo) comparando seu ajuste ao processo ao ajuste do modelo do controlador (....... Modelo antigo) para a variável controlada y3 na simulação.

u1

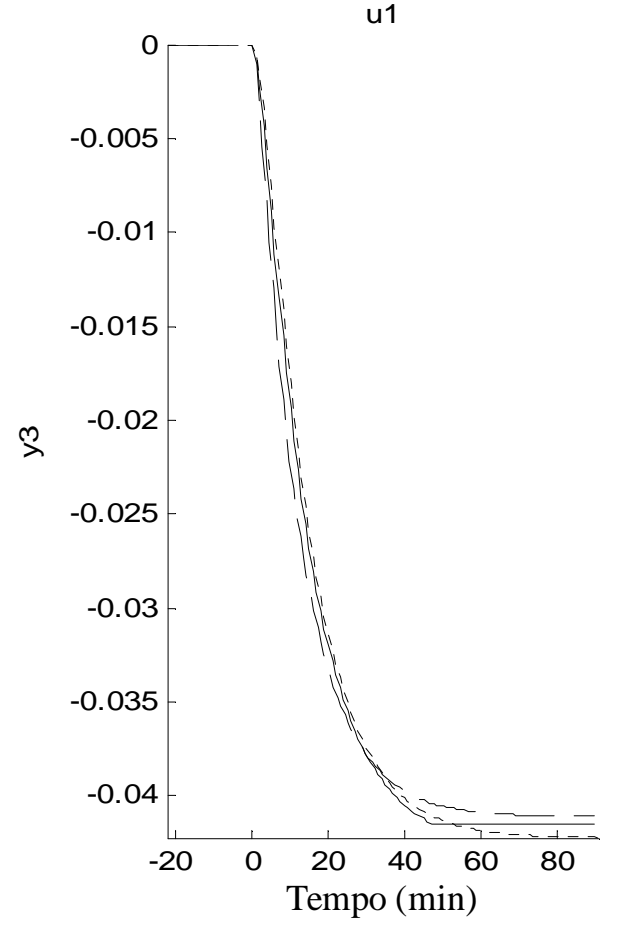

u2

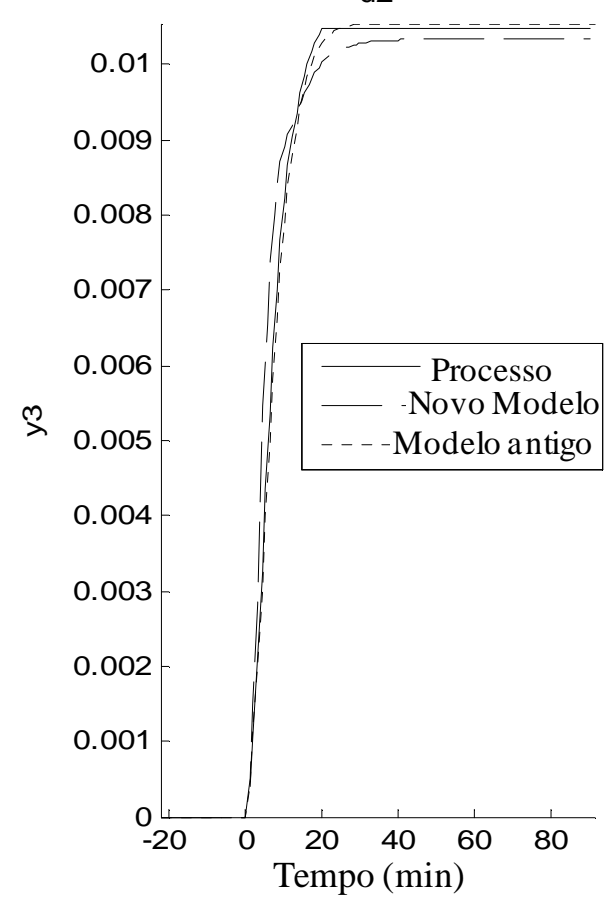

Figura 4-13. Comparação da resposta ao degrau do modelo re-identificado (-- -- Novo Modelo) e do modelo do controlador (....... Modelo antigo) ao modelo usado para representar o processo para a variável controlada $y 3$ referente às manipuladas $u 1$ e $u 2$.

Pode-se observar que tanto na comparação dos ajustes com os dados usados para identificação (Figuras 4-5, 4-8 e 4-11) quanto nos ajustes para a validação cruzada (Figuras 4- 
6, 4-9 e 4-12) os modelos re-identificados apresentam melhor desempenho do que os modelos originais do controlador. Além disso, os modelos de resposta ao degrau também se aproximaram mais do modelo do processo (Figuras 4-7, 4-10 e 4-13) o que indica que a reidentificação foi bem sucedida na simulação em Matlab. As equações dos modelos reidentificados na simulação são apresentadas no domínio de Laplace no Apêndice 2. 


\section{Aplicação Industrial}

Neste capítulo descreve-se o procedimento e os resultados da implementação do procedimento de re-identificação do modelo da Torre Debutanizadora localizada na Refinaria Henrique Lage da Petrobras.

\subsection{Teste de perturbação}

O próximo passo consiste em aplicar o mesmo teste simulado em Matlab na planta real. Para isso foi criado uma variável no controlador que indica o início do teste. Uma vez que essa variável seja ativada (passe de 0 para 1) uma rotina de criação dos vetores com sinais GBN, com tempos médios de chaveamento iguais a 1/3 do maior tempo de estabilização para cada variável manipulada, é chamada. Os sinais GBN com valores \pm 1 são então multiplicados pelos parâmetros $W 1$ antes da resolução da otimização estacionária. Essa multiplicação ocorrerá durante toda duração do teste, duração que, por sua vez, determina os tamanhos dos vetores com sinal GBN. Nesse caso o teste teve a duração de 1080 minutos (18 horas) segundo a equação (4.1). Os parâmetros de sintonia do controlador real em operação na coluna debutanizadora são os mesmos listados nas tabelas 4-1 e 4-2, com exceção de W2 e $\Delta u_{\max }$ que foram modificados assim como na simulação.

Foram realizados dois testes, denominados doravante por testes A e B. Os mesmos foram realizados em épocas distintas, com diferentes tipos de petróleo sendo processados, e com sinais GBN com realizações diferentes (apesar de possuírem o mesmo tempo médio de chaveamento). O intuito da repetição do experimento é comparar os modelos obtidos e avaliar a consistência do método de re-identificação. As Figura 5-1 e Figura 5-2 apresentam o formato do sinal de excitação utilizado para cada variável manipulada em cada teste. 


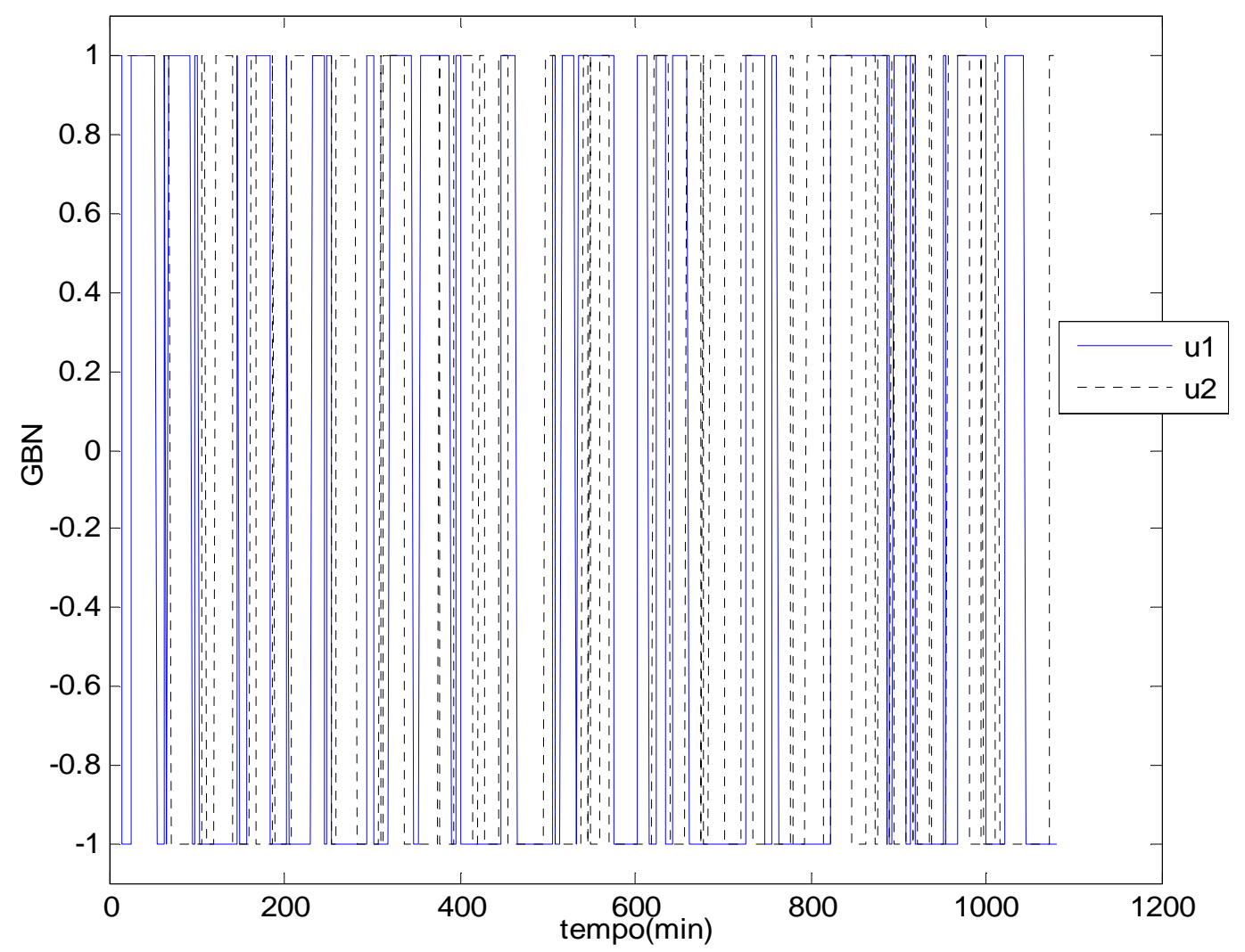

Figura 5-1. Sinal de excitação aplicado no teste de re-identificação A.

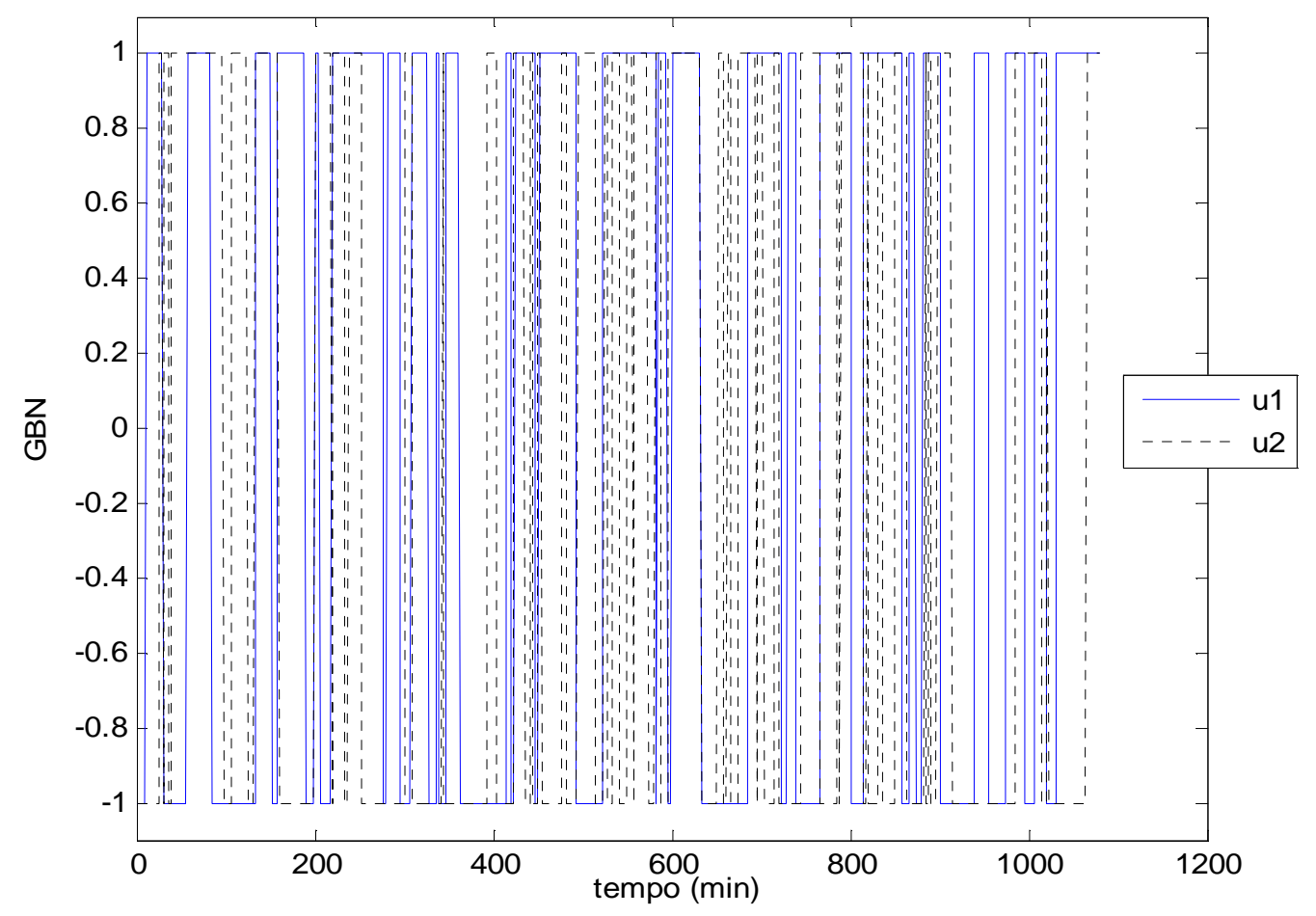

Figura 5-2. Sinal de excitação aplicado no teste de re-identificação B. 
Em ambos os testes foi verificado que as duas principais perturbações que não são consideradas no MPC (vazão de carga e pressão de topo) estavam em estado estacionário não interferindo nas variáveis controladas. Caso houvesse variações significativas na vazão de carga da carga da torre ou em sua pressão de topo os resultados do teste poderiam ser comprometidos.

Durante a realização dos testes de re-identificação real alguns valores de máximo de mínimo que definem as faixas de operação das variáveis manipuladas e controladas estavam diferentes dos valores configurados na simulação apresentada no capítulo 4. Isto ocorre porque algumas dessas faixas são alteradas pelos operadores de painel através da interface apresentada na Figura 3-3. Essas alterações são realizadas visando adequar o controle às novas realidades operacionais da unidade.

São apresentadas a seguir figuras com o comportamento das variáveis manipuladas (Figura 5-3) e variáveis controladas (Figura 5-4, 5-5 e 5-6) para o teste A. O comportamento das variáveis no teste B é apresentado nas Figuras: 5-7, 5-8, 5-9 e 5-10 podendo-se observar que apesar do sinal GBN ser diferente o comportamento geral dos dados foi similar ao teste A. Em ambos os testes as variáveis manipuladas excursionaram por quase todo o range permitido. Pode-se notar que as variáveis controladas se encontram na quase totalidade do tempo do teste contidas entre o limite superior e inferior das zonas de controle configuradas no controlador. Alguma ressalva pode ser feita quanto à variável y3 (razão de refluxo) que permaneceu em média cerca de $30 \%$ do tempo fora dos seus limites. No entanto essa é a variável controlada com menor prioridade sendo mais importante a distribuição dos valores ao redor de 0,8 do que a prevenção rigorosa da violação dos valores máximos e mínimos. 


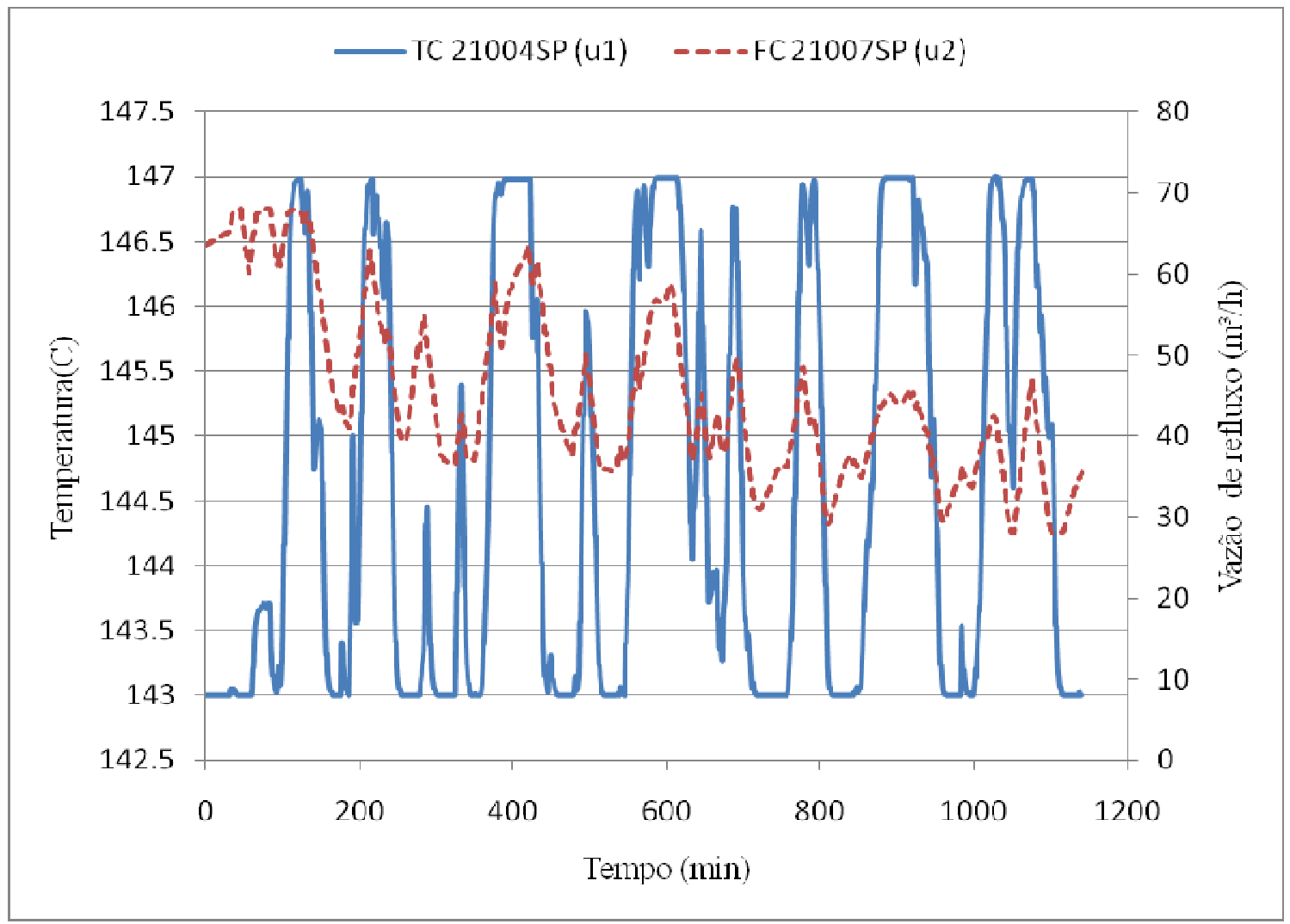

Figura 5-3. "Setpoints" das variáveis manipuladas durante o teste de re-identificação A

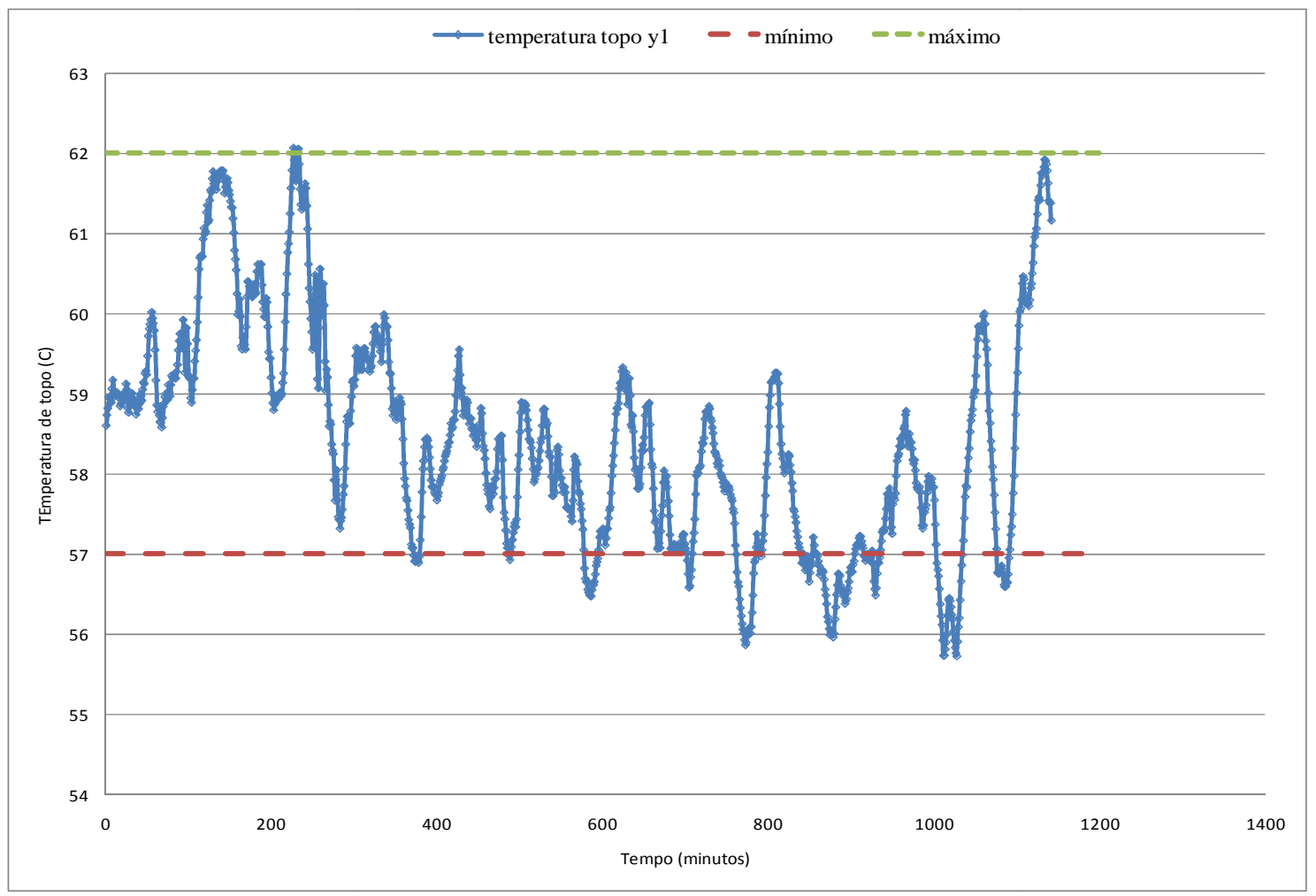

Figura 5-4. Comportamento da controlada $y l$ durante o teste de re-identificação A 


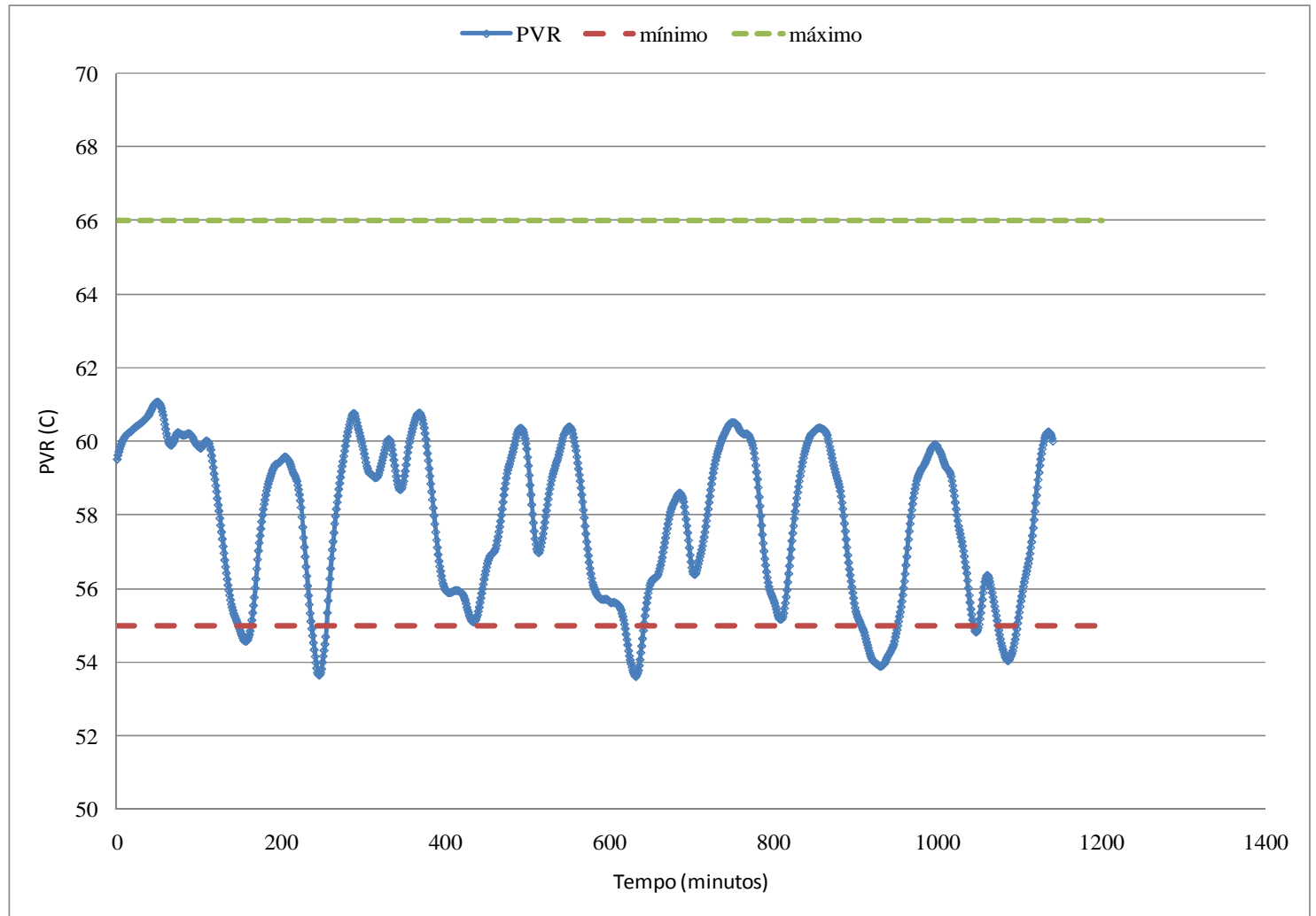

Figura 5-5. Comportamento da controlada $y 2$ durante o teste de re-identificação A

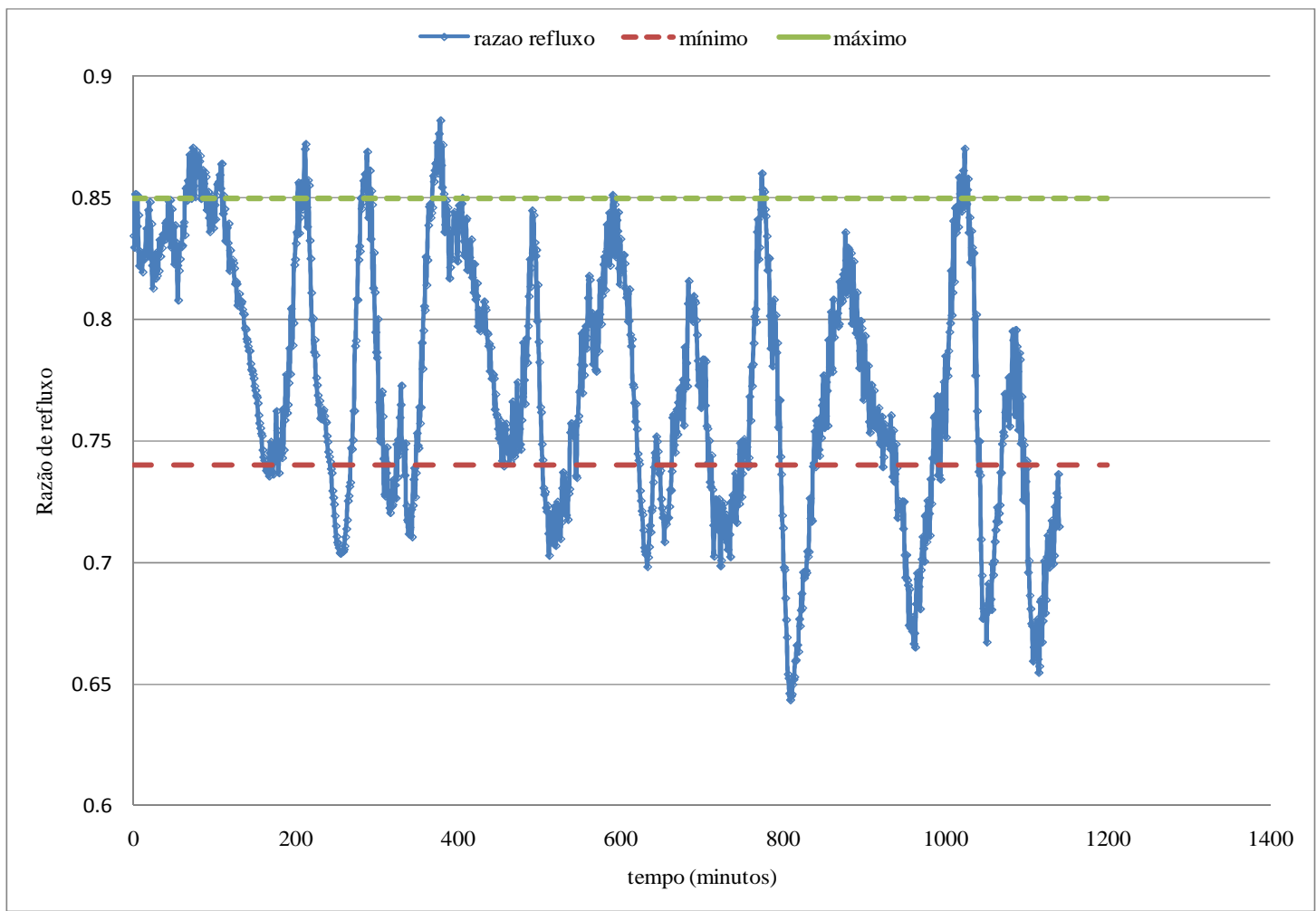

Figura 5-6. Comportamento da controlada y3 durante o teste de re-identificação A 


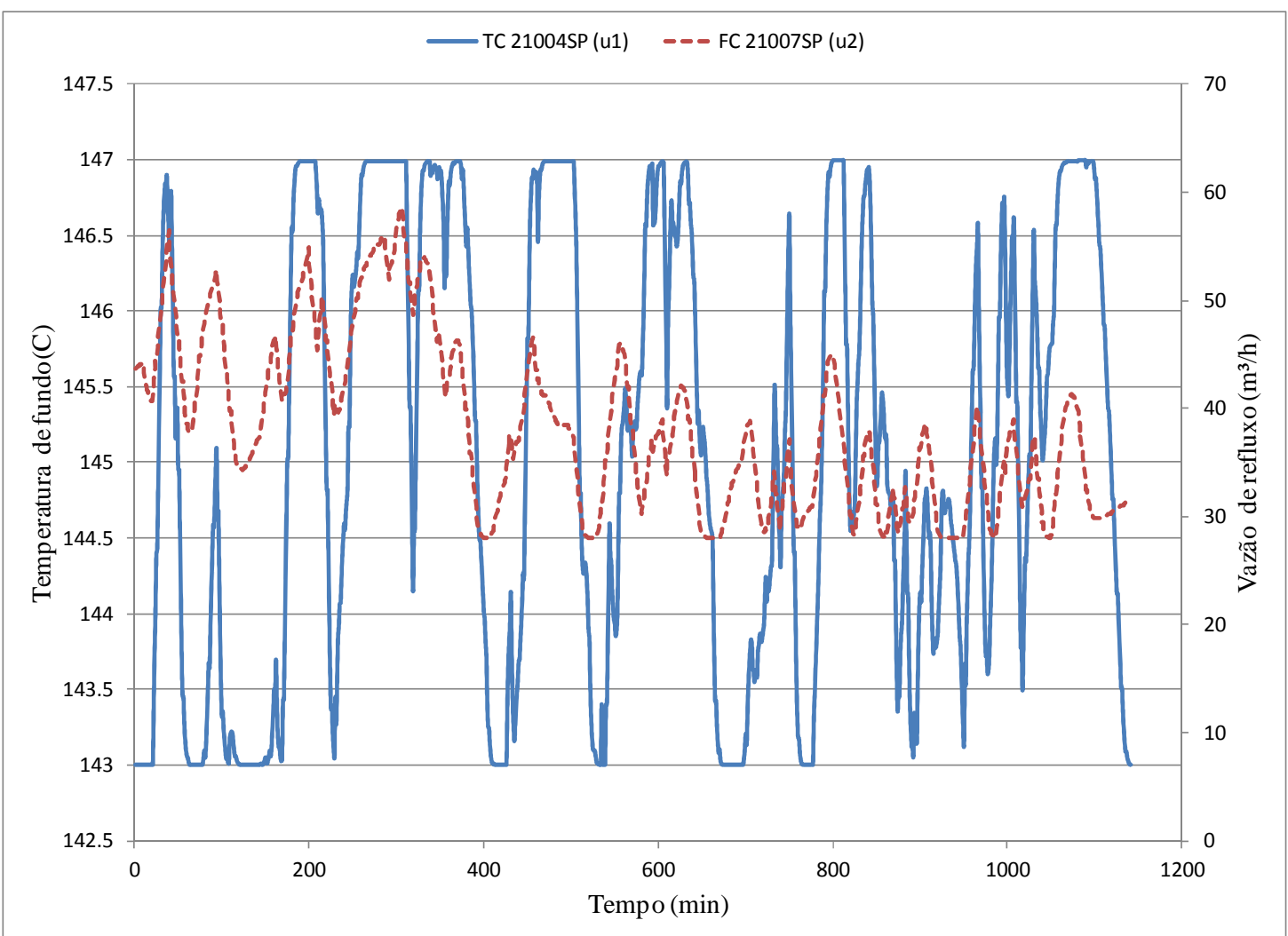

Figura 5-7. "Setpoints" das variáveis manipuladas durante o teste de re-identificação B

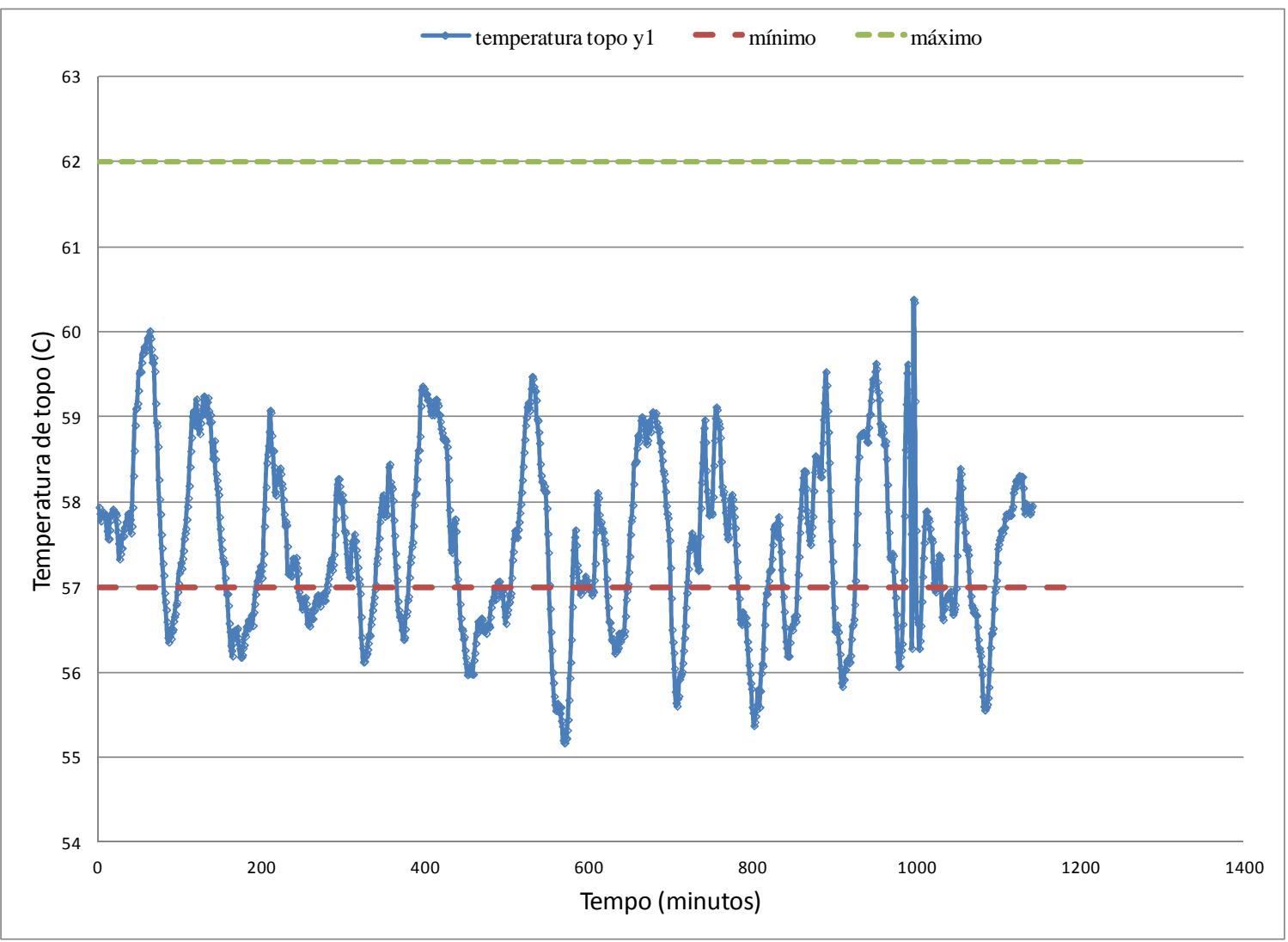

Figura 5-8. Comportamento da controlada $y l$ durante o teste de re-identificação B 


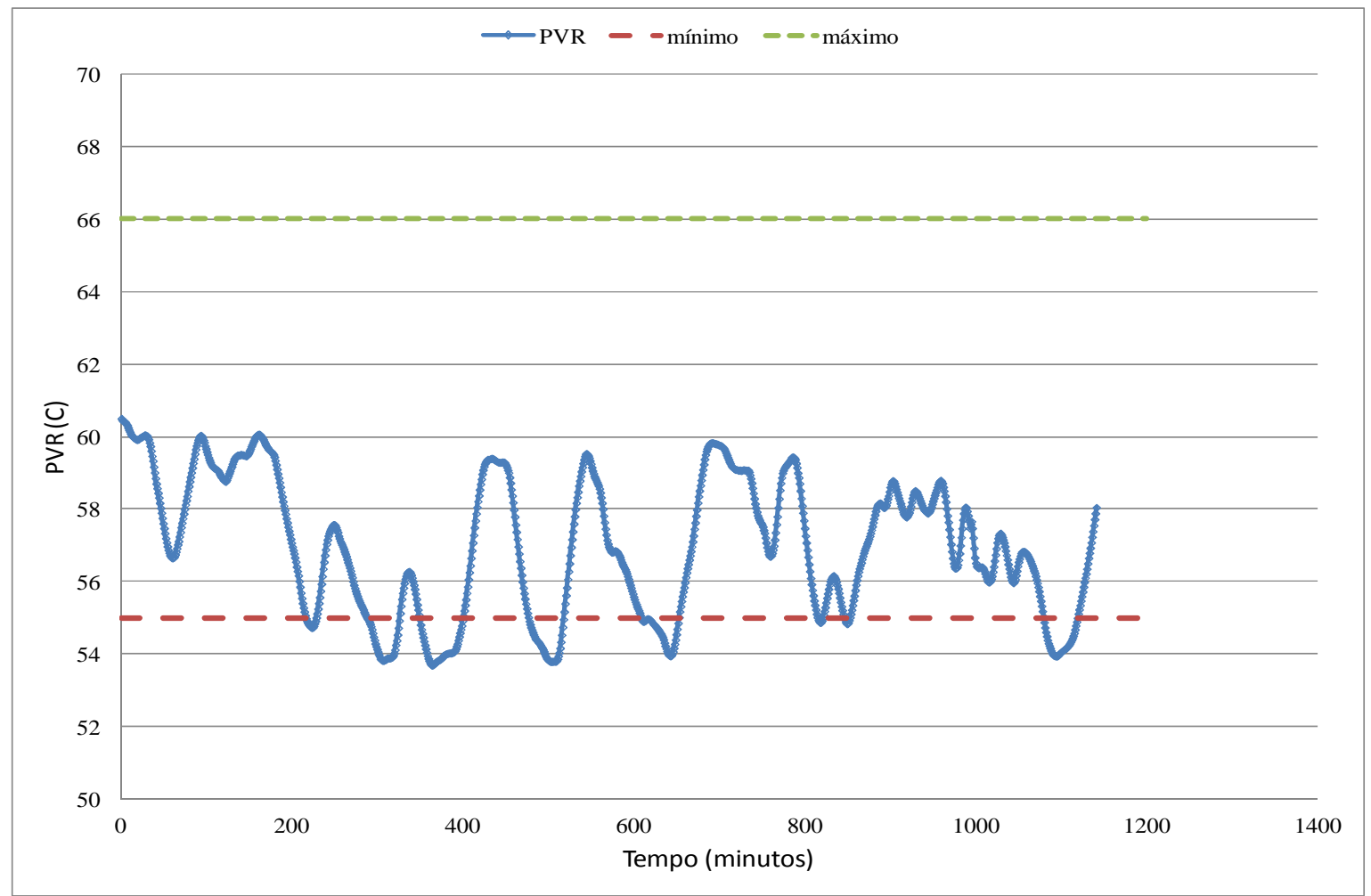

Figura 5-9. Comportamento da controlada $y 2$ durante o teste de re-identificação B

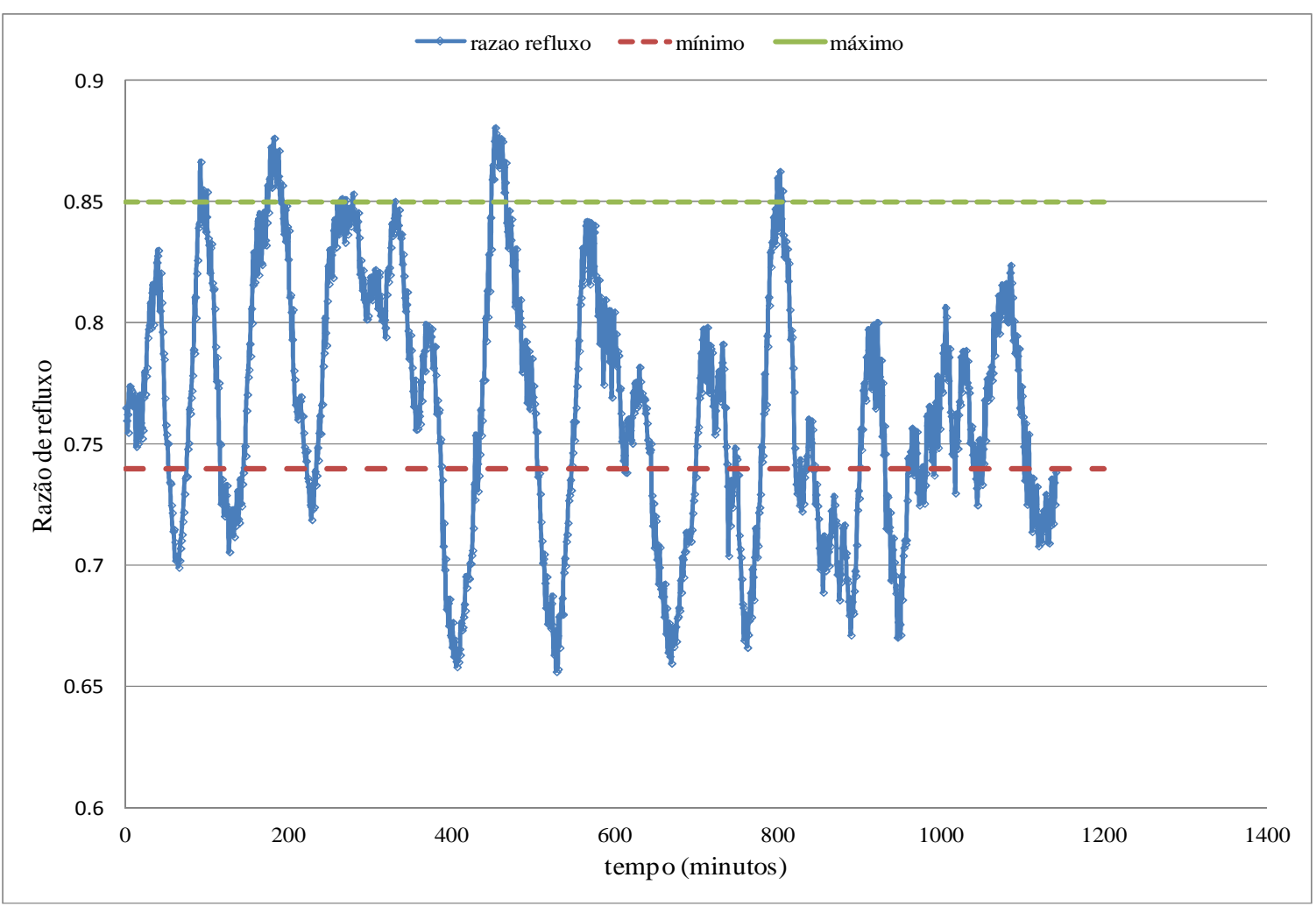

Figura 5-10. Comportamento da controlada $y 3$ durante o teste de re-identificação B 


\subsection{Re-identificação do modelo da debutanizadora}

No experimento de identificação foi usada uma janela de 800 amostras de dados de entrada e saída. O restante dos dados, 350 amostras, foi utilizado para validação cruzada do modelo. Para o tratamento dos dados foi aplicada a rotina "detrend" nas variáveis controladas com o objetivo de remover tendências lineares dos dados. Também foi aplicado um filtro de primeira ordem para eliminar ruídos de alta frequência contidos nas variáveis yl e y3. As constantes de tempo do filtro ( $\tau_{y 1}$ e $\tau_{y 3}$ ) foram ajustadas observando-se o comportamento dos dados filtrados em relação aos dados originais. Procurou-se um valor que atenuasse o ruído nos dados sem que a resposta do processo sofresse atraso chegando aos valores de $\tau_{y l}=2$ minutos $\tau_{y 3}=2,5$ minutos.

Como primeira abordagem de identificação foi utilizado o mesmo método coe usado na simulação sendo que além dos dados de entrada e saída é fornecido para a rotina um modelo inicial que fornecerá a estrutura do modelo (ordem dos polinômios) e valores iniciais dos coeficientes. Como modelos iniciais foram utilizados os modelos ARX e ARMAX já empregados na simulação como modelos do processo e apresentados no Apêndice 1.

Os modelos obtidos na re-identificação pelo método coe são apresentados na Tabela 5-1. Esses modelos ajustam melhor os dados de processo, tanto no conjunto de dados utilizado para a identificação quanto na validação cruzada. No entanto o ajuste da variável yl apresentou fit $<10 \%$ nos dados para validação cruzada. Além disso, os modelos obtidos, talvez por sua elevada ordem, apresentam comportamento oscilatório na parte inicial da curva para as variáveis yl e y3. Esse comportamento pode caracterizar um tempo morto nesse processo já que a rotina coe assume o tempo morto dos novos modelos igual ao tempo morto dos modelos de referência (todos iguais a 1 minuto). Essa análise foi feita baseada na observação dos gráficos contidos nas Figuras 5-11 a 5-19. 
Tabela 5-1 - Modelos MISO contínuos identificados pela rotina coe

$$
\begin{aligned}
& y 1(\mathrm{t})=[\mathrm{B}(\mathrm{s}) / \mathrm{F}(\mathrm{s})] \mathrm{u}(\mathrm{t})+\mathrm{e}(\mathrm{t}) \\
& \text { 을 } \mathrm{B} 1(\mathrm{~s})=2758 * \mathrm{~s}^{\wedge} 6-1481 * \mathrm{~s}^{\wedge} 5+4,468 \mathrm{e} 004 * \mathrm{~s}^{\wedge} 4-4,866 \mathrm{e} 004 * \mathrm{~s}^{\wedge} 3+7,946 \mathrm{e} 004 \\
& * \mathrm{~s}^{\wedge} 24,103 \mathrm{e} 004 * \mathrm{~s}+4875 \\
& \mathrm{~B} 2(\mathrm{~s})=-3,205 \mathrm{e} 004 * \mathrm{~s}^{\wedge} 3+9997 * \mathrm{~s}^{\wedge} 2-1,363 \mathrm{e} 004 * \mathrm{~s}-972,1 \\
& \mathrm{~F} 1(\mathrm{~s})=\mathrm{s}^{\wedge} 7+3,566 \mathrm{e} 004 * \mathrm{~s}^{\wedge} 6+3,543 \mathrm{e} 004 * \mathrm{~s}^{\wedge} 5+5,284 \mathrm{e} 005 * \mathrm{~s}^{\wedge} 4+3,08 \mathrm{e} 005 * \\
& \mathrm{~s}^{\wedge} 3+1,253 \mathrm{e} 006 * \mathrm{~s}^{\wedge} 2+3,97 \mathrm{e} 005 * \mathrm{~s}+1,432 \mathrm{e} 004 \\
& \mathrm{~F} 2(\mathrm{~s})=\mathrm{s}^{\wedge} 4+1,399 \mathrm{e} 005 * \mathrm{~s}^{\wedge} 3+2,44 \mathrm{e} 005 * \mathrm{~s}^{\wedge} 2+1,079 \mathrm{e} 005 * \mathrm{~s}+3,194 \mathrm{e} 004 \\
& y 2(\mathrm{t})=[\mathrm{B}(\mathrm{s}) / \mathrm{F}(\mathrm{s})] \mathrm{u}(\mathrm{t})+\mathrm{e}(\mathrm{t}) \\
& \mathrm{B} 1(\mathrm{~s})=-0,06828 * \mathrm{~s}^{\wedge} 5-1,116 * \mathrm{~s}^{\wedge} 4+13,18 * \mathrm{~s}^{\wedge} 3-2,652 * \mathrm{~s}^{\wedge} 2+0,7152 * \mathrm{~s}- \\
& 1,446 \\
& \stackrel{\stackrel{\alpha}{2}}{\mathrm{~L}} \mathrm{~B} 2(\mathrm{~s})=-0,02555 * \mathrm{~s}^{\wedge} 2+0,06805 * \mathrm{~s}+0,0004363 \\
& \mathrm{~F} 1(\mathrm{~s})=\mathrm{s}^{\wedge} 6+59,5 * \mathrm{~s}^{\wedge} 5+172 * \mathrm{~s}^{\wedge} 4+205,9 * \mathrm{~s}^{\wedge} 3+103,7 * \mathrm{~s}^{\wedge} 2+17,58 * \mathrm{~s}+ \\
& 0,9339 \\
& \mathrm{~F} 2(\mathrm{~s})=\mathrm{s}^{\wedge} 3+3,354 * \mathrm{~s}^{\wedge} 2+0,5858 * \mathrm{~s}+0,02454 \\
& y 3(\mathrm{t})=[\mathrm{B}(\mathrm{s}) / \mathrm{F}(\mathrm{s})] \mathrm{u}(\mathrm{t})+\mathrm{e}(\mathrm{t})
\end{aligned}
$$

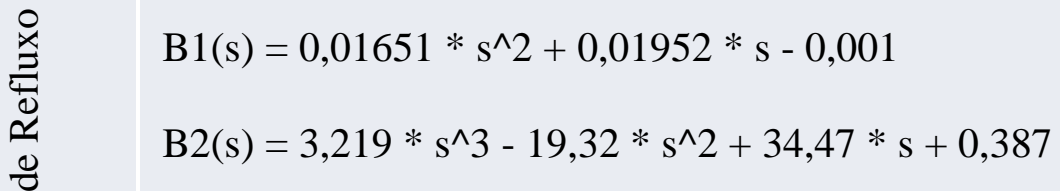

$$
\begin{aligned}
& \mathrm{F} 1(\mathrm{~s})=\mathrm{s}^{\wedge} 3+0,6189 * \mathrm{~s}^{\wedge} 2+0,9462 * \mathrm{~s}+0,1054 \\
& \mathrm{~F} 2(\mathrm{~s})=\mathrm{s}^{\wedge} 4+3,682 \mathrm{e} 004 * \mathrm{~s}^{\wedge} 3+3,018 \mathrm{e} 004 * \mathrm{~s}^{\wedge} 2+6292 * \mathrm{~s}+157,8
\end{aligned}
$$




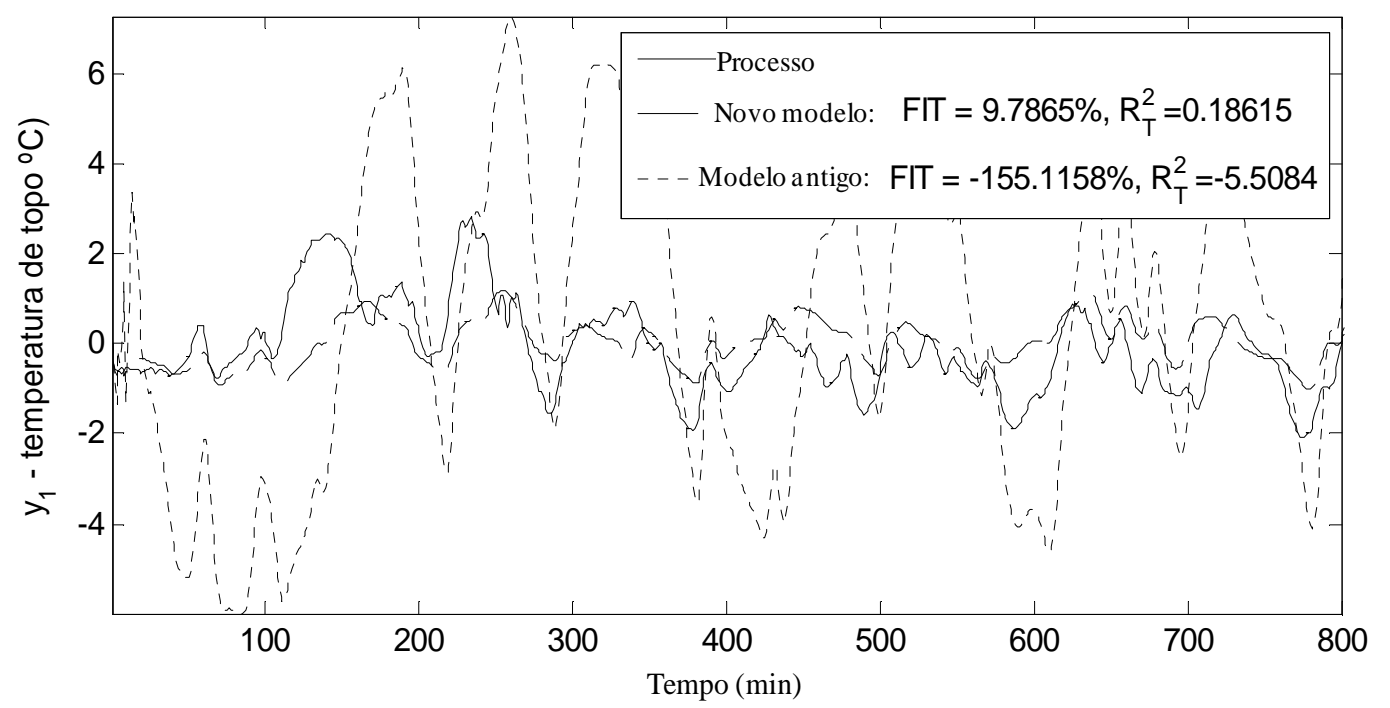

Figura 5-11. Predições do modelo re-identificado (-- --) e do modelo antigo usado no controlador (...). Para a variável controlada $y 1$. Dados utilizados para a re-identificação.

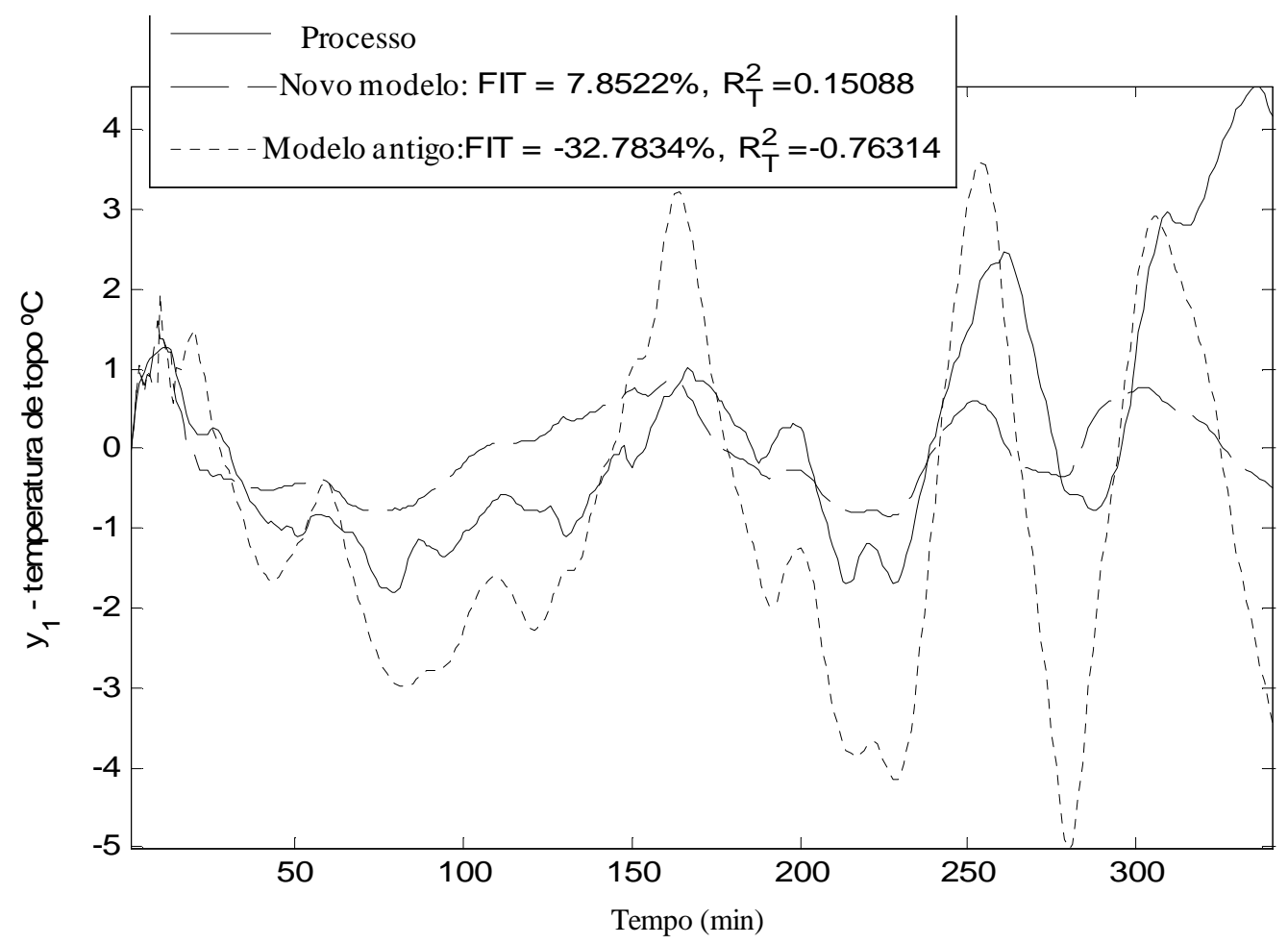

Figura 5-12. Predições do modelo re-identificado (-- --) e do modelo antigo usado no controlador (-.-.). Para a variável controlada $y 1$. Dados para validação cruzada. 

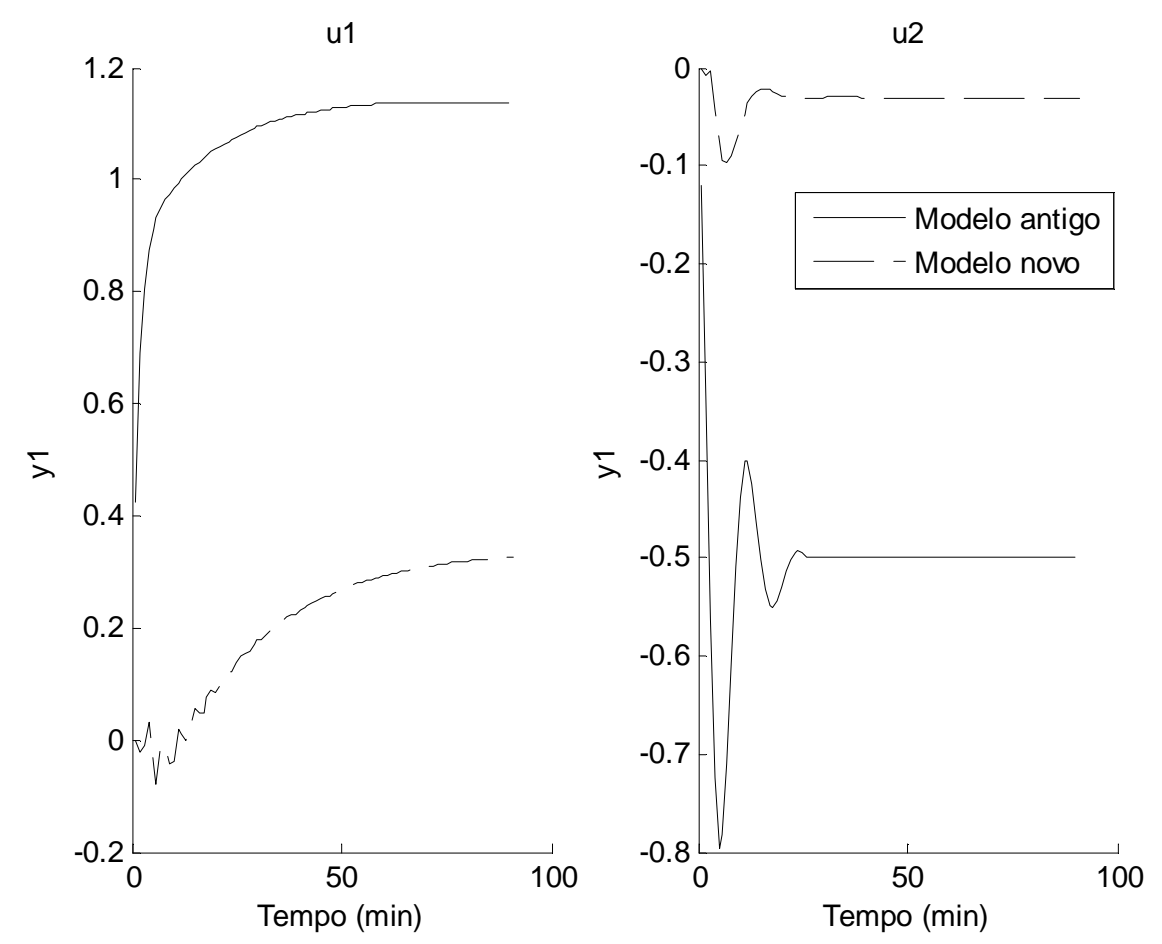

Figura 5-13. Comparação da resposta ao degrau do modelo re-identificado (-- --) e do modelo antigo usado no controlador (-) para a variável controlada $y l$ referente às manipuladas $u l$ e $u 2$.

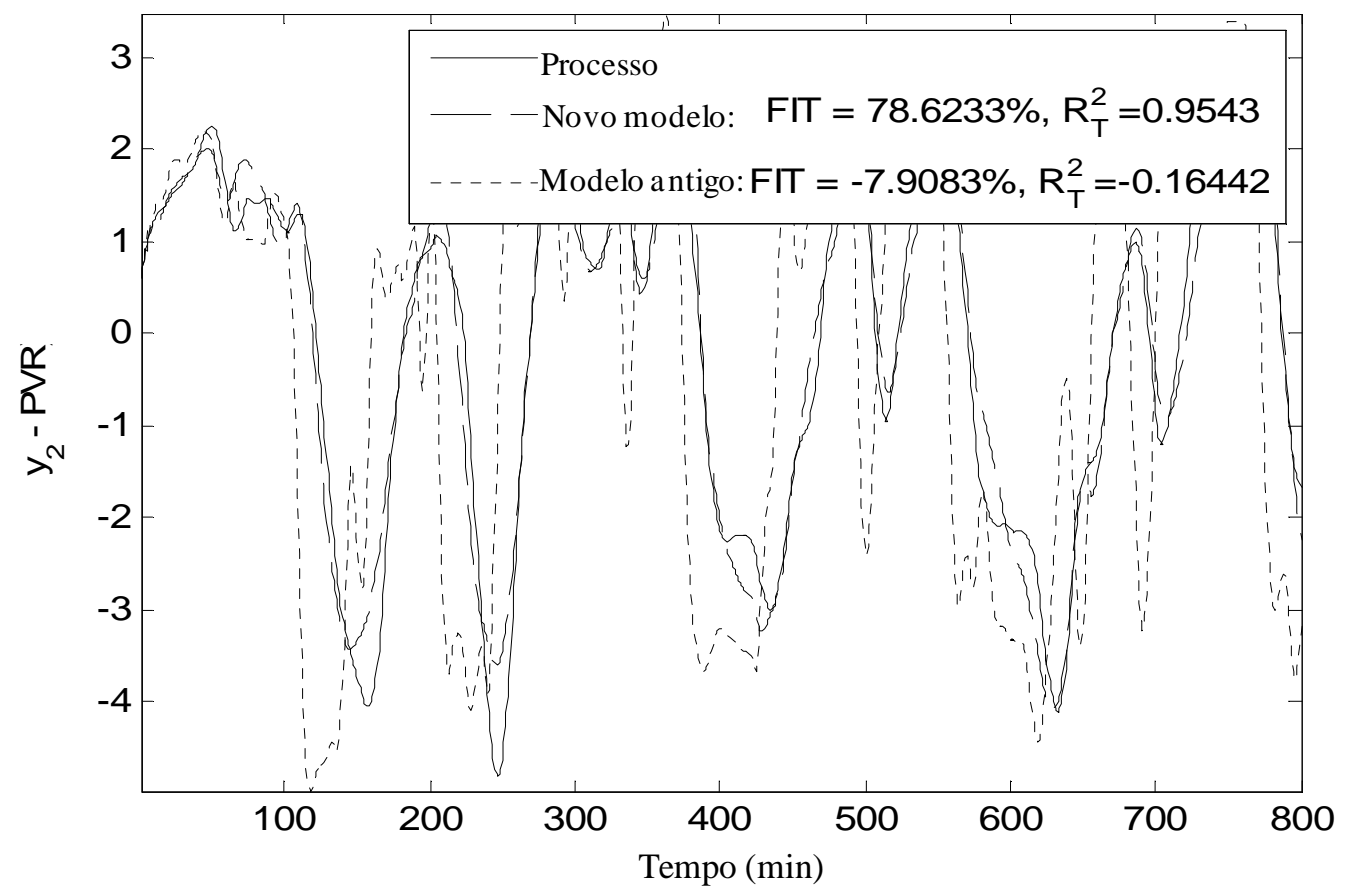

Figura 5-14. Predições do modelo re-identificado (-- --) e do modelo antigo usado no controlador (..-). Para a variável controlada y2. Dados utilizados para a re-identificação. 


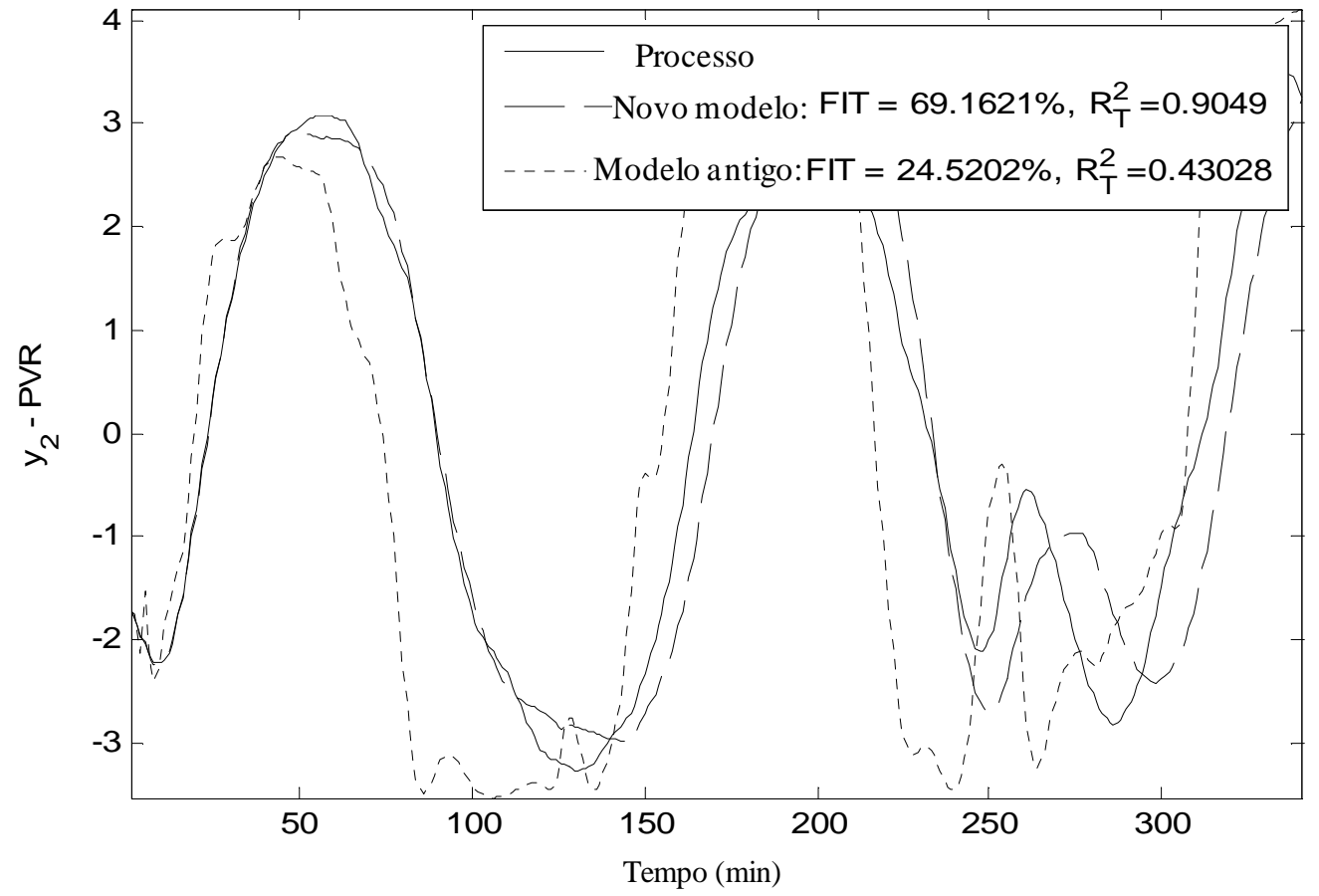

Figura 5-15. Predições do modelo re-identificado (-- --) e do modelo antigo usado no controlador (-..-). Para a variável controlada y2. Dados para validação cruzada.
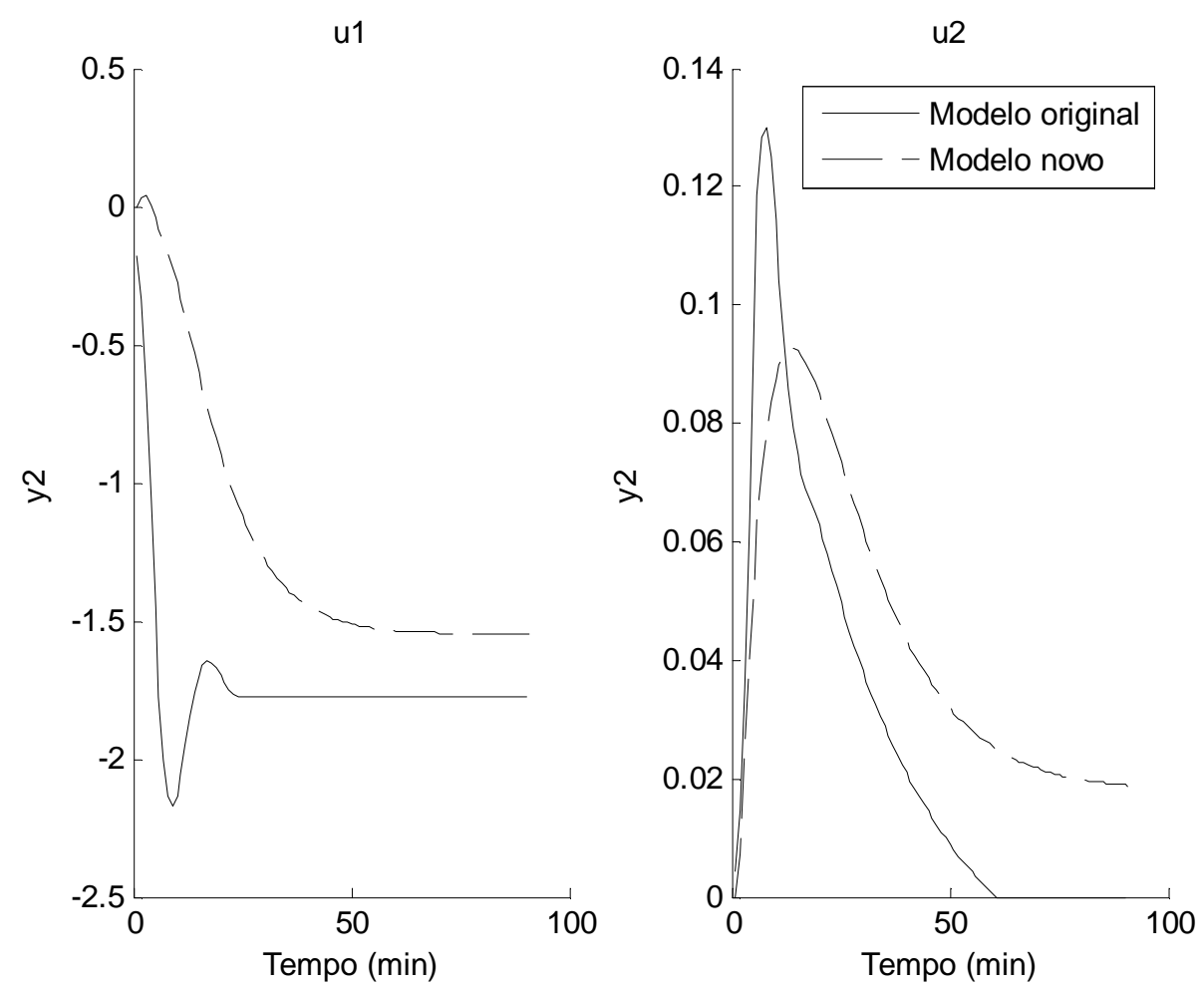

Figura 5-16. Comparação da resposta ao degrau do modelo re-identificado (-- --) e do modelo antigo usado no controlador (-) para a variável controlada $y 2$ referente às manipuladas $u 1$ e $u 2$. 


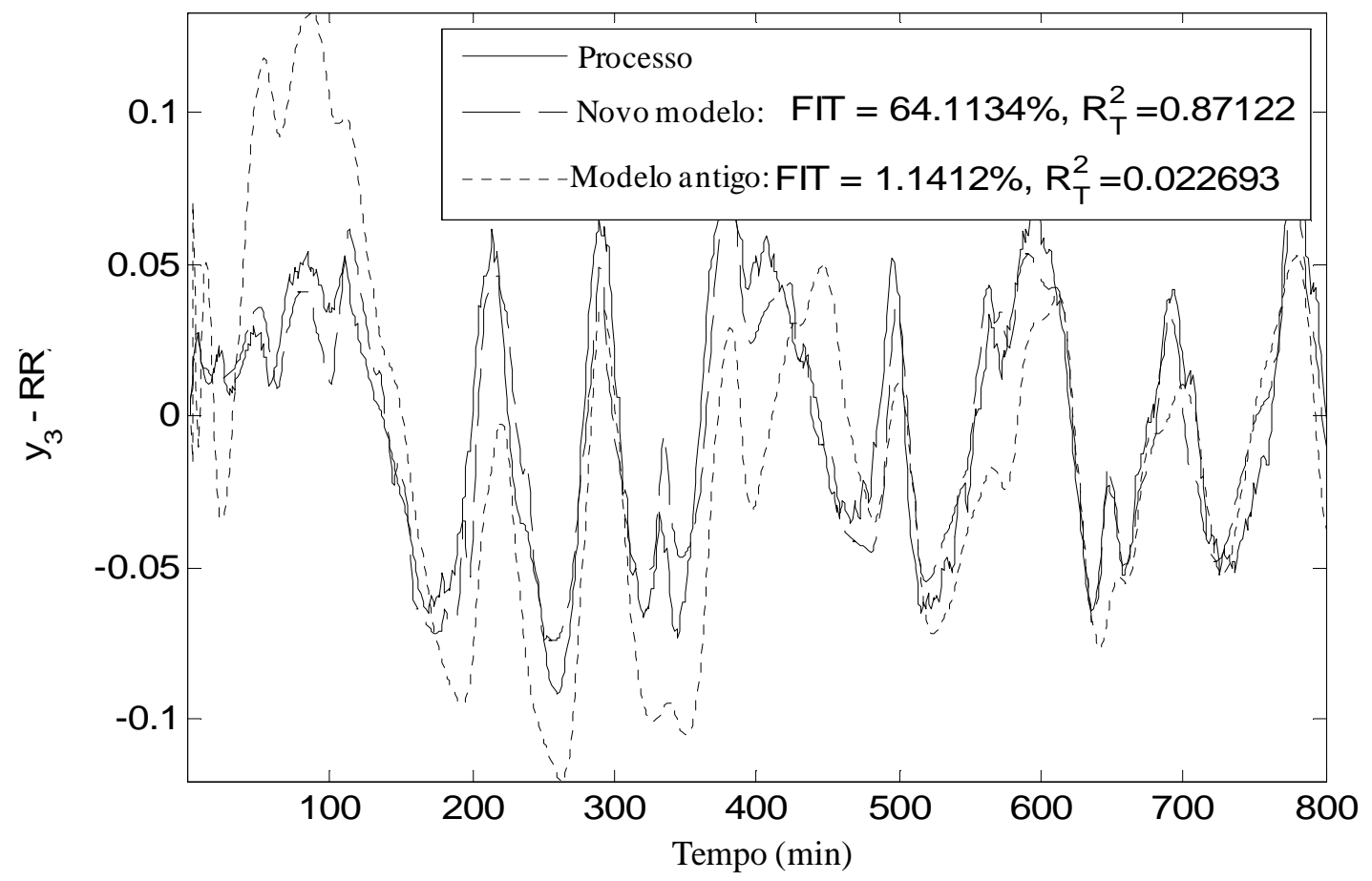

Figura 5-17. Predições do modelo re-identificado (-- --) e do modelo antigo usado no controlador (-..-). Para a variável controlada y3. Dados utilizados para a re-identificação.

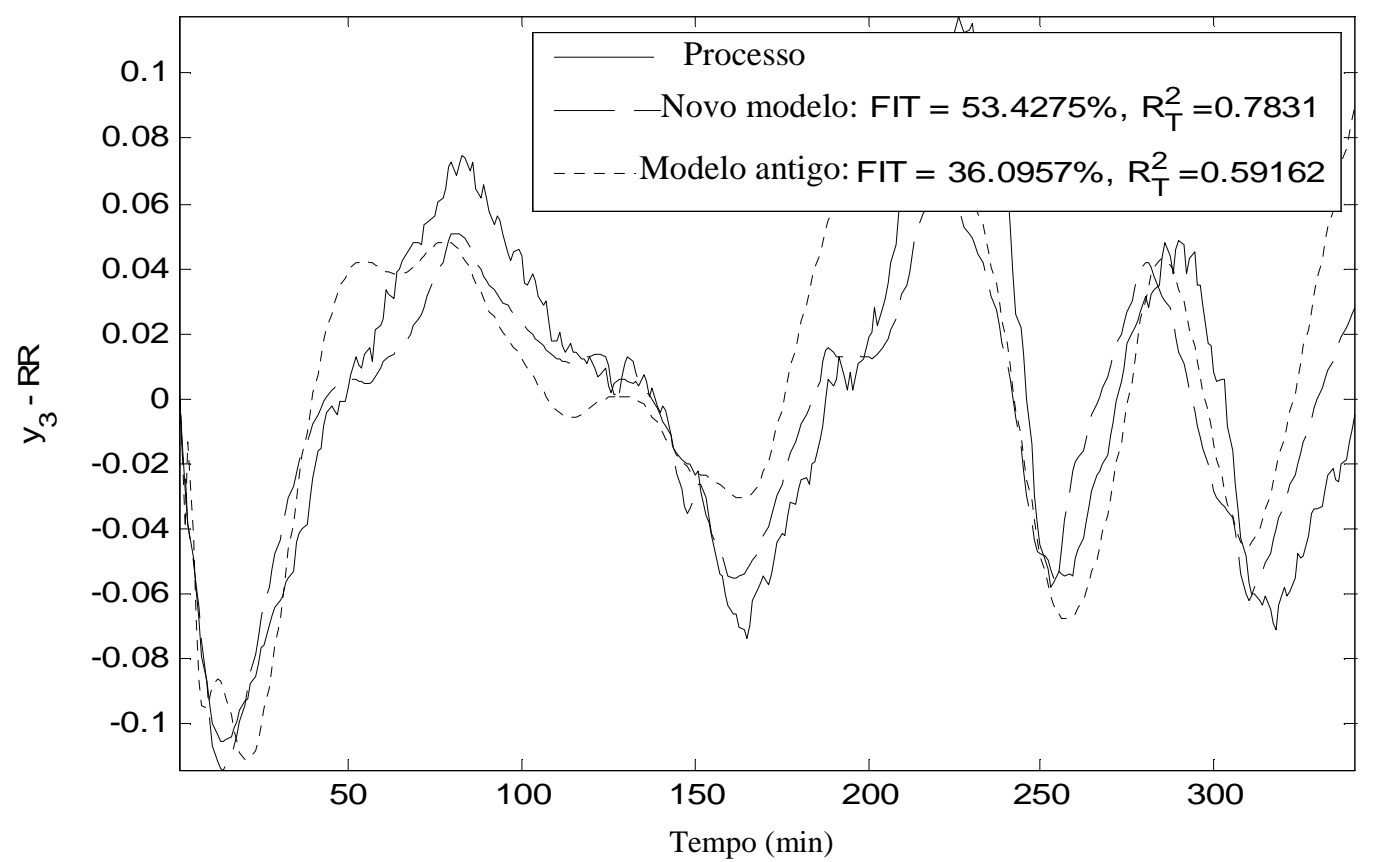

Figura 5-18. Predições do modelo re-identificado (-- --) e do modelo antigo usado no controlador (-..-). Para a variável controlada y3. Dados para validação cruzada. 

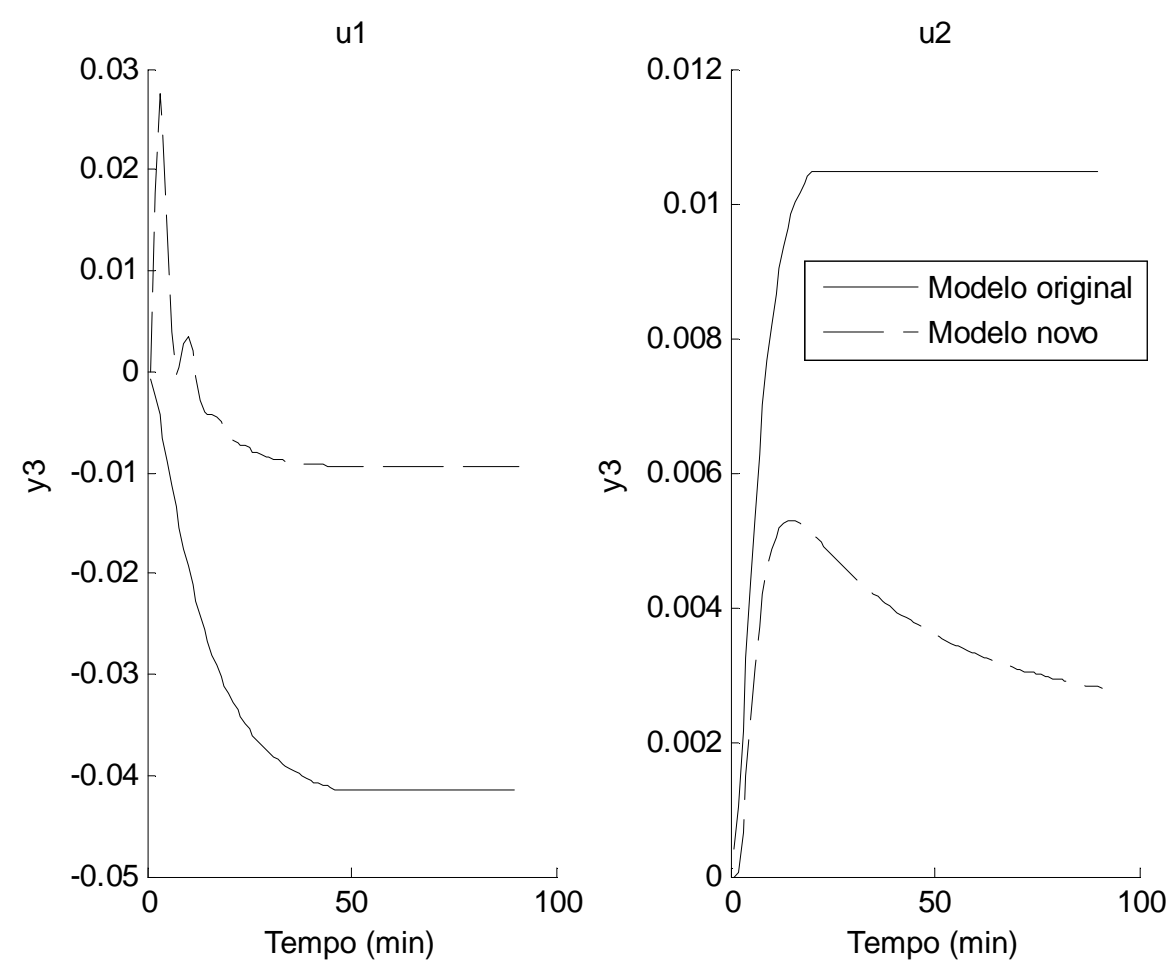

Figura 5-19. Comparação da resposta ao degrau do modelo re-identificado (-- --) e do modelo antigo usado no controlador (-) para a variável controlada $y 3$ referente às manipuladas $u 1$ e $u 2$.

No segundo teste de re-identificação (teste B) os resultados foram bem similares sendo que o modelo para yl apresentou um comportamento ainda mais inesperado indicando um ganho negativo para o par $u l / y l$. Esse comportamento pode indicar que os modelos de $y l$ sejam bastante não lineares, provavelmente por dificuldades de troca térmica no condensador de topo.

Para verificarmos a consistência dos modelos obtidos com os dados do teste foram empregados mais dois tipos de modelos para a re-identificação: ARMAX e espaço de estado (rotina pem do Matlab). Para o método ARMAX foram variadas a ordem do numerador e denominador até ordem cinco e foram experimentados alguns valores de tempo morto. No método pem não são necessários outros parâmetros de entradas que não os próprios dados de entrada e saída do sistema a ser identificado.

Para facilitar a comparação entre os diversos modelos identificados, e também do modelo original usado no MPC, foram agrupados os índices fit e $R_{T}^{2}$, que comparam a predição dos modelos re-identificados com os dados reais do processo para os dados da validação cruzada na Tabela 5-2. Pode-se perceber que todos os modelos re-identificados 
possuem um ajuste melhor aos dados de processo do que o modelo original. Para as variáveis $y 2$, em ambos os testes, e y3 no teste A há uma razoável semelhança no desempenho e todos os modelos são razoavelmente satisfatórios (fit $>44 \%$ e $R_{T}^{2}>0,69$ ).

Para selecionar o modelo que deverá ser atualizado no controlador adotou-se um critério que, além de considerar os índices de ajuste fit e $R^{2}$, baseia-se na semelhança com o modelo antigo, dessa forma o modelo vai gradualmente sendo atualizado, conforme a necessidade, e o desempenho do novo controlador não será drasticamente diferente do desempenho do controlador atual, diminuindo a necessidade de grandes modificações nos parâmetros de sintonia.

A semelhança com o modelo antigo pode ser medida pelo somatório do módulo da diferença de cada coeficiente da resposta ao degrau do modelo antigo e do modelo reidentificado. Para escolher o modelo que melhor representa o processo sem ser muito diferente do modelo atual do controlador propõe-se o seguinte índice:

$$
\text { comp }=\left(\left(\sum_{i=1}^{i=n}\left|n_{\text {orig }}(i)-n_{\text {ident }}(i)\right|\right)^{2} \cdot\left(1-\frac{f i t}{100}\right)^{2} \cdot\left(1-\mathrm{R}^{2} \mathrm{~T}\right)\right)^{-1}
$$

Onde:

$\mathrm{n}=$ horizonte de predição do controlador

$\mathrm{n}_{\text {orig }}(\mathrm{i})=$ coeficientes da resposta ao degrau do modelo original do MPC

$\mathrm{n}_{\text {ident }}(\mathrm{i})=$ coeficientes da resposta ao degrau do modelo re-identificado

O índice comp tem a função de comparar o desempenho dos modelos tanto quanto ao ajuste aos dados de processo, parcela $(1-f i t / 100)^{2}$, quanto à explicação das variações do processo, parcela $\left(1-R_{T}^{2}\right)$, mas também quanto à diferença entre o modelo re-identificado e o modelo original do MPC, parcela da somatória do módulo da diferença de cada coeficiente da resposta ao degrau. Como o índice comp é o inverso da multiplicação desses três fatores quanto maior o seu valor, melhor é a conjunção desses três fatores para um determinado modelo. 
Tabela 5-2: Resumo do desempenho da predição na validação cruzada dos três tipos de modelos usados na re-identificação para os dois testes (A e B) e para as três variáveis controladas através dos índices fit e $R_{T}^{2}$. Esses índices são também apresentados para os modelos originais do MPC. São destacados os três modelos que tem o maior índice comp entre os modelos de cada variável controlada.

\begin{tabular}{|c|c|c|c|c|c|c|}
\hline & & & Original & COE & ARMAX & pem \\
\hline \multirow{6}{*}{$Y 1$} & \multirow{3}{*}{ A } & fit & $-32,0 \%$ & $7,9 \%$ & $-13,0 \%$ & $-11,2 \%$ \\
\hline & & $R_{T}^{2}$ & $-0,76$ & 0,15 & $-0,27$ & $-0,25$ \\
\hline & & comp & & $1,1 \mathrm{E}-04$ & $7,7 \mathrm{E}-05$ & $7,9 \mathrm{E}-05$ \\
\hline & \multirow{3}{*}{ B } & fit & $-82,3 \%$ & $23,4 \%$ & $13,3 \%$ & $2,1 \%$ \\
\hline & & $R_{T}^{2}$ & $-2,3$ & 0,41 & 0,25 & 0,04 \\
\hline & & comp & & $1,2 \mathrm{E}-04$ & $1,5 \mathrm{E}-04$ & $1,1 \mathrm{E}-04$ \\
\hline \multirow{6}{*}{ Y2 } & \multirow{3}{*}{ A } & fit & $24,5 \%$ & $69,2 \%$ & $71,0 \%$ & $70,7 \%$ \\
\hline & & $R_{T}^{2}$ & 0,43 & 0,90 & 0,92 & 0,91 \\
\hline & & comp & & 0,047 & 0,079 & 0,068 \\
\hline & \multirow{3}{*}{ B } & fit & $-9,9 \%$ & $72,8 \%$ & $74,0 \%$ & $72,3 \%$ \\
\hline & & $R_{T}^{2}$ & $-0,21$ & 0,93 & 0,92 & 0,92 \\
\hline & & comp & & 0,090 & 0,065 & 0,056 \\
\hline \multirow{6}{*}{ Y3 } & \multirow{3}{*}{ A } & fit & $36,1 \%$ & $53,4 \%$ & $44,6 \%$ & $44,9 \%$ \\
\hline & & $R_{T}^{2}$ & 0,59 & 0,78 & 0,69 & 0,70 \\
\hline & & comp & & 2,11 & 2,29 & 2,68 \\
\hline & \multirow{3}{*}{ B } & fit & $-1,9 \%$ & $45,7 \%$ & $24,5 \%$ & $19,0 \%$ \\
\hline & & $R_{T}^{2}$ & $-0,04$ & 0,70 & 0,43 & 0,34 \\
\hline & & comp & & 0,71 & 0,49 & 1,96 \\
\hline
\end{tabular}

As respostas ao degrau de cada um dos 18 modelos MISO identificados (3modelos MISO $\times 3$ estruturas $\times 2$ testes) são apresentadas nas Figuras 5-20, 5-21 e 5-22. A tabela 5-3 apresenta a função de transferência contínua dos modelos escolhidos. 
$\mathrm{CO}$

ARMAX

PEM

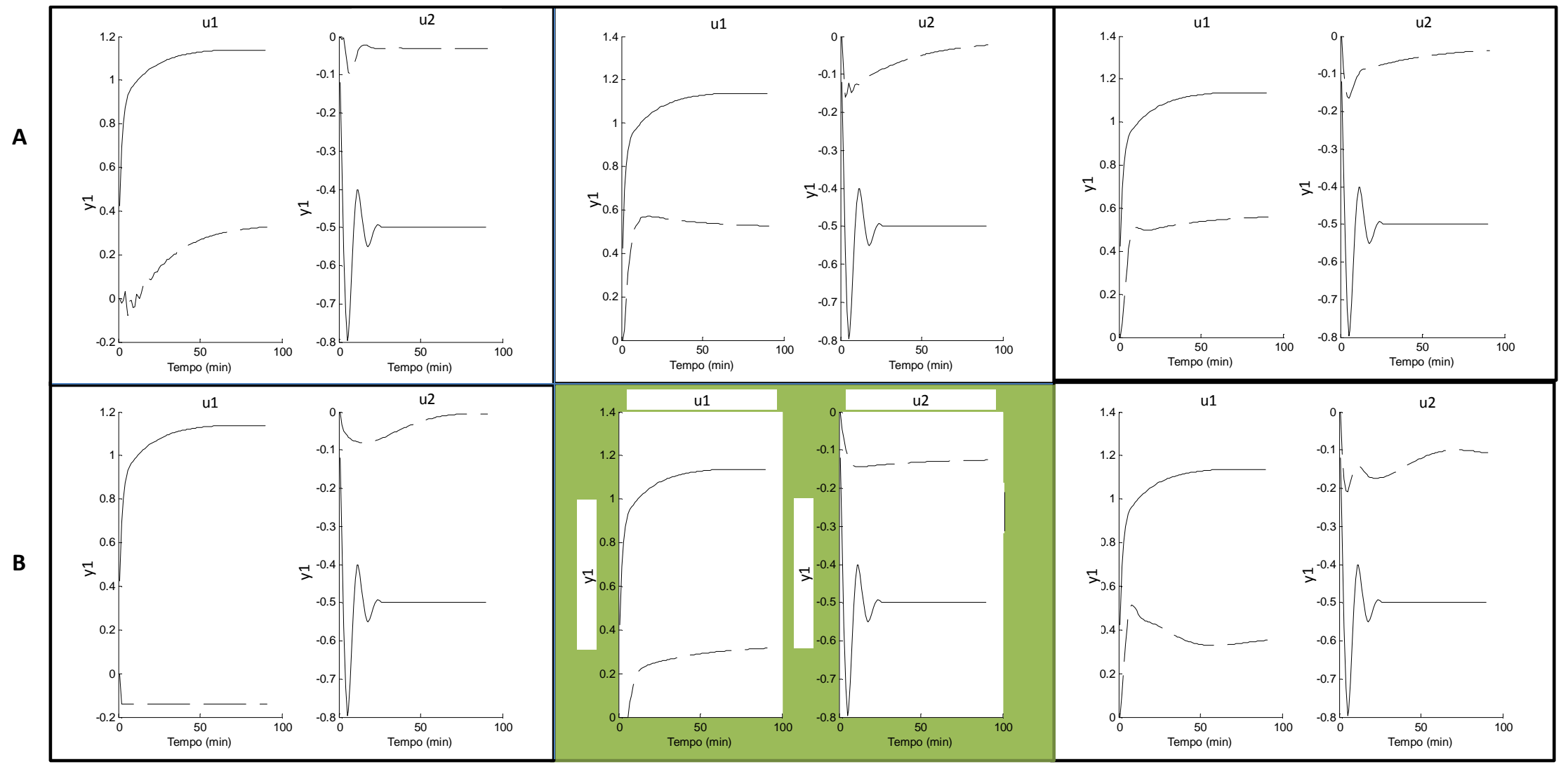

Figura 5-20. Comparação da resposta ao degrau do modelo re-identificado (-- --) e do modelo usado no controlador (-) para a variável controlada y1 referente as manipuladas $u 1$ e $u 2$ para as 3 estruturas de modelo diferentes (COE,ARMAX,PEM) e para os dois testes A e B. O modelo com maior índice comp está destacado. 
COE

ARMAX

PEM

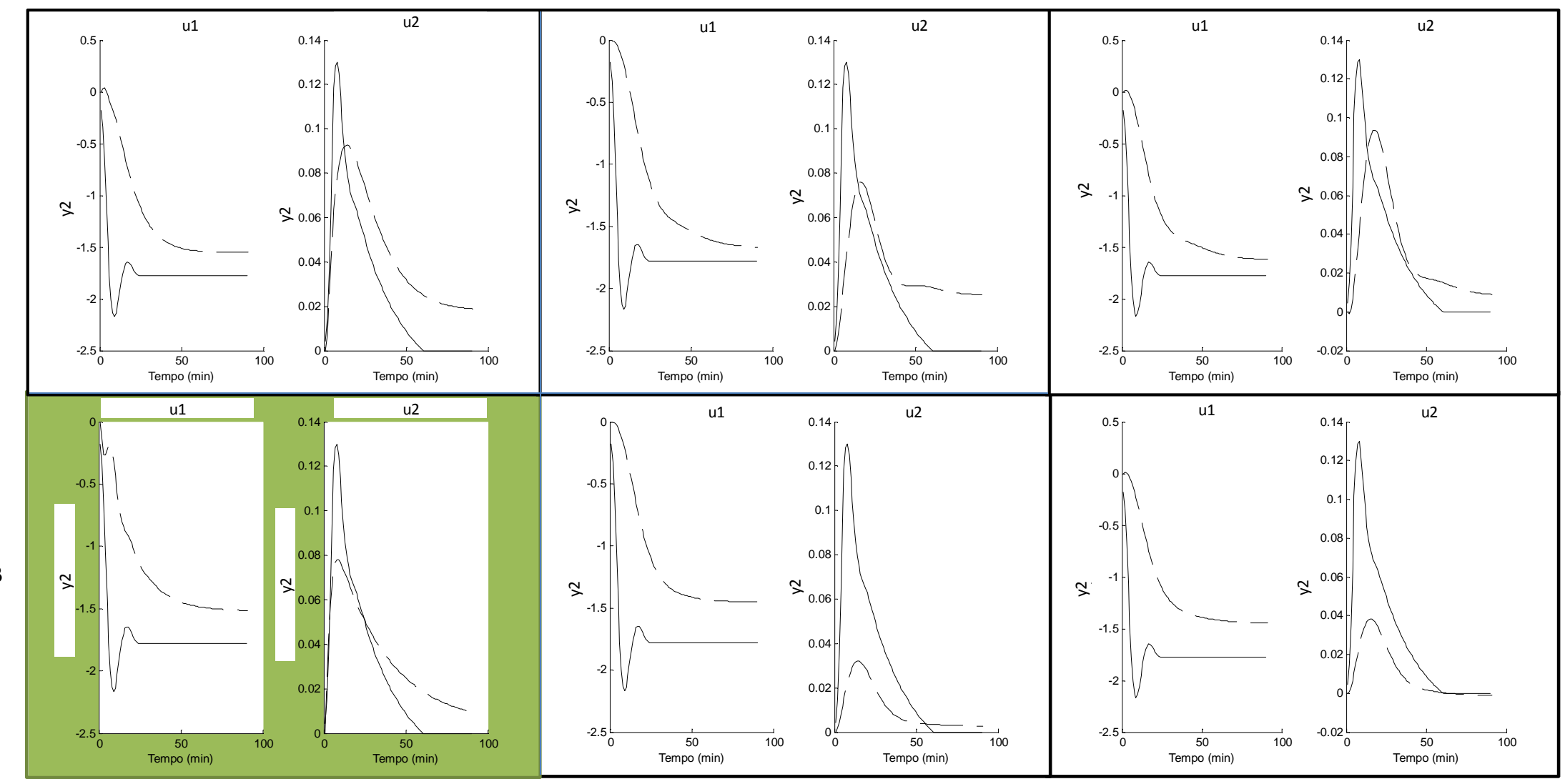

Figura 5-21. Comparação da resposta ao degrau do modelo re-identificado (-- --) e do modelo usado no controlador (-) para a variável controlada $y 2$ referente as manipuladas $u 1$ e $u 2$ para as 3 estruturas de modelo diferentes (COE,ARMAX,PEM) e para os dois testes A e B. O modelo com maior índice comp está destacado. 
COE

ARMAX

PEM

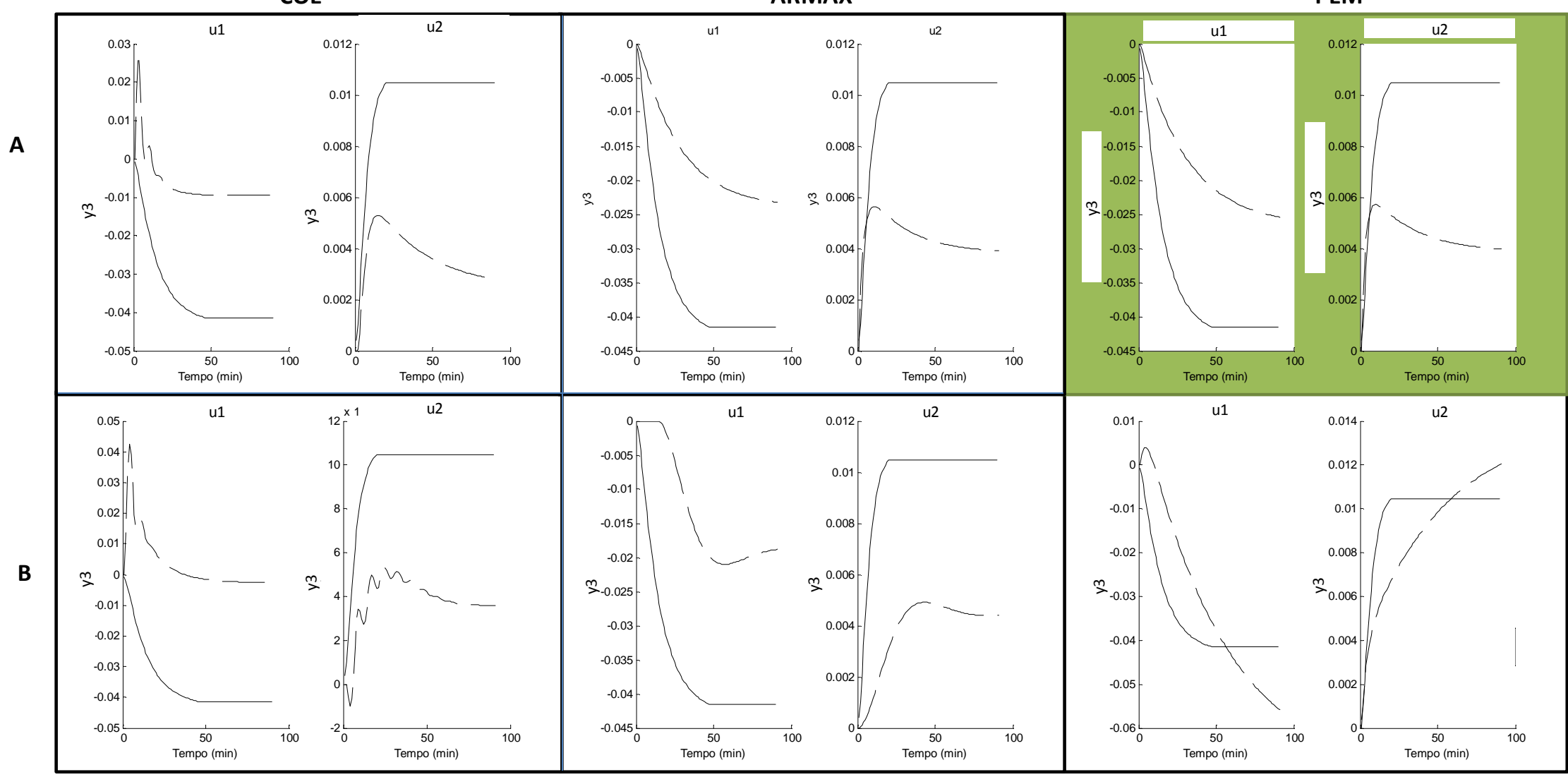

Figura 5-22 Comparação da resposta ao degrau do modelo re-identificado (-- --) e do modelo usado no controlador (-) para a variável controlada $y 3$ referente as manipuladas $u 1$ e $u 2$ para as 3 estruturas de modelo diferentes (COE,ARMAX,PEM) e para os dois testes A e B. O modelo com maior índice comp está destacado. 
Tabela 5-3: Funções de transferência dos modelos substituídos no controlador

$$
\widehat{G}_{11}(s)=\frac{0.04999 s^{3}+0.09801 s^{2}+0.04018 s+0.001417}{s^{4}+1.672 s^{3}+0.9523 s^{2}+0.192 s+0.004296} e^{-5 s}
$$$$
\widehat{G}_{12}(s)=\frac{-0.03482 s^{3}-0.06779 s^{2}-0.02686 s-0.0005292}{s^{4}+1.672 s^{3}+0.9523 s^{2}+0.192 s+0.004296}
$$

$$
\widehat{G}_{21}(s)=\frac{-0.07493 s^{5}-1.206 s^{4}-1.379 s^{3}-7.675 s^{2}+0.9486 s-0.9387}{s^{6}+8.778 s^{5}+15.17 s^{4}+38.36 s^{3}+15.76 s^{2}+10.33 s+0.6175}
$$

$\stackrel{x}{2}$

$$
\widehat{G}_{22}(s)=\frac{0.02098 s^{2}+0.03324 s+3.758 \times 10^{-5}}{s^{3}+1.218 s^{2}+0.3861 s+0.011}
$$

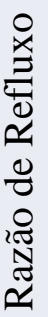

$$
\begin{aligned}
& \widehat{G}_{31}(s)=\frac{-0.0007499 s-0.0003704}{s^{2}+0.4442 s+0.01386} \\
& \widehat{G}_{32}(s)=\frac{0.002621 s+5.316 \times 10^{-5}}{s^{2}+0.4442 s+0.01386}
\end{aligned}
$$

Um ponto de preocupação quanto aos modelos identificados vem do fato de que as manipuladas $u 1$ e $u 2$ apresentam, durante a re-dentificação, correlação-cruzada sem atraso conforme apresentado na Figura 5-23. A Figura 5-24, demonstra, como era esperado, que essa correlação não vem do sinal GBN utilizado para excitação. A correlação deve-se ao fato de que a predição das controladas $y 1$ e $y 3$ permaneceram grande parte do tempo do teste próximas ou mesmo violaram seus limites de controle o que introduziu um forte sinal de "feedback" no sistema, principalmente devido à variável yl que possui peso elevado para o MPC. É importante ressaltar que apesar das Figuras 5-23 e 5-24 apresentarem os dados somente para o teste de identificação A o mesmo comportamento foi observado no teste B. 
Os modelos ajustados para os dados da unidade de processo foram consistentes entre si nos dois testes (A e B) realizados nesse trabalho. Essa consistência pode ser expressa, por exemplo, pela proximidade dos ganhos estacionários obtidos pelos diferentes métodos, nos dois testes realizados em semanas diferentes, podendo ser observada nas Figura 5-20, Figura 5-21 e Figura 5-22. Mesmo com essa correlação das manipuladas é importante ressaltar também que todos os modelos re-identificados apresentaram melhor desempenho na predição dos dados de validação cruzada do que os modelos originais conforme demonstrado pelos índices apresentados na Tabela 5-2.

Os novos modelos de resposta ao degrau re-identificados, comparados aos modelos antigos na Figura 5-25, foram substituídos no controlador em questão havendo uma melhora significativa no desempenho deste. Esta melhora pode ser observada através do PCAT, ou Percentual de Controladas Ativas (Pinotti et al., 2008), principal índice de acompanhamento dos MPCs da Petrobras.

O PCAT considera que o ganho econômico das aplicações de MPC está relacionado com a habilidade de manter as variáveis controladas operando sobre as restrições, ou seja, em mantê-las ativas. A variável controlada é considerada ativa quando o seu "target" atinge um dos limites operacionais (valor mínimo ou máximo da faixa de controle). Conforme expressado na equação 5.2 quanto maior o número de variáveis controladas ativas relativo ao total de variáveis manipuladas do controlador maior será o índice PCAT e melhor o desempenho do controlador será considerado.

Com os novos modelos observou-se, conforme ilustrado na Figura 5-26, um aumento médio de cerca de $50 \%$ no PCAT, considerando os três meses de operação com os novos modelos comparados aos três meses imediatamente anteriores. Esse aumento médio do PCAT é consequência direta da maior utilização do controle avançado desta unidade, o que, por sua vez, deve-se a um comportamento menos oscilatório das variáveis controladas. Essa redução da variabilidade pode ser atribuída a modelos mais aderentes ao processo visto que nenhum outro parâmetro (sintonia e limites de variáveis) do controlador foi modificado até o final desse trabalho.

$$
\text { PCAT }=100 \times \frac{\text { Número de controladas ativas }}{\text { Número total de manipuladas }}
$$




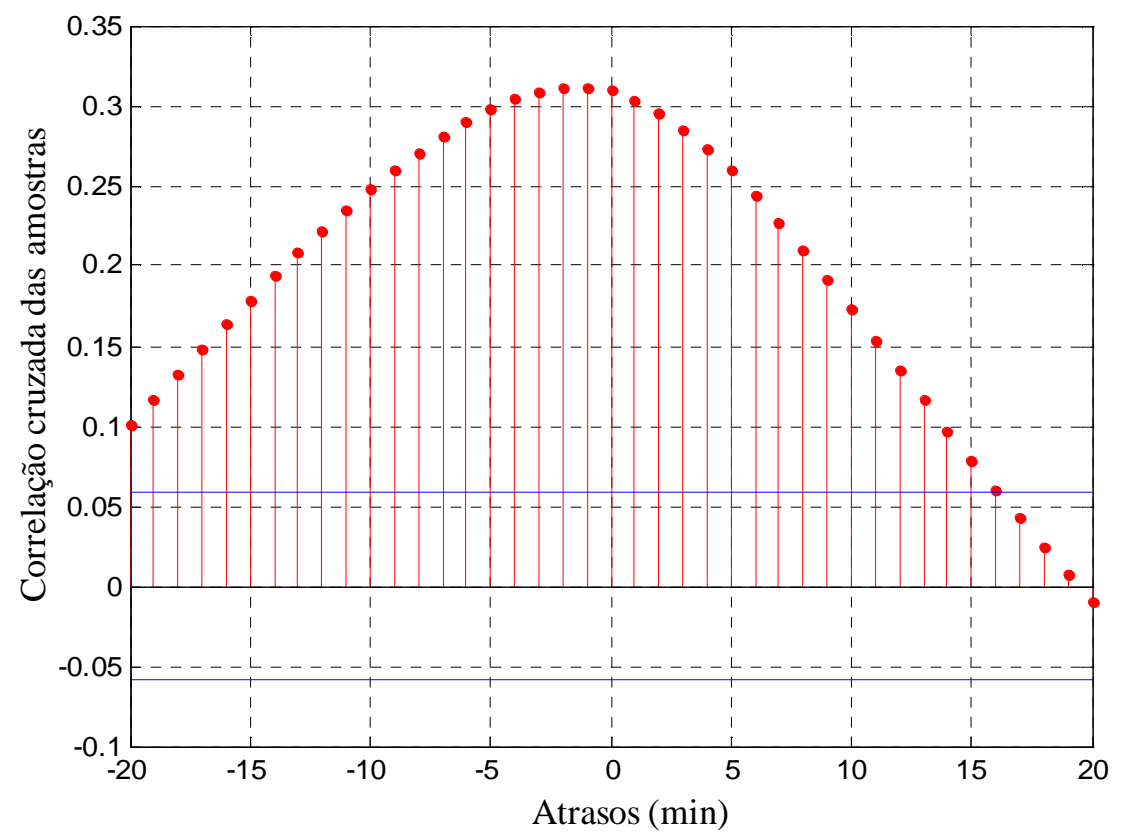

Figura 5-23. Correlação cruzada entre as entradas $u 1$ e $u 2$ do teste A.

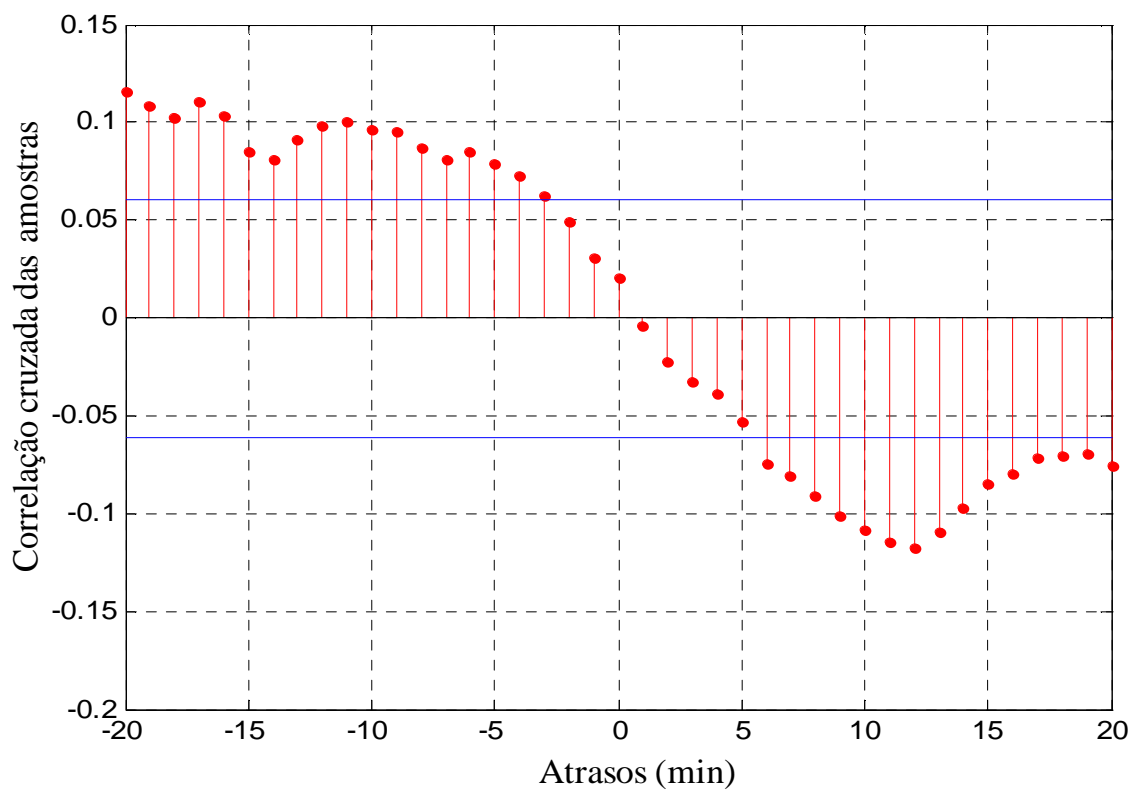

Figura 5-24. Correlação cruzada entre os sinais GBN do teste A. 


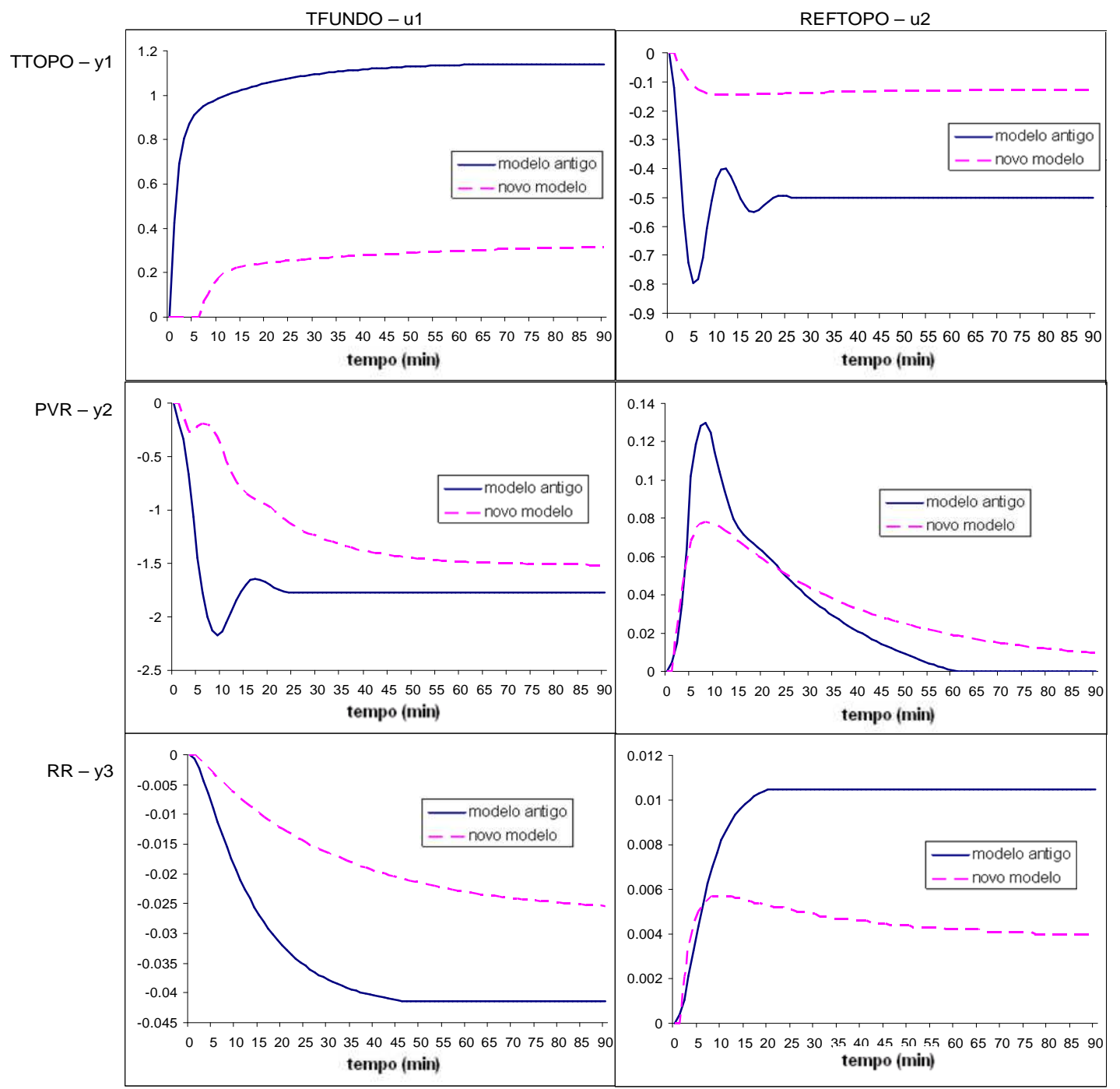

Figura 5-25. Comparação entre os modelo originais do controlador (-) e os novos modelos reidentificados (-- --). 


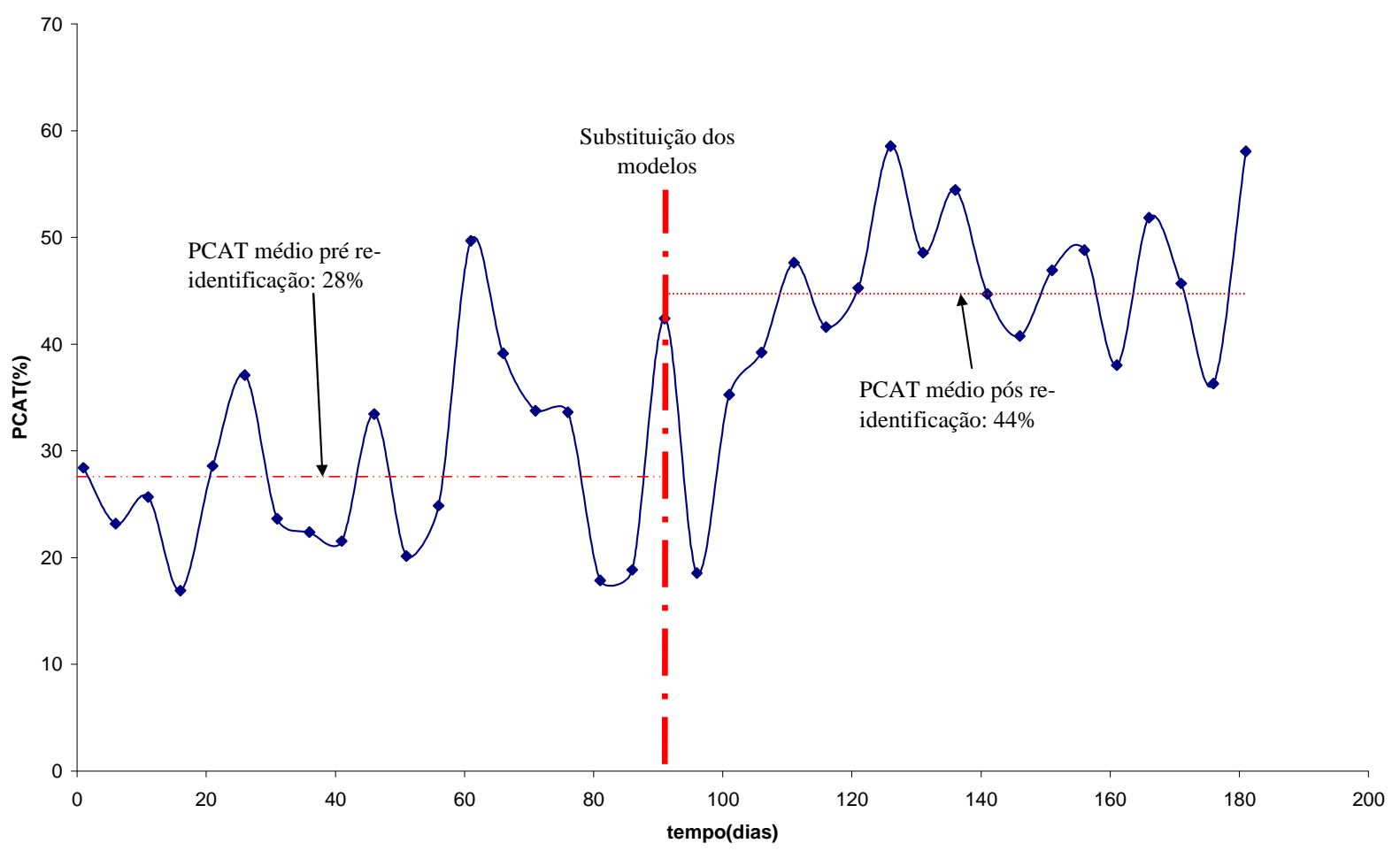

Figura 5-26. Aumento do PCAT médio após a utilização dos modelos re-identificados 


\section{Conclusões e Recomendações}

O método de excitação em malha fechada proposto em Sotomayor et al. (2009) mostrou-se válido para a aplicação industrial em questão, visto que, através deste, foram obtidos modelos de processo mais representativos para o controlador e o seu desempenho foi melhorado. Os resultados positivos aliados à praticidade e segurança do teste de reidentificação no caso apresentado indicam que a metodologia possui grande aplicabilidade industrial. Cabe destacar a necessidade de se modificar a sintonia do controlador durante o teste para se obter uma excitação adequada do processo, necessidade que foi percebida já na etapa de simulação do teste

Embora os resultados do teste prático de re-identificação em malha fechada com controlador MPC em duas camadas tenham sido bastante positivos, certamente existe espaço para melhorias no método, particularmente no procedimento de excitação da planta. Assim, propõe-se estudar as causas da correlação entre as entradas observada nos dados coletados na planta. Outro estudo seria o do efeito dessa correlação na qualidade dos modelos obtidos. A definição do nível máximo de correlação que não prejudica a obtenção de um modelo suficientemente correto para os objetivos de controle será um trabalho importante. Como sugestão para diminuir o nível de correlação entre as entradas manipuladas, pode-se, por exemplo, buscar um meio de manter a predição das variáveis controladas mais afastadas dos seus limites de controle. Dessa forma o controlador não tentará usar as manipuladas para trazer as predições das controladas para dentro das faixas. Para isso sugere-se, por exemplo, iniciar o sinal GBN do teste em -1 por tempo suficiente para que as controladas se afastem das restrições ativas inicialmente. Adicionalmente aumentar o valor do peso das variáveis de folga (W3) também contribui sobremaneira para que a predição das controladas permaneça dentro da faixa de controle.

Outra sugestão para estudo seria mudar a concepção da aplicação do controle das saídas por faixas. Na concepção atual, o controle por faixas é descontinuo no sentido que existem "set-points" para as variáveis controladas apenas quando elas estão fora das respectivas faixas. Na concepção mais moderna e que é comprovadamente mais eficiente sob o aspecto de controle, os "set-points" das variáveis controladas passam a ser variáveis do problema de controle com as restrições de máximo e mínimo que definem as faixas das saídas. 
Propõe-se também realizar os testes em sistemas de dimensões maiores, como por exemplo, o processo de FCC que tem um número bem maior de variáveis controladas e manipuladas. Nesse caso, o problema de excitação do processo deve se tornar bem mais complexo e existe a possibilidade de grande correlação entre as entradas. 


\section{Referências Bibliográficas}

Aguirre, L. A. Introdução à identificação de sistemas: técnicas lineares e não-lineares aplicadas a sistemas reais. $2^{\mathrm{a}}$ ed. Editora UFMG, Belo Horizonte, 2004.

Aling, H., J. Heintze. Closed loop identification of a 600 MW Benson boiler. In: Proceedings of the $31^{\text {st }}$ Conference on Decision and Control (CDC'92), p.909-914, Tucson, Arizona, 1992.

Andersen, H.W., M. Kümmel. Evaluating estimation of gain directionality - Part 2: a case study of binary distillation. Journal of Process Control, 2(2), p.67-86, 1992.

Ballin, S.L. Controlador Preditivo Multivariável com Restrição de Excitação para identificação de processos em malha fechada. Dissertação de Mestrado, Departamento de Engenharia Química, Escola Politécnica da USP, São Paulo, 2008.

Bauer, M., Craig, I.K. Economic assessment of advanced process control—a survey and framework. Journal of Process Control, 18(1), p .2-18, 2008.

Celaya, P., B. Tkatch, Y. Zhu, R. Patwardhan . Closed-loop identification at the Hovensa refinery. NPRA Decision Support and Automation Conference, San Antonio, Texas, 2004.

Conner, J.S., D.E. Seborg . An evaluation of MIMO input designs for process identification. Industrial and Engineering Chemistry Research, 43(14), p .3847-3854, 2004.

Cutler, C.R., B.L. Ramaker. Dynamic matrix control - A computer control algorithm. Proceedings of the Joint Automatic Control Conference, San Franciso-CA, Paper WP5B, 1980.

Doma, M.J., P.A. Taylor, P.J. Vermeer. Closed loop identification of MPC models for MIMO processes using genetic algorithms and dithering one variable at a time: application to an industrial distillation tower. Computers and Chemical Engineering, 20(Suppl.): S1035S1040, 1996.

Friedman, Y.Z. Tuning of averaging level controller. Hydrocarbon Processing Journal, 1994.

Garcia, C. Identificação de sistemas. Notas de aula. Universidade de São Paulo, 2005.

Garnier, H., M. Mensler, A. Richard. Continuous-time model identification from sampled data: implementation issues and performance evaluation. International Journal of Control, 76(13), p.1337-1357, 2003. 
Garnier, H., M. Gilson, O. Cervellin. Lasted development for the Matlab CONTSID toolbox. In: Proceedings of the $14^{\text {th }}$ IFAC Symposium on System Identification (SYSID 2006), Newcastle, Australia, 2006.

Genceli, H., M. Nikolaou. New approach to constrained predictive control with simultaneous model identification. AIChE Journal, 42(10), p.2857-2868, 1996.

Huang, B., Tamayo,E.C. Model validation for industrial model predictive control systems. Chemical Engineering Science, 55(12),2315-2327, 2000.

Jenkins, G.M., D.G. Watts. Spectral analysis and its applications. Holden Day: London, 1968.

Kline, S., R. Street, R.S. Patwardhan, A. Bae. Closed loop identification for multivariable model predictive controller on a catalytic gasoline splitter. Proceedings of the Seventh International Conference on Chemical Process Control (CPC 7), Lake Louise - Alberta, Canada, 2006.

Landau, I.D. Identification in closed loop: a powerful design tool (better design models, simpler controllers). Control Engineering Practice, 9(1), p . 51-65, 2001.

Ljung, L. Asymptotic variance expressions for identified black-box transfer function models. IEEE Transactions on Automatic Control, 30(9): p. 834-844, 1985.

Ljung, L. System identification - Theory for the user. $2^{\text {nd }}$ Ed., Prentice Hall: Upper Saddle River, NJ, 1999.

Miranda, F.C.P. Identificação de sistemas em malha fechada usando controlador preditivo multivariável: um caso industrial. Dissertação de Mestrado, Departamento de Engenharia Química, Escola Politécnica da USP, São Paulo, 2005.

Moro, L.F.L. Sicon - Uma solução cliente servidor para controle avançado. IV Congresso Petrobras de Informática e Telecomunicações - INFTEL, São Paulo, 1997.

Östring, M., S. Gunnarsson, M. Norrlöf. Closed-loop identification of an industrial robot containing flexibilities. Control Engineering Practice, 11(3), p .291-300, 2003.

Pasadyn, A.J., S.J. Qin, S. Valle-Cervantes. Closed-loop and open-loop identification of an industrial wastewater reactor. Proceedings of the 1999 American Control Conference (ACC'99), p.3965-3969, San Diego-CA, 1999. 
Pinotti, R., A.C. Zanin, L.F.L. Moro. Advanced control monitoring in petrobras' refineries: Quantifying economic gains on a real-time basis. Computer Aided Chemical Engineering, vol. 25, p. 495-500, 2008.

Rotava, O. , Zanin A.C. Multivariable control and real-time optimization - an industrial practical view. Hydrocarbon Processing, 84(6) ,p .61-71, 2005.

Sagias, D., M. Nikolaou. Closed-loop identification of processes operating under model predictive control without external excitation. In: 2001 AIChE Annual Meeting, Reno, Nevada, 2001.

Sloley, A.W. Effectively control column pressure. Chemical engineering progress, 2001.

Söderström, T., P. Stoica. Instrumental variable methods for system identification. Springer Verlag: Berlin, 1983.

Söderström, T., P. Stoica. System Identification, Prentice Hall, Upper Saddle River, N.J., 1989.

Sotomayor, O.A.Z., Odloak, D., Moro, L.F.L. Closed-loop model re-identification of processes under MPC with zone control. Control Engineering Practice, v.17, p. 551$563,2009$.

Tulleken, H.J.A.F. Generalized binary noise test-signal concept for improved identificationexperiment design. Automatica, 26(1), p. 37-49, 1990.

Van Overschee, P., B. De Moor .Subspace identification for linear systems: theory, implementation, applications. Kluwer Academic Publishers: Dordrecht, 1996.

Young, R.E. Petroleum refining process control and real-time optimization. IEEE Control System Magazine, 26(6), p . 73-83, 2006.

Zhu, Y., F. Butoyi. Case studies on closed-loop identification for MPC. Control Engineering Practice, 10(4),p. 403-417, 2002.

Zhu, Y. Multivariable system identification for process control. Elsevier Science Ltd.:

Oxford, UK, 2001.

Zhu, Y. New development in industrial MPC identification. In: Proceedings of the $13^{\text {th }}$ IFAC Symposium on System Identification (SYSID 2003), CDRom, Rotterdam, The Netherlands, 2003. 


\section{Apêndice 1 - Modelos ARX e ARMAX identificados a partir da resposta ao degrau para simulação}

\begin{tabular}{|c|c|c|}
\hline & Temperatura de fundo & Vazão de Refluxo \\
\hline 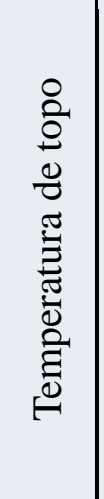 & $\begin{array}{l}A(q) y(t)=B(q) u(t)+e(t) \\
A(q)=1-0.1403 q^{\wedge}-1-0.2256 q^{\wedge}-2-0.1821 q^{\wedge}-3- \\
0.07773 q^{\wedge}-4-0.3787 q^{\wedge}-5+0.08754 q^{\wedge}-6+ \\
0.06343 q^{\wedge}-7 \\
B(q)=0.05592 q^{\wedge}-1+0.05592 q^{\wedge}-2+0.05592 q^{\wedge}-3\end{array}$ & $\begin{array}{l}A(q) y(t)=B(q) u(t)+C(q) e(t) \\
A(q)=1-1.66 q^{\wedge}-1+0.8158 \\
q^{\wedge}-2+0.1239 q^{\wedge}-3-0.1211 q^{\wedge}- \\
4 \\
B(q)=-0.04006 q^{\wedge}-1-0.04006 \\
q^{\wedge}-2 \\
C(q)=1+0.1205 q^{\wedge}-1\end{array}$ \\
\hline$\frac{a}{2}$ & $\begin{array}{l}A(q) y(t)=B(q) u(t)+e(t) \\
A(q)=1-1.888 q^{\wedge}-1+1.105 q^{\wedge}-2+0.006023 q^{\wedge}-3 \\
-0.1706 q^{\wedge}-4+0.04009 q^{\wedge}-5+0.0007952 q^{\wedge}-6\end{array}$ & $\begin{array}{l}A(q) y(t)=B(q) u(t)+C(q) e(t) \\
A(q)=1-2.527 q^{\wedge}-1+2.202 \\
q^{\wedge}-2-0.6709 q^{\wedge}-3 \\
B(q)=0.01784 q^{\wedge}-1-0.01796 \\
q^{\wedge}-2 \\
C(q)=1-0.8916 q^{\wedge}-1-0.1084 \\
q^{\wedge}-2\end{array}$ \\
\hline 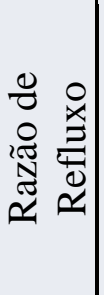 & $\begin{array}{l}\mathrm{A}(\mathrm{q}) \mathrm{y}(\mathrm{t})=\mathrm{B}(\mathrm{q}) \mathrm{u}(\mathrm{t})+\mathrm{e}(\mathrm{t}) \\
\mathrm{A}(\mathrm{q})=1-2.065 \mathrm{q}^{\wedge}-1+1.371 \mathrm{q}^{\wedge}-2-0.2921 \mathrm{q}^{\wedge}-3 \\
\mathrm{~B}(\mathrm{q})=-0.0005725 \mathrm{q}^{\wedge}-1\end{array}$ & $\begin{array}{l}A(q) y(t)=B(q) u(t)+e(t) \\
A(q)=1-1.631 q^{\wedge}-1+0.5706 \\
q^{\wedge}-2+0.1952 q^{\wedge}-3-0.09443 \\
q^{\wedge}-4 \\
B(q)=0.0004314 q^{\wedge}-1\end{array}$ \\
\hline
\end{tabular}




\section{Apêndice 2 - Modelos re-identificados na simulação no domínio de Laplace}

\begin{tabular}{|c|c|c|}
\hline & Temperatura de fundo & Vazão de Refluxo \\
\hline 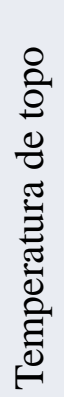 & $\begin{array}{l}\mathrm{y}(\mathrm{t})=[\mathrm{B}(\mathrm{s}) / \mathrm{F}(\mathrm{s})] \mathrm{u}(\mathrm{t})+\mathrm{e}(\mathrm{t}) \\
\mathrm{B}(\mathrm{s})=-0.548 \mathrm{~s}^{\wedge} 6+1.115 \mathrm{~s}^{\wedge} 5+18.44 \mathrm{~s}^{\wedge} 4+ \\
36.81 \mathrm{~s}^{\wedge} 3+35.27 \mathrm{~s}^{\wedge} 2+12.59 \mathrm{~s}+0.7813 \\
\mathrm{~F}(\mathrm{~s})=\mathrm{s}^{\wedge} 7+7.19 \mathrm{~s}^{\wedge} 6+30.73 \mathrm{~s}^{\wedge} 5+63.23 \mathrm{~s}^{\wedge} 4+ \\
69.91 \mathrm{~s}^{\wedge} 3+43.47 \mathrm{~s}^{\wedge} 2+14 \mathrm{~s}+0.7005\end{array}$ & $\begin{array}{l}\mathrm{y}(\mathrm{t})=[\mathrm{B}(\mathrm{s}) / \mathrm{F}(\mathrm{s})] \mathrm{u}(\mathrm{t})+\mathrm{e}(\mathrm{t}) \\
\mathrm{B}(\mathrm{s})=-0.03627 \mathrm{~s}^{\wedge} 3-2.36 \mathrm{~s}^{\wedge} 2- \\
2.017 \mathrm{~s}-0.6308 \\
\mathrm{~F}(\mathrm{~s})=\mathrm{s}^{\wedge} 4+2.028 \mathrm{~s}^{\wedge} 3+7.071 \mathrm{~s}^{\wedge} 2+ \\
2.549 \mathrm{~s}+1.286\end{array}$ \\
\hline$\frac{a}{2}$ & $\begin{array}{l}\mathrm{y}(\mathrm{t})=[\mathrm{B}(\mathrm{s}) / \mathrm{F}(\mathrm{s})] \mathrm{u}(\mathrm{t})+\mathrm{e}(\mathrm{t}) \\
\mathrm{B}(\mathrm{s})=-0.1333 \mathrm{~s}^{\wedge} 5-7.046 \mathrm{~s}^{\wedge} 4-12.51 \mathrm{~s}^{\wedge} 3- \\
14.87 \mathrm{~s}^{\wedge} 2-9.78 \mathrm{~s}-2.235 \\
\mathrm{~F}(\mathrm{~s})=\mathrm{s}^{\wedge} 6+24.35 \mathrm{~s}^{\wedge} 5+25.52 \mathrm{~s}^{\wedge} 4+39.47 \mathrm{~s}^{\wedge} 3 \\
+19.84 \mathrm{~s}^{\wedge} 2+7.119 \mathrm{~s}+1.283\end{array}$ & $\begin{array}{l}\mathrm{y}(\mathrm{t})=[\mathrm{B}(\mathrm{s}) / \mathrm{F}(\mathrm{s})] \mathrm{u}(\mathrm{t})+\mathrm{e}(\mathrm{t}) \\
\mathrm{B}(\mathrm{s})=-0.02541 \mathrm{~s}^{\wedge} 2+0.02979 \mathrm{~s}- \\
0.0001192 \\
\mathrm{~F}(\mathrm{~s})=\mathrm{s}^{\wedge} 3+0.3205 \mathrm{~s}^{\wedge} 2+0.2588 \mathrm{~s}+ \\
0.0117\end{array}$ \\
\hline 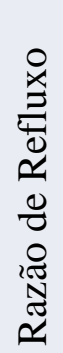 & $\begin{array}{l}\mathrm{y}(\mathrm{t})=[\mathrm{B}(\mathrm{s}) / \mathrm{F}(\mathrm{s})] \mathrm{u}(\mathrm{t})+\mathrm{e}(\mathrm{t}) \\
\mathrm{B}(\mathrm{s})=-0.0003045 \mathrm{~s}^{\wedge} 2-0.002311 \mathrm{~s}-0.001557 \\
\mathrm{~F}(\mathrm{~s})=\mathrm{s}^{\wedge} 3+1.153 \mathrm{~s}^{\wedge} 2+0.5327 \mathrm{~s}+0.03792\end{array}$ & $\begin{array}{l}\mathrm{y}(\mathrm{t})=[\mathrm{B}(\mathrm{s}) / \mathrm{F}(\mathrm{s})] \mathrm{u}(\mathrm{t})+\mathrm{e}(\mathrm{t}) \\
\mathrm{B}(\mathrm{s})=0.0002524 \mathrm{~s}^{\wedge} 3+0.00115 \mathrm{~s}^{\wedge} 2 \\
+0.001923 \mathrm{~s}+0.000643 \\
\mathrm{~F}(\mathrm{~s})=\mathrm{s}^{\wedge} 4+2.124 \mathrm{~s}^{\wedge} 3+1.299 \mathrm{~s}^{\wedge} 2+ \\
0.572 \mathrm{~s}+0.06233\end{array}$ \\
\hline
\end{tabular}

